Florida International University FIU Digital Commons

3-29-2011

\title{
GRE as a Predictor of Graduate Student Success at a Hispanic Serving Institution of Higher Education
}

Katherine Perez

Florida International University, kpere039@fiu.edu

DOI: $10.25148 /$ etd.FI1 1042602

Follow this and additional works at: https://digitalcommons.fiu.edu/etd

\section{Recommended Citation}

Perez, Katherine, "GRE as a Predictor of Graduate Student Success at a Hispanic Serving Institution of Higher Education" (2011). FIU Electronic Theses and Dissertations. 361.

https://digitalcommons.fiu.edu/etd/361 


\title{
FLORIDA INTERNATIONAL UNIVERSITY \\ Miami, Florida
}

\section{GRE AS A PREDICTOR OF GRADUATE STUDENT SUCCESS AT A HISPANIC SERVING INSTITUTION OF HIGHER EDUCATION}

\author{
A dissertation submitted in partial fulfillment of the \\ requirements for the degree of \\ DOCTOR OF EDUCATION \\ in \\ HIGHER EDUCATION \\ by \\ Katherine Perez
}


To: Dean Delia C. Garcia

College of Education

This dissertation, written by Katherine Perez, and entitled GRE as a Predictor of Graduate Student Success at a Hispanic Serving Institution of Higher Education, having been approved in respect to style and intellectual content, is referred to you for judgment.

We have read this dissertation and recommend that it be approved.

Deanne Butchey

Roger Geertz Gonzalez

Thomas Reio

Janice R. Sandiford

Leonard B. Bliss, Major Professor

Date of Defense: March 29, 2011

The dissertation of Katherine Perez is approved.

Dean Delia C. Garcia

College of Education

Interim Dean Kevin O'Shea

University Graduate School

Florida International University, 2011 


\section{DEDICATION}

I dedicate this study to the two greatest motivators in my life: family and friends. To my mother and sister, you have always inspired me and helped me move forward in everything I have accomplished. To my friends, you each contributed to my growth and to my overall well-being. Thank you all for everything you have helped me become. 


\section{ACKNOWLEDGMENTS}

Many people helped me throughout the process of completing my dissertation. I would like to thank Dr. Abbas Tashakkori for helping me get started in this process. As my first chair, his feedback and support throughout the conceptualization and proposal stages was pivotal to the direction I took in terms of my research topic and design. I would also like to acknowledge Dr. Leonard Bliss for adopting me midway through the dissertation and helping me complete it. He will always be one of my greatest mentors and friends. The lessons I learned from Len will stay with me throughout the rest of my years.

Also, my committee members made a great impact on my work and on my view of my topic. My deepest appreciation goes to each of my committee members. Listed in alphabetical order, I would like to start with Dr. Deanne Butchey who helped me by always encouraging me and supporting me both academically and professionally. Dr. Roger Geertz Gonzalez taught me so much about higher education throughout my coursework in my master's and doctoral programs, that many of the ideas that I had for my dissertation emerged from his courses. Dr. Thomas Reio gave me great ideas for adding psychosocial factors to my analysis of the topic. Dr. Janice Sandiford introduced me to higher education research and played a pivotal role in my decision to change my graduate major to higher education.

Additionally, I would like to extend my appreciation to Dr. Linda Bliss and Dr. Isadore Newman, who were both excellent professors and made significant contributions to my dissertation and to my development as a researcher. Another person who helped me throughout my graduate student life was, Dr. Patricia Barbetta. I greatly appreciate 
her; she was one of the first people I met at the college and always supported me and expected the best from me. Furthermore, I want to thank the rest of the College of Education faculty and staff with whom I was lucky to learn from as a student or work with as a graduate student.

For inspiring me to conduct this research and for supporting me as friends and classmates, I would like to thank all of the graduate students who I have met through my graduate studies. I would also like to include in this group all of the graduate students who volunteered to participate in this study. It was an incredible learning experience to spend time interviewing them. It was an honor to have met so many students from across the university with whom I would have normally never had the chance to discuss such personal and emotionally charged aspects of their lives as they balanced academics with everything else.

I would also like to thank my colleagues and friends at the APA and OPIR offices. As I completed my dissertation, they helped me in everything from extracting data from records to offering unconditional support and guidance. Even though I do not think they will ever understand how much they truly helped me, I will never be able to forget their kindness and their encouragement.

Without all of these wonderful people, I would not have been able to reach the end of this journey through my doctoral program. Thank you all. 


\title{
ABSTRACT OF THE DISSERTATION \\ GRE AS A PREDICTOR OF GRADUATE STUDENT SUCCESS AT A HISPANIC SERVING INSTITUTION OF HIGHER EDUCATION
}

\author{
by
}

Katherine Perez

Florida International University, 2011

Miami, Florida

Professor Leonard B. Bliss, Major Professor

Accurately predicting the success of graduate students is an important aspect of determining which students should be admitted into graduate programs. The GRE is a pivotal factor to examine since it is one of the most widely used criteria for graduate school admission. Even though the GRE is advertised as an accurate tool for predicting first year graduate GPA, there is a lack of research on long term success factors such as time to degree and graduate rate (Luthy, 1996; Powers, 2004). Furthermore, since most studies have low minority sample sizes, the validity of the GRE may not be the same across all groups (ETS, 2008b; Kuncel, Hezlett, \& Ones, 2001). Another gap in GRE studies is that few researchers analyze student characteristics, which may alter or moderate the prediction validity of the GRE. Thus, student characteristics such as degree of academic involvement, mentorship interactions, and other academic and social experiences have not been widely examined in this context. These gaps in the analysis of GRE validity are especially relevant given the high attrition rates within of some graduate programs (e.g., an estimated $68 \%$ of doctoral student never complete their programs in urban universities; Lovitts, 2001). 
A sequential mixed methods design was used to answer the research questions in two phases. The quantitative phase used student data files to analyze the relationship of two success variables (graduation rate and graduate GPA) to the GRE scores as well as other academic and demographic graduate student characteristics. The qualitative phase served to complement the first phase by describing a wider range of characteristics from the 11 graduate students who were interviewed.

Both proximal and distal moderators influence student behaviors and success in graduate school. In the first phase of the study, the GRE was the distal facilitator under analysis. Findings suggested that both the GRE Quantitative and the GRE Verbal were predictors of success for master's students, but the GRE Quantitative was not predictive of success for doctoral students. Other student characteristics such as demographic variables and disciplinary area were also predictors of success for the population of students studied. In the second phase of the study, it was inconclusive whether the GRE was predictive of graduate student success; though it did influence access to graduate programs. Furthermore, proximal moderators such as student involvement, faculty/peer interactions, motivational factors, and program structure were perceived to be facilitators and/or detractors for success. 


\section{TABLE OF CONTENTS}

CHAPTER

PAGE

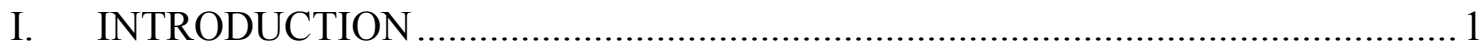

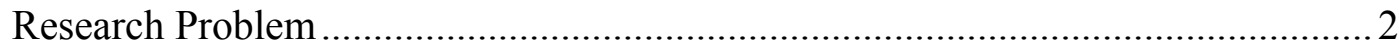

Purpose of the Study .................................................................................... 3

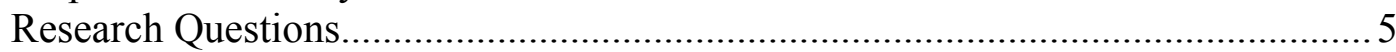

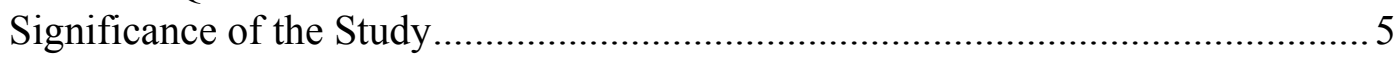

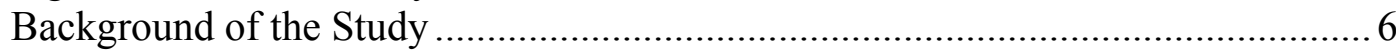

Theoretical Framework..................................................................................

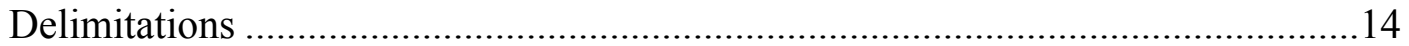

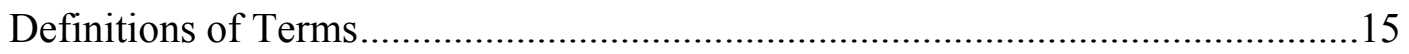

Overview of the Remaining Chapters ………………......................................16

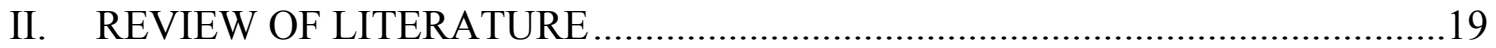

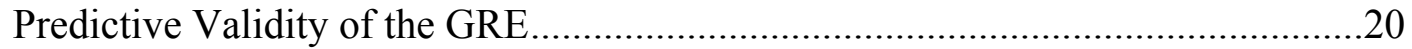

Predicting GRE Validity Across Disciplines......................................................23

Predictive Validity for Minority Students ……………........................................25

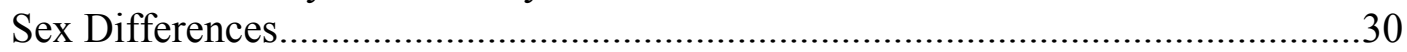

GRE Prediction Among Different Age Groups.....................................................34

Characteristics of Graduate Student Success............................................................

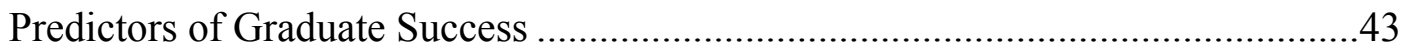

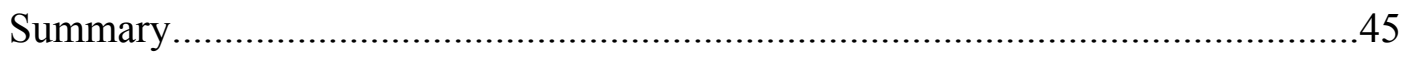

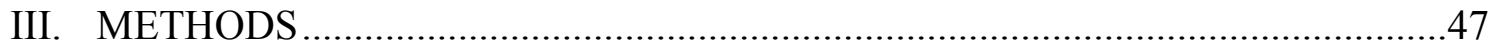

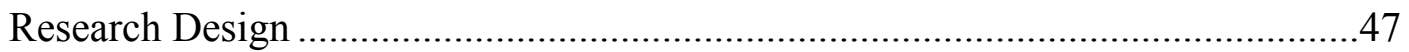

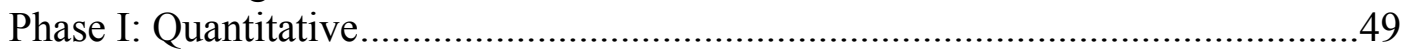

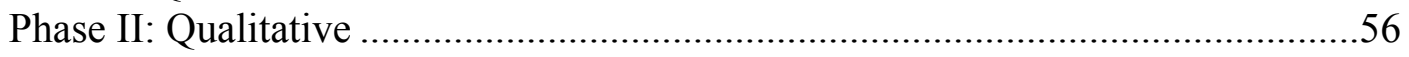

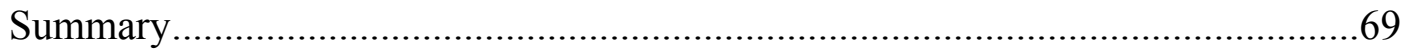

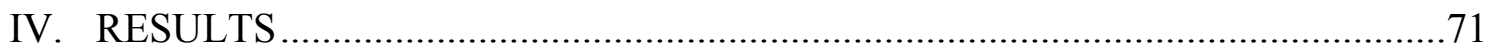

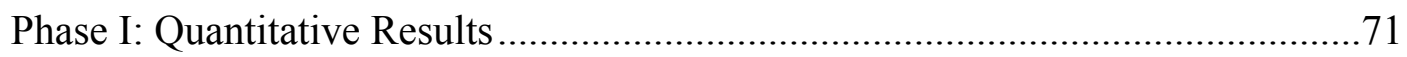

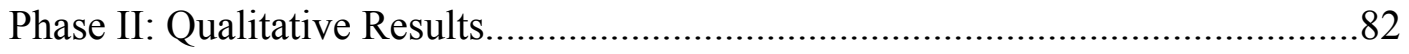

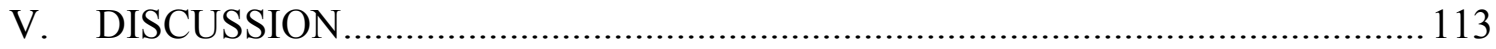

Predictive Validity of the GRE Across Disciplines................................................113

Predictive Validity of the GRE and Other Student Characteristics....................... 114

Facilitators and Detractors of Achievement ....................................................... 119

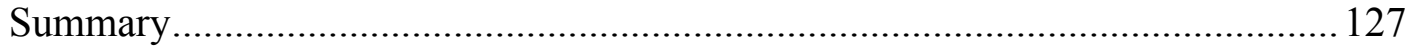

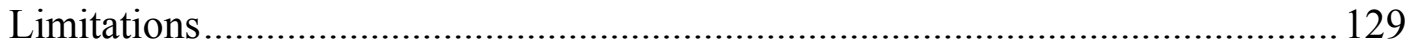

Implications and Recommendations............................................................... 130

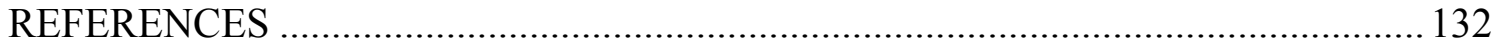




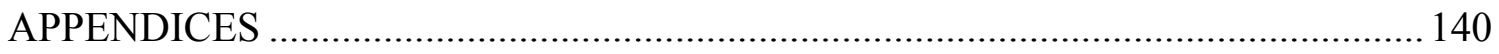

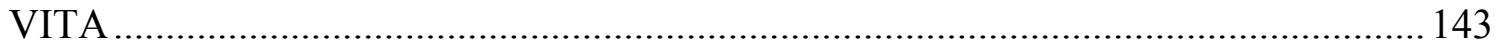




\section{LIST OF TABLES}

TABLE

PAGE

1. Summary of Major Studies Measuring the Predictive Validity of the GRE

2. Summary of Major Studies Measuring the Predictive Validity of the GRE Across

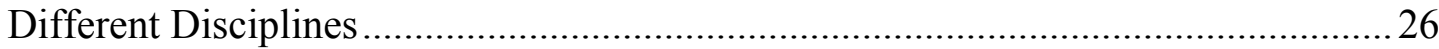

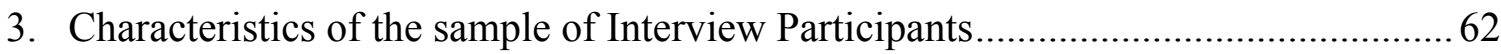

4. Number of Master's and Doctoral Level Students by Racial/Ethnic Group ............. 72

5. Number of Master's and Doctoral Level Students by Major................................. 73

6. GRE as a Predictor of GPA for Master's Students Controlling for Student

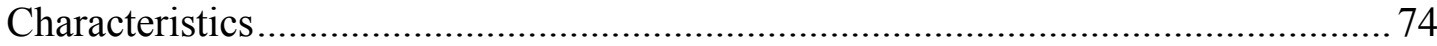

7. GRE as a Predictor of GPA for Doctoral Students Controlling for Student Characteristics.

8. GRE as a Predictor of GPA for Master's Students Controlling for Discipline ......... 78

9. GRE as a Predictor of GPA for Doctoral Students Controlling for Discipline ......... 79

10. Standardized Canonical Coefficients for Master's and Doctoral Students' Graduation Status

11. Test of Equality for Group Means for Master's and Doctoral Students' Graduation Status .81

12. Coding Map for Major Themes and Categories 84 


\section{CHAPTER I \\ INTRODUCTION}

Screening graduate students for admission into higher education is a source of a long standing controversy. The focal point for the controversy lies in determining the most appropriate means for predicting student success. Amongst the various prediction variables used for determining admission, the Graduate Record Examination (GRE) General Test is one of the most extensively used and deeply criticized measure of student success. The main criticism of the GRE is that it may under-predict the success of marginalized groups, thus limiting their access and choice to graduate education.

Internationally competitive job markets are increasingly elevating the expected degree level of the potential employees. The ability to obtain a graduate education is rapidly becoming essential to finding good employment opportunities and greater lifetime earnings. However, to gain access to graduate education, successfully completing the GRE General Test is usually one of the first steps. In fact, the majority of graduate programs require the GRE as a part of their admission criteria. In the field of psychology, for example, as many as $93 \%$ of doctoral programs and $81 \%$ of master's programs require GRE scores to be reported in order to gain admission into their programs (Norcross, Hanych, \& Terranova, 1996). Simultaneously, vast changes in the demographics of the United States are occurring as the number of individuals of racial and ethnic minorities is quickly becoming a greater proportion of the population, projected to account for more than half of the total population by 2050 (Young, 2007). 


\section{Research Problem}

One of the original arguments for using standardized tests for admission selection in American higher education was that these tests can provide a wider range of students the opportunity to obtain university degrees. Proponents have argued that the GRE is an equalizing factor that measures student attitude and helps in the admission of students who have a higher likelihood of success in graduate studies. They believe the GRE is necessary to counteract issues such as grade inflation and differential grading systems in undergraduate coursework. Furthermore, other admission measures such as letters of recommendation and sample essays may yield data that cannot be easily compared, thus diminishing the accuracy of measuring student ability (Edwards \& Schleicher, 2004). However, critics argue that the GRE and other high stakes standardized tests may underpredict academic performance for marginalized populations such as racial/minorities, women, and older graduate students (Stricker \& Rock, 1995).

Since the value placed on GRE scores to gain admission, scholarships, and assistantships can be a determining factor in the access and choice of potential graduate students, this study was undertaken because it is important to examine the ways in which GRE prediction value varies across groups and disciplines. Currently, there are many gaps and much contradictory evidence regarding these differences.

Few studies attempt to analyze what student characteristics may alter the prediction value of the GRE. This is especially relevant since a high number of graduate students at the doctoral level do not complete their degrees even if they were admitted using GRE scores as one of the admission selection cut off points. The exact number is difficult to measure; however, most researchers agree that doctoral attrition rate is $50 \%$. 
These numbers also tend to vary according to institutional location with a $33 \%$ attrition rate for rural universities and a 68\% attrition rate for urban universities (Lovitts, 2001). It is crucial to understand alternative characteristics that can predict graduate student success. The studies that have explored additional types of student characteristics in relation to the GRE have mainly focused on psychological factors and not on mentoring or other factors more commonly associated with graduate student success (Edwards \& Schleicher, 2004; Powers \& Kaufman, 2002). Thus, the currently available research in the literature regarding the predictive validity of the GRE is lacking evidence on possible extraneous variables (in the form of student characteristics) that can act as modifiers in graduate student success.

Research is scarce or inconclusive regarding the GRE's prediction value in predominantly language minority institutions. This study was conducted because there is a need to identify the best predictors of success in graduate school in such institutions. The current study attempted to identify the best predictors of success in a Hispanic Serving Institution. Understanding what variables and student characteristics are important in predicting student success is becoming more important as the population of students in graduate studies shifts and an increasing number of those seeking opportunities to enroll are racial/minorities, women, and/or older adults (Young, 2007).

\section{Purpose of the Study}

This study had two principle purposes. The first purpose was to evaluate whether the GRE is a valid predictor of graduate student success across disciplines and populations in a HSI. While various researchers have attempted to analyze the validity of the GRE, very few of these studies have conducted an analysis of its predictive validity 
within separate disciplines. In one study, GRE scores of graduate students from nine majors were used to examine prediction validity. However, that study was not comprehensive in the range of disciplines analyzed, only used graduate GPA as predictors of success, did not consider minority student status since there were too few in the sample, and did not differentiate between master's and doctoral students (Luthy, 1996). Similarly, Kuncel, Hezlett, and Ones' (2001) benchmark meta-analysis of 1,753 studies provided data on GRE validity across various disciplines, but only used first year graduate GPA as a predictor of success when in reality GPA in graduate studies tends to be restricted in range and does not necessarily equate with degree completion (which is a more significant outcome of graduate studies).

The second goal was to understand the student attributes and reported circumstances that lend to success/failure in a HSI graduate school contrary to what is predicted by the GRE. No studies were found that analyzed HSIs regarding this phenomenon. However, the few studies that utilize measures to explore graduate student characteristics primarily gather data from faculty advisors and not from students (Kuncel, et al., 2001; Luthy, 1996; Stricker \& Rock, 1995). Of the studies involving student characteristics other than demographics, all focus on psychological characteristics that are difficult to measure or utilize for admissions (Edwards \& Schleicher, 2004; Powers \& Kaufman, 2002). One of the principle goals of this study was to gain an understanding of these characteristics in order to supplement current methods of accepting applicants into graduate school and develop an understanding how these characteristics play a role in graduate student success using a combination of quantitative and qualitative methods. 
Analyzing this relationship is an essential component of understanding alternative factors that can influence graduate student success.

\section{Research Questions}

The focus of this study was to gain a deeper understanding of the predictive validity of the GRE in a HSI by asking and answering the following research questions:

1. How well does the GRE predict graduate student success in a minority serving institution across academic disciplines?

2. Does the GRE predict graduate student success when controlling for academic discipline, race/ethnicity, sex, and age?

3. What are the facilitators and detractors of achievement for successful graduate students?

This study was guided by all three of these research questions.

\section{Significance of the Study}

Accurately predicting the success of graduate students is an important part of determining which students should be admitted into graduate programs. The GRE is a pivotal factor to examine since it is one of the most widely used tools for predicting graduate student success. Even though the GRE is advertised as accurately predicting

first year graduate GPA, long term success factors such as time to degree and graduation rate have not been widely studied (Luthy, 1996; Powers, 2004). Furthermore, since most studies have low racial/minority sample sizes, the validity of the GRE may not be the same across all groups (Educational Testing Services, 2008a; Kuncel et al., 2001). Student characteristics such as degree of academic involvement, mentorship interactions, 
and other academic and social experiences have not been widely researched in the context of the predictive validity of the GRE.

An analysis of the predictive validity of the GRE in a HSI presented a new perspective on how well standardized admissions tests predict success across different types of institutions. Additionally, this study used a mixed methods approach where qualitative analysis of student interviews complemented the quantitative analysis of student data in order to provide a broader view of factors that may be related to graduate student success. The body of knowledge was expanded by exploring the influence of proximal and distal facilitators of success and by providing a rich description of the role of these facilitators in graduate studies.

\section{Background of the Study}

Recent trends in the United States have concentrated on increasing accountability in education. In this case, accountability is strongly associated with establishing measures by which administrators and governmental agencies can gather quantifiable data. Presently, data gathering is mainly manifested in the form of increased testing efforts. The No Child Left Behind Act of 2001 solidified the influence of high stakes standardized testing and accountability movement and expanded federal control of state run educational systems (Linn, Baker, \& Betebenner, 2002). The expansion of the role of standardized testing into higher education became evident when the Education Department Secretary Spellings' Commission on the Future of Higher Education recommended that high stakes standardized tests should be used for assessing students in colleges and universities (The Secretary of Education's Commission on the Future of U.S. Higher Education, 2006). 
The Educational Testing Service (ETS) began publishing the Graduate Record Examination in 1949 as a means of providing admission personnel a common measure by which to compare applicants from diverse educational backgrounds. The GRE was originally designed to be a supplementary measure to inform admission decisions and not the sole measure to establish strict cut-off points for admission. There are three major components to the GRE General Test: Verbal Reasoning (GRE V), Quantitative Reasoning (GRE Q), and Analytical Writing (GREAW). In the mid 1990s, both of the multiple-choice components began using a computer-adaptive testing (CAT) method by which the remaining questions on the test change based on whether the test taker selects right or wrong answers. According to the ETS, the correlation between the GRE General Test and graduate GPA equal to $r=.32$ in the verbal section and $r=.26$ in the quantitative section amongst master's level students and $r=.27$ in the verbal section and $r=.30$ in the quantitative section amongst doctoral level students (Educational Testing Services, 2008a). These low correlations should be interpreted in the context of the possibility that GPA in graduate school has a restricted range. Obviously, other indicators of success are needed.

Furthermore, when considering these correlations, the GRE's scope in accurately predicting graduate student success is limited to only the first year grades (Educational Testing Services, 2008a; Goldberg \& Alliger, 1992). The prediction value for the GRE significantly drops for the second year of graduate studies and beyond (Sternberg \& Williams, 1997). Thus, the practice of using the GRE score as the exclusive determinate of whether or not an application is reviewed may greatly limit the number of admitted candidates who may show success beyond first year GPA. 
Opponents of using the GRE as the principle criterion for selecting graduate students have questioned the fairness and validity of the test. Various researchers have demonstrated inconsistencies concerning how well the GRE can predict graduate student success across different groups. At best, their conclusions indicate modest correlations between GRE scores and race/ethnicity, sex, and age (Stricker \& Rock, 1995). The fact that these extraneous variables are related to GRE test results has also been illustrated in other studies (Awad, 2007; Ferguson \& Crandall, 2007; Lightfoot \& Doerner, 2008). It is not clear if these differences are indictors of true ability differences across the groups or an indicator of test validity. If the differences are true representations of actual aptitude differences, then sex, SES, and ethnicity variations actively support the GRE's construct validity. Understanding how the predictive validity of the GRE varies across groups is significant when considering utilizing scores to accept students into graduate programs or to distribute graduate assistantships, scholarships, and other merit based awards.

\section{Using the GRE as a Predictor of Success in MSIs}

The relevance of these criticisms regarding the predictive validity of the GRE across groups has not been widely studied in minority serving institutions (MSI). Increasingly, understanding the most appropriate predictors of student success is becoming more important since higher education trends in recent years have indicated that racial/ethnic minority students are the group that has demonstrated the highest increases in population when compared to White students. Furthermore, despite being more involved in higher education than ever before, minority students are still underrepresented. For example, the 2000 census reported that Hispanics accounted for $12.5 \%$ of the total population and $17.5 \%$ of the college age population, yet they only 
represented $4.6 \%$ of all master's recipients and $4.1 \%$ of all doctoral recipients (Chapa \& De La Rosa, 2006). This trend was similar across other racial/ethnic minority groups.

There are four types of MSIs including: Historically Black Colleges and Universities (HBCUs), Hispanic Serving Institutions (HSI), Tribal Colleges and Universities (TCUs), and Asian American and Pacific Islander Serving Intuitions (AAPIs). For any given type of institution, the criterion to be an MSI is to be a not-forprofit college or university that has an undergraduate student body consisting of at least $25 \% \mathrm{racial} /$ ethnic minority students (Baez, Gasman, \& Viernes-Turner, 2008). Little is known about the predictors of success in Hispanic Serving Institutions of the type that is the focus of the current study. Based on the Integrated Postsecondary Education Data System (IPEDS), in 2005-2006 there were 252 institutions that were classified as HSIs. Among these institutions, 90 offered graduate programs (Santiago, 2006). Prior to the current study, scarce research has been conducted on graduate Hispanic students in higher education institutions and no studies were found on the validity of the GRE in HSIs. As the population of Hispanic students grows at a faster rate than other racial/ethnic groups in the United States, it is becoming increasingly urgent to identify the predictors of success in these schools, especially the usefulness of the GRE for that purpose (Chapa \& De La Rosa, 2006).

\section{HSI: Florida International University}

The Hispanic Serving Institution selected for the current study was Florida International University. FIU is one of the 25 largest universities in the United States in terms of size and Hispanic student enrollment. Out of the 44,000 students attending the university, $60 \%$ are Hispanic (Florida International University, 2011). This high 
proportion of Hispanics, its location (Miami, Florida), and its strong link to the Hispanic community in South Florida, mades FIU an ideal institution for the current study.

When only accounting for the graduate students, according to the Fall 2008 Fact Book data, $43 \%$ of the 5,594 masters level students were Hispanic $(n=2,422)$ and $28 \%$ of the 1,035 doctoral or professional degree students were Hispanic $(n=291$; Florida International University, 2008a). However, in the case of degree attainment, there is a slight drop in the number of Hispanic students attaining degrees. Amongst the Hispanic population, master's students represent $42 \%$ of the degrees awarded and $26 \%$ of the doctorate and professional degrees awarded. As a comparison point, White graduate students represent $22 \%$ of master's level enrollment and $20 \%$ of earned master's degrees, but they represent $26 \%$ of the doctoral/professional degree enrollment and $42 \%$ of the earned doctoral/professional degrees (Florida International University, 2008b). Even in a university known to grant the most degrees to Hispanic students compared to all other universities in the United States, there is disproportional representation of White students earning degrees at the doctoral and professional levels. This trend is consistent with universities across the United States and is one of the reasons why investigating minority student access, retention, and academic success at the graduate level are important areas of study.

\section{Theoretical Framework}

The literature on adult achievement factors emphasizes the importance of establishing a multidimensional approach to predicting success. Therefore, in order to improve the accuracy of predicting success, multiple characteristics should be evaluated. These characteristics range from factors that continuously and directly influence adult 
learner behavior to factors that occur infrequently and have limited influence on adult learner behavior. The first extreme of this range is referred to as a proximal facilitator or proximal influence. Proximal facilitators tend to be factors that influence daily life. Some examples of meaningful life events include recent life events, motivation, interpersonal interactions, environmental interactions, and other similar behaviors (Martin \& Martin, 2002). On the other hand, distal facilitators are defined as past events or influences that do not affect daily life but may affect beliefs such as self-efficacy. For graduate students, examples of distal facilitators include undergraduate GPA and GRE scores. Both proximal and distal facilitators influence students. However, no research has analyzed the differences between these two factors in terms of predicting graduate student success.

Motivation research has also used the concepts of proximal and distal to examine success factors and perseverance in adulthood. According to this research, proximal constructs are more likely to influence processes that are closest to actual behavior and distal constructs are more likely to influence processes that are distant to actual behavior. In other words, the more proximal the influence, the more probable it is to affect day-today behaviors. On the other hand, distal influences may affect beliefs and dispositions, but may not have a direct impact on behaviors (Kanfer, 1992).

The current study reviewed both proximal facilitators such as mentoring experiences and distal facilitators such as the GRE in order to understand the characteristics that influence students to either succeed or fail in graduate studies. Thus the theoretical framework focused on these two mediators to guide the research. Below, Figure 1 illustrates the overarching theoretical model of the study whereby proximal and 
distal facilitators influence graduate students and guides the behaviors that impact their level of academic success.

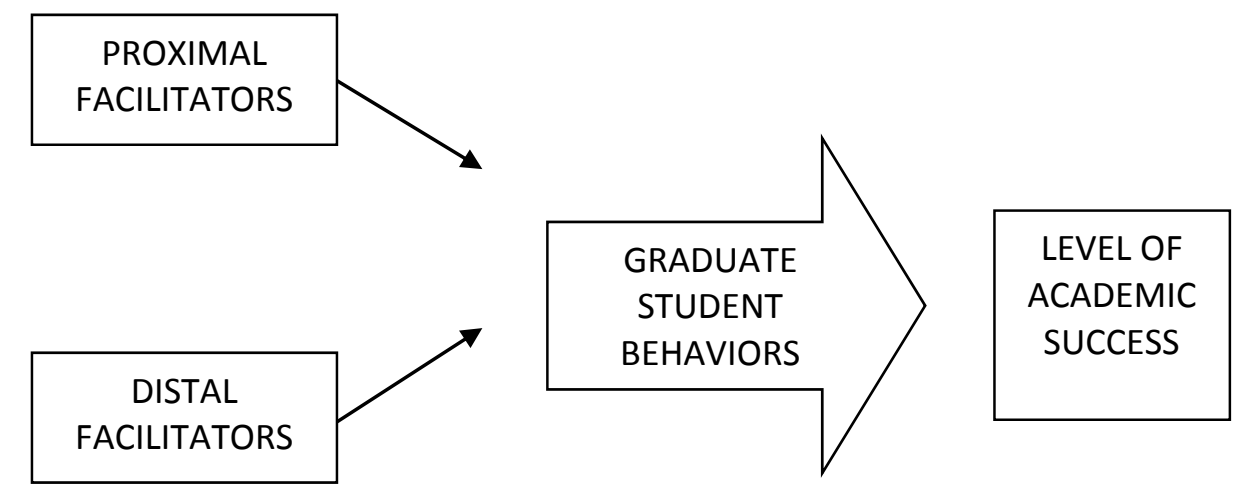

Figure 1. Model of factors influencing graduate student success.

Most of the research on graduate student success focuses on proximal facilitators affecting graduate student success. A common theme amongst these studies is that mentorship relations are pivotal to graduate student development and success. One of the major roles of graduate education is to provide students with the tools necessary to become stewards of the discipline (Stacy, 2006; Walker, Golde, Jones, Conklin Bueschel, \& Hutchings, 2008). This process involves fostering relationships between faculty and students that will lead to engagement in scholarly research and dispositions. Mentoring relationships may not solely focus on the interactions between one faculty member and one student. Instead, mentorship relationships can occur amongst various faculty members and students. The process of interaction is essential in actively engaging students in their graduate studies experiences rather than having these students be passive recipients of knowledge.

Another proximal facilitator closely associated with graduate student success focuses on the importance of fostering intellectual communities. Concurrent with the 
literature on mentorship, researchers have also addressed the importance of community in graduate student learning and success. Walker et al. (2008) discussed eight ways of developing and maintaining active intellectual communities. The first way is to foster student engagement in their department through activities such as seminar series. A second method is to involve students in developing the curriculum so that this collaboration can help build a professional community. Third, research should be shared across departments and disciples to establish connections and broaden intellectual discourse. Fourth, is to open activities in the classroom to other faculty and students within the program in order to allow expansion and self-reflection. The fifth method is to foster an environment that is open to risk and the possibility of failure, both of which are vital components of learning. The sixth way to develop an intellectual community is to set time to reflect upon current practices and engage in intellectual dialogue and thought. Closely related to the sixth method, the seventh method describes building physical environments where intellectual reflection and informal learning could take place. The final method of establishing and maintaining intellectual communities is to create and participate in social activities that strengthen existing intellectual bonds and encourage further involvement with academic engagement. All of these methods lead to active student engagement in their academic community and all fall within the context of proximal facilitators that can influence graduate student success.

Other theorists have conducted research related to proximal facilitators of success in higher education. One theory that is closely linked to the research mentorship and academic communities is Astin's (1984) theory of involvement. The fundamental premise of this theory is that student involvement is an essential part of student learning 
and student success. Students who partake in student organizations, attend campus activities, interact with faculty, engage in scholarly activities, attend classes, cooperate with peers, and participate in other aspects of campus life are more likely to persist, and are more likely to succeed (Astin, 1984, 1996, 1999, Chickering \& Gamson, 1987; Tinto, 1975). This theory is focused on holistic learning/development concepts whereby students are able to expand their knowledge base both inside and outside of the traditional classroom (Astin, 1984; Tinto, 1975). Though this theory has been mainly applied to undergraduate students, the one study located that was conducted on graduate students indicated that Astin's theory is also relevant to students in their graduate studies (Garner \& Barnes, 2007). In recent years, a growing movement to understand and promote graduate student engagement has begun, but the movement is supported by minimal empirical research to study and assess this process (Pontious \& Harper, 2006). The current study used Astin's theory of involvement and other literature on involvement, academic communities, and mentorship as a means of understanding the role of proximal facilitators in graduate student success while simultaneously exploring the role of the GRE as a distal facilitator of graduate student success.

\section{Delimitations}

There are several factors that may limit the generalizability of this study. First, the sample of participants only includes students who have already been admitted into a graduate program. As in most studies related to prediction validity of admission measures, this study did not represent the entire range of possible GRE scores since data on students who applied and were not admitted were not available. Second, the study does not measure the variances in language proficiency that may affect scores on the 
GRE. However, a portion of this variance is eliminated because some of the international students applying for graduate school take the Test of English as a Foreign Language (TOEFL) in place of the GRE.

\section{Definitions of Terms}

\section{Distal Facilitators}

Contrary to proximal facilitators, distal facilitators are characteristics that are not directly impacting students' daily behavior, but may modify student perceptions or beliefs (Kanfer, 1992; Martin \& Martin, 2002). This study used the GRE scores as a distal facilitator and analyzed how this type of predictor relates to graduate student success in a Hispanic Serving Institution.

\section{Graduate Student Success}

The definition of graduate student success varies greatly according to the researchers and institutions that investigate it. For the current study, this concept is defined as the ability for students enrolled in master's and doctoral degree programs to obtain high graduate GPA (GGPA) and to complete their degree (graduation rates with 6 years for master's students and 9 years for doctoral students). The latter variable was selected because graduate school grades are restricted in range and because degree completion is an important, though often ignored, success measure.

\section{Proximal Facilitators}

Research on adult learning and adult achievement has centered on analyzing characteristics that are directly impacting student behavior and characteristics that are indirectly impacting student behavior (Martin \& Martin, 2002). This study uses the term proximal facilitator to describe characteristics or incidents that directly affect students. 
Examples of these characteristics include mentorship opportunities, social interactions, scholarly experiences, and motivational factors, which tend to be measured through interview data collection.

\section{Student Engagement}

Student engagement includes a myriad of characteristics and behaviors that are most closely linked to the concept of proximal facilitators. Theorists have long argued that the degree to which students are actively engaged in their environment directly impacts their success. Astin's involvement theory extensively describes the importance and relevance of the relationship between student engagement and student success. This study, defines student involvement as guided by the five of the commonly accepted dimensions outlined by previous student engagement research (Astin, 1984; Chickering \& Gamson, 1987; Tinto, 1997). These dimensions are: student-faculty interaction, participation in campus activities, energy expended on academic activities, peer interactions, and participation in organizations or student groups. All of these characteristics are proximal facilitators.

\section{Overview of the Remaining Chapters}

As competition in job markets increase globally, more jobs require graduate degrees than ever before. The number of students applying to graduate programs is likewise increasing. Thus, the significance of attaining a graduate education yields exponentially higher life time earnings and a greater array of career opportunities than are available with a high school or undergraduate degree. Using the Graduate Student Record score as a means of selecting students into graduate studies or to award financial and academic benefits such as university scholarships, fellowships and assistantships can 
limit the access and choice of historically under-performing standardized test takers. This study explored the GRE's predictive validity across different racial/ethnic, sex, and age groups in different disciplines. To further investigate this phenomenon, the study also examined the types of student characteristics that were either facilitators or detractors to student success. In the final chapter, these facilitators and detractors are explored through the lens of proximal and distal facilitators of adult student persistence and adult student success.

The study was guided by the following research questions:

1. How well does the GRE predict graduate student success in a minority serving institution across academic disciplines?

2. Does the GRE predict graduate student success when controlling for academic discipline, race/ethnicity, sex, and age?

3. What are the facilitators and detractors of achievement for successful graduate students?

This study is organized into five chapters. The current segment, Chapter 1, focuses on providing a brief overview of the controversies related to the prediction validity of the GRE General Test and describing the purposes, research questions, theoretical framework, and central concepts related to this study. In Chapter 2, a summary and analysis are presented of the literature pertaining to other GRE validity studies and to student characteristics relevant to graduate student success. The focus of Chapter 3 is a description of the research methods that were used to answer the central research questions of this study. In the fourth chapter, the results of Phase I and Phase II of the study will be included. Finally, in Chapter 5 the data presented in Chapter 4 will be 
analyzed and interpreted as they relate to the three research questions. Conclusions and recommendations finalize the report of this study. 


\section{CHAPTER II}

\section{REVIEW OF LITERATURE}

The ability to accurately select the most qualified candidates for graduate training programs has been a source of great controversy. The Graduate Record Examination is one of the most frequently used gatekeepers to admission into graduate school. As with other standardized tests whose origins stem from intelligence tests designed to measure predominantly White male populations, questions arise regarding the generalizability of the GRE in measuring student success across diverse groups. In the United States and abroad, obtaining access to higher levels of education is essential to lifetime gains in knowledge, skills, employment opportunities, and socioeconomic progress (Young, 2007). The current study was aimed to investigate whether the GRE accurately predicts graduate student success across different minority, sex, and age groups in a HSI.

This chapter contains a review of previous research on these factors and other related issues. The literature review presented encompasses mainly articles and books published within the last decade with the exception of benchmark or historically important research. In order to obtain the documents, various databases were queried (i.e., ERIC, Educational Full Text, PsychINFO, ProQuest, and the FIU library catalog) using of the following search criteria: GRE, graduate success, predictors, and other related variations. The chapter is organized by presenting relevant research about the GRE and graduate student success as described by the following summary.

Though various studies have attempted to measure whether the GRE is an accurate prediction tool, few studies have attempted to research the predictive validity of the GRE across disciplines when accounting for other variables such as race/ethnicity, sex, and 
age. This study attempted to investigate these issues and expand the current body of knowledge on the infrequently studied graduate student population through the following research questions:

1. How well does the GRE predict graduate student success in a minority serving institution across academic disciplines?

2. Does the GRE predict graduate student success when controlling for academic discipline, race/ethnicity, sex, and age?

3. What are the facilitators and detractors of achievement for successful graduate students?

It should be noted that recent studies have not addressed these research questions in the context of other HSIs. Hence, much of this chapter will examine the literature on the predictive validity of the GRE in general, followed by literature on the predictive validity of the GRE across disciplines. The subsequent sections focus on summarizing the literature relating the correlation of GRE scores with student success amongst different minority, sex, and age groups. The final segment addresses research on various student characteristics and how these characteristics may influence and/or measure graduate student success. The purpose of this chapter is to describe previous research in order to clarify the background and importance of the research topic and to expand our understanding of GRE prediction validity and graduate student success factors.

\section{Predictive Validity of the GRE}

The general predictive validity of the Graduate Record Examination: General Test varies across different studies and the measures by which success is defined are different for each study. Some studies indicate that all segments of the GRE are valid predictors of 
student success, but have inadequate measure of success. For instance, one study found that the GRE was a good predictor of success for students entering veterinary medicine (Powers, 2004). However, the measure used to determine success was the correlation between GRE and first year graduate GPA, which may not be an adequate measure of long term success or of degree completion. A similar study also measured graduate GPA and also found a high correlation between GRE and grades $(r=.45)$ for students who had completed at least half of their program (Nilsson, 1995). As in the study by Powers, the study conducted by Nilsson was limited in the ability to predict long term success as measured by program completion variables.

Another approach has centered on utilizing a field specific measure to determine graduate student success. For example, Smaby, Maddus, Richmond, Lepkowski, and Packman (2005) examined how the GRE and GPA scores of graduate students in a master's counselor education program $(n=80)$ correlated with their scores in the Skilled Counselors Scale (SCS). Their study concluded that only two variables, the GRE Verbal and graduate GPA, predicted the Skilled Counselors Scale scores the students received ( $r$ $=-.25)$. However, as in the previous study, the indicator for student success does not necessarily relate to the long term success of this student population.

Studies that use multiple variables as measure of graduate student success, have shown inconsistent results. One of the benchmark studies analyzing the predictive validity of the GRE was a meta-analysis conducted by Kuncel, Hezlett, and Ones (2001). According to this meta-analysis, the GRE is a better predictor of success for overall graduate GPA, first year GPA, comprehensive exam scores, and faculty ratings than for research productivity, number of publication citations, time to degree attainment, and 
degree completion. A smaller scale meta-analysis also concluded that the GRE was a predictor of the comprehensive exam scores (Verbal $r=.37$ and Quantitative $r=.27$ ), but reported a lower correlation with graduate GPA (Verbal $r=.15$ and Quantitative $r=.15$ ). Unlike in the previous meta-analysis, other predictors of student success were not analyzed and the population studied only included graduate students in the field of psychology (Chernyshenko \& Ones, 1999).

A summary of the major studies regarding the predictive validity of the GRE is organized in Table 1. The table is sorted by the type of measure of success evaluated in each study and serves as an overview of the predictors and their corresponding correlation coefficients.

As Table 1 demonstrates, the predictive validity of the GRE greatly varies according to what variables are used as predictors of success and across different studies measuring different populations. Few studies measure the ultimate indicators of graduate student success which are degree completion and time-to-degree. Furthermore, the studies discussed in this segment did not include information about the predictive ability of these variables among different sex, racial/ethnic, or age groups, thus the results may not apply to all graduates students in the same manner. 
Table 1

Summary of Major Studies Measuring the Predictive Validity of the GRE

\begin{tabular}{|c|c|c|c|c|c|}
\hline Researcher(s) & $\begin{array}{l}\text { Measure of } \\
\text { Success }\end{array}$ & $\begin{array}{l}\text { Sample } \\
\text { Size }\end{array}$ & GRE V & GRE Q & GRE T \\
\hline \multirow{2}{*}{$\begin{array}{l}\text { Chernyshenko \& Ones } \\
\text { (1999) }\end{array}$} & GGPA & 963 & .15 & .15 & -- \\
\hline & $\begin{array}{l}\text { Comprehensive } \\
\text { Exam }\end{array}$ & $152+$ & .37 & .27 & -- \\
\hline Nilsson (1995) & GGPA & 30 & -- & -- & .45 \\
\hline \multirow{8}{*}{$\begin{array}{l}\text { Kuncel, Hezlett, \& } \\
\text { Ones (2001) }\end{array}$} & GGPA & $14,156+$ & .23 & .21 & -- \\
\hline & $1^{\text {st }}$ Year GGPA & $45,615+$ & .24 & .24 & -- \\
\hline & $\begin{array}{l}\text { Comprehensive } \\
\text { Exam Scores }\end{array}$ & $1,198+$ & .34 & .19 & -- \\
\hline & Faculty Ratings & $4,766+$ & .23 & .25 & -- \\
\hline & $\begin{array}{l}\text { Research } \\
\text { Productivity }\end{array}$ & 3,328 & .07 & .08 & -- \\
\hline & $\begin{array}{l}\text { Publication } \\
\text { Citations }\end{array}$ & 2,306 & .13 & .17 & -- \\
\hline & $\begin{array}{l}\text { Degree } \\
\text { Attainment }\end{array}$ & 6,304 & .14 & .14 & -- \\
\hline & Time to Degree & 160 & .21 & -.08 & -- \\
\hline Powers (2004) & GGPA & 1,420 & .21 & .26 & .53 \\
\hline $\begin{array}{l}\text { Smaby, Maddux, } \\
\text { Richmond, Lepkowski, } \\
\& \text { Packman (2005) }\end{array}$ & $\begin{array}{l}\text { Skilled } \\
\text { Counselor } \\
\text { Scale }\end{array}$ & 80 & -.25 & .06 & .24 \\
\hline
\end{tabular}

Note. $p<.05$

\section{Predicting GRE Validity Across Disciplines}

When analyzing the correlation of GRE scores to the different disciplines of study, there are some differences in how well the GRE could predict graduate student success. The ETS uses the findings of a meta-analysis conducted by Kuncel, et al. (2001) to describe the predictive validity of the GRE across disciplines. That study reported that the GRE Verbal was a stronger predictor of first year graduate GPA for the humanities and social sciences fields than for the math, physical sciences, and life sciences fields. 
The GRE Quantitative, on the other hand, was a greater predictor if first year graduate GPA for the math, physical sciences, and social sciences, than for the life sciences and the humanities. When comparing the prediction validities of the GRE for first year graduate GPA and degree attainment, the results vastly vary. The following correlations describe the differences between the predictive validity of first year GGPA and degree attainment respectively (Educational Testing Services, 2008a; Kuncel et al.):

- Humanities GRE V $=.40$ and GRE $\mathrm{Q}=.35$ vs. GRE V $=.73$ and GRE $\mathrm{Q}=.17$

- Social sciences GRE V $=.34$ and GRE $\mathrm{Q}=.35$ vs. GRE $\mathrm{V}=.22$ and GRE $\mathrm{Q}=$ .31

- Life sciences GRE V $=.24$ and GRE $\mathrm{Q}=.37$ vs. GRE $\mathrm{V}=.03$ and GRE $\mathrm{Q}=-.09$

- Math and physical sciences GRE V $=.37$ and GRE $\mathrm{Q}=.37$ vs. GRE V $=.26$ and GRE $\mathrm{Q}=.31$.

In summary, the study reported a similar trend to the majority of the literature in which the predictive ability of the GRE varies across disciplines and across measures of graduate success. Furthermore, with the exception of the GRE V in the field of humanities, the tendency is that graduate degree completion is less related to the GRE score when compared to first year GGPA.

Finally, at best, the GRE accounts for less than approximately $16 \%$ of variation in success (the largest $r$ was $r^{2}=.16$ ). Comparing the predictive validity of the GRE Verbal and Quantitative, Luthy (1996) found that the GRE Verbal was a higher predictor of graduate GPA for English (.32) and political sciences, than for fields like psychology (.09) and nursing (.14). In the case of the GRE Quantitative, the test was a higher predictor of graduate GPA in computer science (.26) and in political science (.21) than in 
educational administration (.09) and psychology (.11). Despite the relative low correlations, these results are consistent with those of other researchers who argue that the GRE General Test is a less valid predictor of success for particular disciplines than more discipline specific tests.

Researchers have often advocated for utilizing tests related specifically to the intended field of study such as the GRE Subtests or other disciplines specific tests to replace the GRE for admissions requirements (Bridgeman \& Cline, 2004; Payne, Briel, Hawthorn, \& Riedeburg, 2006). Table 2 summarizes the findings of the major studies that have used discipline as one of the variables of analysis within the context of measuring the predictive value of the GRE. As described before, these results demonstrate the inconsistencies in the predictive value of the GRE across disciplines and across test segments (i.e., GRE qualitative and GRE verbal). Few scholars have attempted to investigate or explain this inconsistency. Also, an investigation of possible variation in the predictive value of the GRE within different minority, sex, and age groups are rare.

\section{Predictive Validity for Minority Students}

The ETS report Graduate Records Examinations: Guide to the Use of GRE Scores (2008a) cautions that though the GRE is a valid predictor of first year graduate GPA when averaging all studies, the sample sizes of minority student populations have been very small. Thus, the data derived from the GRE may not take into account potential differences in culture, linguistic background, and educational experiences for these 
Table 2

Summary of Major Studies Measuring the Predictive Validity of the GRE Across Different Disciplines

\begin{tabular}{|c|c|c|c|c|}
\hline Researcher(s) & Discipline & Sample Size & GRE V & GRE Q \\
\hline \multirow{4}{*}{$\begin{array}{l}\text { Kuncel, Hezlett, \& Ones } \\
\text { (2001) }\end{array}$} & Humanities & 6,152 & .40 & .35 \\
\hline & Life Sciences & 8,616 & .34 & .35 \\
\hline & Math/Science & 8,076 & .24 & .37 \\
\hline & Social Science & 22,375 & .37 & .37 \\
\hline \multirow[t]{9}{*}{ Luthy (1996) } & $\begin{array}{l}\text { Adult Continuing } \\
\text { Education }\end{array}$ & 388 & .24 & .17 \\
\hline & Computer Science & 298 & .23 & .26 \\
\hline & $\begin{array}{l}\text { Communicative } \\
\text { Disorders }\end{array}$ & 229 & .16 & .14 \\
\hline & $\begin{array}{l}\text { Educational } \\
\text { Administration }\end{array}$ & 615 & .21 & .09 \\
\hline & Engineering & 376 & .15 & .18 \\
\hline & English & 367 & .32 & .15 \\
\hline & Nursing & 286 & .14 & .15 \\
\hline & Political Science & 357 & .29 & .21 \\
\hline & Psychology & 219 & .09 & .11 \\
\hline
\end{tabular}

Note. $p<.05$

populations. Across the three subtests of the GRE, minority students score significantly lower than White students, with the exception of Asian students who score higher on the GRE Quantitative section (Educational Testing Services, 2008b). However, it has been argued that test performance may not be a good predictor of academic performance in graduate school among minorities. For instance, Reisig and DeJong (2005) investigated the validity of the GRE in predicting graduate student success in a criminal justice program ( $n=267$ master's students and $n=120$ doctoral students). When sorted by race/ethnicity, GRE/undergraduate GPA was a predictor of low grades for doctoral 
minority students $(r=-.45)$, but not for White students $(r=.17)$. It should be noted, however, that analysis of the relationship between the combined GRE and undergraduate GPA scores and graduate GPA indicated that there was a negative correlation for minority students and a positive, though not significant, correlation for White students.

There are several major difficulties in understanding the predictive validity of the GRE General Test for minority groups. First, most of the research related to the GRE has focused on overall statistics rather than on individual ethnic or racial groups. Even the massive meta-analysis conducted by Kuncel et al. (2001) that covered almost a large variety of factors and variables from 1,753 independent studies did not mention the role race and ethnicity had in the predictive validity of the GRE. In some other studies, minority students are lumped into one category regardless of whether they are Hispanic, African American, Asian, or other minorities. This lack of specificity does not provide a clear understanding of how the GRE predictive validity differs among groups (Lightfoot \& Doerner, 2008; Reisig \& DeJong, 2005).

Second, some studies are either poorly designed and/or have questionable findings and thus, credible conclusions about the predictive validity of the GRE are not available. For example, a study comparing Black and Asian students by using the GRE and the chosen disciplines as measures of intelligence, concluded that lower scores among Black students indicated "biologically ingrained differences" in the intelligence of different ethnic groups (Templer, Tomeo, Arikawa, \& Williams, 2003, pp. 241). A later study conducted by Tampler and Arikawa (2006), arrived at the conclusion that White and Asian students were comparable in terms of intelligence. These two studies are key 
examples of how GRE scores may be used in ways that are not intended by the publisher and indicate a poor match between the research questions, the methods, and the findings.

Third, there is contradictory evidence of the predictive ability of the GRE General Test. For instance, a study using degree completion rates as the graduate success variable concluded that minority status and low GRE scores were predictors of obtaining doctoral degrees in criminal justice $\left(r^{2}=.26\right)$. Even if the evidence is accepted as credible, no such evidence was found for minority students in the master's program. Instead, high GRE scores were predictors of degree completion (Lightfoot \& Doerner, 2008). Questionable evidence and inconsistent findings highlight the need for further investigation of how the GRE scores predict success among minority groups within different degree levels.

Fourth, is that factors such as country of origin, English as a Second Language (ESL), and first generation in college have not been explored extensively in studies. All of these factors are especially important for the vast number of immigrants from nonEnglish speaking countries who are entering the United States (especially from Spanish speaking countries). The only research found that attempted to analyze GRE test performance for ESL students was conducted by Pennock-Roman (2002) and did not study the GRE prediction of success for these students. Instead, the study investigated how well the GRE scores correlated with another Spanish language standardized test among Puerto Rican students. It concluded that students did better on the Spanish test than on the GRE. When addressing other factors that may be relevant to the predictive validity of the GRE, it is also important to consider that many minorities entering higher education are first generation college students (Chapa \& De La Rosa, 2006). According 
to an ETS report, Factors That Can Influence Performance on the GRE General Test 2006-2007, first generation college students scored significantly lower in all three segments of the GRE General Test than students whose parents have obtained college degrees (Educational Testing Services, 2008b). This finding is confounded by the fact that low SES and minority students are more likely to fall within the category of first generation students when compared to others groups.

Fifth, whenever the predictive validity of the GRE is reported, the magnitude of prediction is relatively low and ranges between $1 \%$ and $16 \%$ of the variance. This means that even under the best scenario at least $85 \%$ of the variation is unexplained. Most of the research related to minorities has focused on understanding how perceived racial biases influence student standardized test performance. Some studies suggest that negative stereotypes may be a factor that affects students' perceptions of achievement and consequently affects students' performance in high stakes tests where White men tend to exhibit higher levels of performance. Steele (1997) uses the term "stereotype threat" to define this phenomenon. According to his study, African Americans scored lower in tests that were diagnostic of academic aptitude (such as admission tests), than in tests that were non-diagnostic $(M=12.38$ vs. $M=18.53)$. When comparing the performance of Black and White student in the non-diagnostic condition, Black students narrowed the gap in performance so that mean difference was only 2.93 points rather than a difference of 8.55 points in the diagnostic condition.

In terms of perceived achievement, Black students in the diagnostic condition viewed their performance as worse than Black students in other conditions $(M=4.89$ vs. $M=6.54$ ), while White students' perceptions did not significantly change between 
condition types (Steele \& Aronson, 1995). Similar results were found for women who were tested under similar conditions when compared to men (especially in the area of math). These studies prompt further concerns over the validity of standardized achievement tests for marginalized students. When reviewing the previous studies, if socially constructed inequalities contribute to the final scores of achievement test such as the GRE, then these tests may only serve to further instigate and reinforce these inequalities (Steele, 1997; Steel, \& Aronson).

In a meta-analysis of various studies analyzing stereotype threat, Steele's (1997) findings were supported. The meta-analysis conducted by Nguyen and Ryan (2008) compiled and examined the results of 112 studies measuring relationship between stereotypes threat and test performance across various populations including women, African Americans, and Hispanics. The study concluded that stereotype threat was a more significant moderator of student test performance for minorities than for women (since minority group status accounted for $38 \%$ of the variance as opposed to $26 \%$ of the variance for sex group).

\section{Sex Differences}

In recent years, women have reversed historical trends to become the group with the highest attendance rates for both undergraduate programs and graduate programs. Despite this fact, there are still vast disparities when the data are aggregated and analyzed. According to a report from the Council of Graduate Studies, from 1997 to 2007 only about $40 \%$ of all female graduate students were enrolled in Doctoral/Research Extensive universities compared to $53 \%$ of male graduate students. Women only outnumbered men at Master's and Specialized institutions (i.e., 53\% of all female 
graduate students are in such institutions vs. $31 \%$ of all male graduate students). This trend poses implications for the level of access available across sex groups and is an important factor to consider while reviewing studies on women in graduate programs (Bell, 2008).

When using the GRE as a means of predicting female graduate student success for women, the existing evidence is not consistent across studies. Studies indicate that women have lower scores on the GRE when compared to men. Templar and Tomeo (2002) found that men outscored women in all segments of the GRE General test. Men scored a mean of 496 Verbal, 557 Quantitative, and 552 Analytic when compared to the respective women's score of 472, 506, and 529. Furthermore, these findings were also supported in an Educational Testing Services (2008b) report where all of the GRE test takers from 2006-2007 were studied. The report indicated that men had a mean score of 502 Verbal, 598 Quantitative, and 4.3 Analytic Writing, while women scored a 469, 521, and 4.2 respectively.

Despite this trend of men outperforming women, studies have reported that women's GPA tends to be higher than men's GPA (Chapell et al., 2005). However, this is not consistent across studies. Luthy (1996) conducted a study in which graduate GPA was consistently higher than predicted by the GRE score for women in computer science, psychology, and educational administration programs. However, there was no significant under-prediction for women in the other six disciplines studied. The lack of studies analyzing the sex differences in the GRE predictive validity between disciplines and minority groups warrants the need for further research. 
According to several studies, the content of the test may influence test performance differences between sex groups. Researchers have indicated that certain types of test items in standardized tests can affect sex differences in terms of scores. Contradicting this premise is the above mentioned ETS (2008b) study showing that women also lag in the GRE Analytic Writing subtest. In a study about GRE validity, researchers investigated whether there were sex differences when comparing performance on different types of questions of the GRE Quantitative test. The study concluded that test item context such as spatial reasoning versus verbal skills was related to performance. In a second part of their study, test items were modified to decrease sex differences while maintaining difficulty levels. When using the modified context, the performance of women improved (women scored a mean of 676 and men scored a mean of 674) (Gallagher, Levin, \& Cahalan, 2002). In a similar study, test item content was also associated with sex differences. When calculating the difference between men's scores and women's scores, women perform better in test items that were classified as "female favored" even though men out performed women in all item types of the GRE Quantitative. For instance, in one semester, the difference for the mean scores of "male favored" items was higher, than for the female favored items $(d=.11)$. As in the previous study, items where the most sex differences existed were related to spatial reasoning and the items where the fewest sex differences existed were related to storage and retrieval from memory and verbal skills (Gallagher et al., 2000).

In addition to test item content, the format of the test itself is also cited as a potential factor related to sex differences. According to some researchers, women perform better when answering open-ended items such as essays and are less likely to 
guess. Again, the ETS (2008b) study shows that sex differences existed in both the closed ended verbal section and the open-ended analytical writing section. In terms of the fast-paced nature of the standardized tests, critics also argue that evidence shows that women have a different approach to problem solving, in which they are more likely than men to completely work out problems, consider more than one answer, and check their answers (Bridgeman, Burton, \& Cline, 2003). Furthermore, women tend to score significantly lower in computer based tests than in written tests according to a study comparing GRE performance across racial, language, and sex groups (GRE Verbal $t$ $[56,653]=2.86, p<.01$; GRE Quantitative $\mathrm{t}[56,653]=2.13, p<.05$; Gallagher, Bridgeman, \& Cahagan, 2002). These differences may result in under-prediction of the GRE for women now that most students take their admissions tests on a computer based system.

As described in the segment related to minorities, it is important to understand the research on stereotype threat and the influence it may have on standardized test performance. Both Steele's work and the meta-analysis by Nguyen and Ryan concluded that stereotype threat was a moderator of test performance (Nguyen \& Ryan, 2008; Steele, 1997; Steele \& Aronson, 1995). For instance, Nyugen and Ryan studied the mean difference between men and women in the high stereotype threat condition and calculated a group mean effect of $d=|.39|$. Even in studies where the findings concluded that stereotype threat was not a significant predictor of test performance, sex differences were found in the level of test anxiety among the participants (Chapell et al., 2005). In a study by Stricker and Bejar (2004), level of stereotype threat was not a predictor of women's performance on a standardized test; however, the level of anxiety experiences by the 
participants was significantly higher for women than for men. These findings about standardized tests and women are important since, as previously discussed, access to graduate studies and choice of graduate studies institutions is largely dependent on GRE scores. In addition, age might be a proxy for time to degree in undergraduate studies, academic problems, and even SES (e.g., longer time to graduate due to the reality of a full time job).

\section{GRE Prediction Among Different Age Groups}

Various studies have indicated that GRE test performance is lower among older students. A report by the ETS supports this premise. For White GRE test takers in the 2006-2007 period, scores for the GRE Q decreased with age, but for the GRE V scores increased with age. However, when taking into account race/ethnicity and sex, minority groups and women demonstrated a negative correlation between age and GRE score on all parts of the test (Educational Testing Services, 2008b). In Awad's (2007) study, students GRE test performance was compared across racial identity, race/ethnicity, sex, age and other psychological characteristics. Beyond any other variable, age was the best predictor of test performance. As age increased, GRE scores decreased.

Another study by Lightfoot and Doerner (2008) found higher GRE scores in younger students in a criminal justice master's program were related to higher rates of degree completion. However, the same results were not replicated for the doctoral students within the same major. In Luthy's (1996) study, similar contradictions were found across disciplines rather than across degree levels. Luthy's study reported that older students (defined as all students over the age of 24) tended to obtain lower scores in the GRE than younger students. The mean difference between the two was 100 points. 
However, these results were more prevalent in the fields of adult and continuing education, educational administration, engineering, political sciences, and communicative disorders than in the other four disciplines measured (i.e., computer science, English, nursing, and psychology).

All of these studies indicate that age tends to be negatively correlated with GRE scores and may reflect a need to study other variables that may confound the results. Nevertheless, there were some limitations as to generalizability of these findings to other institutions. In Luthy's (1996) study, there were differences among the disciplines and in Lightfoot and Doerner's (2008) study, there were differences among degree levels. Furthermore, the exact cut off point of older and younger students is debatable, since it was not well defined in Light and Doerner's study and may have been too restrictive in Luthy's study considering that an increasing number of students are taking longer to finish undergraduate studies and are taking longer to enter graduate school. Defining older and younger by assuming all graduate students follow a continuous track from undergraduate school to graduate school may limit the validity of the study since extraneous variables can alter the results (e.g., number of years since last attending math courses).

\section{Characteristics of Graduate Student Success}

In chapter 1, the theoretical framework used in this study addressed research describing proximal and distal characteristics that may influence student success in graduate school. Most of the research on the GRE has focused on psychological characteristics that may interact with GRE scores. However, no research has described the role of the types of characteristics most discussed in the literature about graduate 
students. Namely, proximal facilitators such as mentoring relationships, environment, and student involvement may affect graduate student behavior more closely than distal facilitators such as the GRE scores and previous academic experiences. It is unclear how these two influences affect student success, but judging from the literature both demonstrate some type of correlations with academic success. The following paragraphs will focus on describing the proximal facilitators most commonly associated with retention and program completion in adult learners. Thus, this segment discusses the literature on graduate student characteristics as related to the GRE mentoring relationships and theories of involvement. These proximal facilitators contrast with the GRE which is a distal facilitator of student success.

The literature on the relationship between the GRE test performance and psychosocial student characteristics has focused on quantitatively assessing various types of psychological factors using existing instruments. The conclusions vary greatly and do not develop significant theoretical frameworks. In a study by Awad (2007), four student characteristics were measured amongst 313 African American students in a historically Black university. Amongst these characteristics, racial identity, academic self-concept, and self-esteem, were not correlated with GRE test scores. The only trait that was correlated with GPA, their secondary measure of student success, was academic selfconcept. However, it is not known if higher GRE has created high self-concept or vice versa. However, the results may not be applicable to students of other racial groups and they may not be applicable in universities that are not HBCUs where racial identity may play a different role. 
In another study, Powers and Kaufman (2004) sought to investigate whether student psychological characteristics such as conscientiousness, rationality, ingenuity, quickness, creativity, and depth (in terms of analytics ability) correlate with GRE scores. A sample of 342 participants who completed the GRE General Test and indicated that English was their best language completed self-report inventories. The findings indicated that there was a slight negative correlation between GRE scores and conscientiousness, rationality, and ingenuity and a slight positive correlation between the GRE scores and quickness, depth, and creativity. However, none of the indicators had a sufficiently high correlation to be able to draw any credible conclusions. Also, since African Americans, Hispanic Americans, and Asians Americans were over sampled in this study, it is not possible to generalize this study to the general population of GRE test takers. Thus, as indicated by the insufficient literature, there is a need for further analysis of inaction between student characteristics and student success measures.

\section{Institutional Correlates of Achievement in Graduate School}

Most of the literature on graduate student success centers on impact of mentoring on scholarly performance and degree completion. One of the most prominent scholars in mentoring literature, Kram (1985), split the concept of mentoring into two dimensions based on function. The first is psychosocial mentoring; this type of mentoring focuses on providing students with role modeling, counsel, sense of competence, and identity. The second, career mentoring, focuses on scholarly development and fostering discipline specific professionalism. In a study about factors that influence student retention, mentoring experiences was one of the most emergent themes reported in the interviews. 
Mentoring was more prevalent that other themes such as isolation, alienation, and nonsupportive environment (Quarterman, 2008).

Supporting this research, a study by Young and Brooks (2008) described that the most effective forms of support for minority student in a graduate program involved adequate mentorship experiences as well as multiple dimensions of formal/informal support systems and diversity sensitive research. Furthermore, in a quantitative longitudinal study on mentoring, collaborative mentoring experiences with a faculty member was the most highly correlated variable among various predictors of publication productivity $(r=.30)$. Other variables such as prior test scores and level of self efficacy had little to no correlation (Paglis, Green, \& Bauer, 2006). As the research indicates, using effective mentoring strategies as an integrated part of the academic environment may be a considerable factor contributing to increased graduate student success and persistence. However, further research should be conducted on the significance of faculty mentoring and academic climate on predicting graduate success when compared to other predictors such as the GRE.

\section{The Role of Student Involvement}

A large body of research has been generated that links student persistence and academic achievement to the quantity of student engagement behaviors. Most of the higher education literature focuses on student engagement on the undergraduate level. The National Survey of Student Engagement (NSSE) has been widely used to study levels of undergraduate student involvement and often relate this research to measures of student success including retention rates, GPA, and degree completion rates. A study conducted by Wang (2003) attempted to compare the NSSE to select items in the 
Graduate Student Survey and found a high correlation between the measures in some of the categories in both surveys. However, an equivalent instrument to the NSSE does not exist for graduate students because the Graduate Student Survey is not as comprehensive and as specific as the NSSE. Moreover, the research that is available for student engagement has been criticized for not having a diverse range of institution types and for not addressing the level of engagement for graduate or professional degree students (Braxton \& Lien, 2000; Garner \& Barnes, 2007).

Despite criticisms, student success has been increasingly linked to the degree to which students are involved inside and outside of the classroom. Thus, if engagement has been demonstrated to be a sizeable facilitator of success in undergraduate studies, then such an effect may also be relevant to graduate studies. Engagement may be described differently (e.g., as mentoring), however, it is still a component of graduate students' experience. Since this is the case, various theorists such as Astin (1984) have relevance when exploring graduate student characteristics and predictors of success.

Even before Astin's theory emerged in 1984, the idea that student characteristics influenced behaviors and success was discussed by other theorists. In Kurt Lewin's (1935) notable book, A Dynamic Theory of Personality, he used the philosophical foundations of Aristotle and Galileo to create a theory of behavior. According to Lewin's fundamental equation, $\mathrm{B}=f(\mathrm{P} \times \mathrm{E})$, human behaviors are a result of the interaction between a person with a given set of characteristics and the environment that person is in at the moment. The concept that people's interactions with the environment are directly tied to their interactions with their surroundings deeply ties in with Astin's theory. 
Another theorist who further cemented the concept that involvement is an influential factor in people's behaviors was Vincent Tinto. In his theory of student departure, Tinto (1975) explored the factors that interacted with students and the effect that these factors had on student retention. According to student departure theory, students entering college bring with them certain characteristics derived from their prior experiences and backgrounds (e.g., parent educational background, debt, family events, learning support, etc.). With all of these elements combined, students then interact with their campus and the level of social and academic integration influence how much goal commitment and institutional commitment they develop. In turn, the degree of goal commitment and institutional commitment then determine the likelihood a student has of dropping out from college.

Tinto's theory has been criticized because there is little evidence in defining how well the theory can be generalized to all types of institutions and populations. Braxton and Lien (2000), argued that it is essential for the academic context to be taken into consideration when applying Tinto's theory. Most of the literature investigating Tinto's model, focuses on traditional undergraduate students who attend traditional 4- year institutions. This criticism may be especially relevant when considering graduate students who do not fit the characteristics described by these studies.

As a rebuttal to the criticisms concerning differences between traditional and commuter schools, Tinto conducted a study that addressed the importance of the classroom as a means of building a community (Tinto, 1997). By defining the classroom as a primary means of academic and social integration, his theory even applies to student populations that characteristically center all interactions with their campus on attending 
class and getting passing grades. In his study, undergraduate students described the concept that the more they were involved in class, the more they wanted to continue such interactions in study groups and that this dynamic helped them achieve higher levels of academic success when compared to peers without this dynamic. However, in the literature there is a need to add further evidence to explore whether this same concept applies to other groups, namely, graduate students in Minority Serving Institutions.

Chickering and Gamson (1987), in their Seven Principles for Good Practice in Undergraduate Education, also outlined the importance of student involvement in student success. As outlined in their proposition, colleges and universities should focus on providing services to students that increase their level of involvement with their institutions. The seven principles were meant to be followed by faculty, students and other constituents in the campus. In these principles, concepts central to Astin's theory are included such as student/faculty interactions, peer relations, active learning, and dynamic communication.

The assumptions highlighted by these theories highly correspond with Astin's theory of involvement. His theory is composed of five assumptions: (a) involvement is defined as the expenditure of physical and mental energy (b) the degree of involvement varies across time along a continuum (c) involvement has quantitative and qualitative aspects (d) amount of student learning and development increases as involvement increases in quality and scope (e) educational policies are more effective if they are tied with increasing student involvement (Astin, 1984, 1999). When describing types of student involvement, some of the key areas were student-faculty interaction, academic involvement, and place of residence. These areas have been explored among 
undergraduate students, but not among graduate students. The next segment provides an overview of the limited research on student involvement in graduate studies.

\section{Student Engagement During the Graduate Years}

Graduate student involvement differs from undergraduate involvement. In a study that interviewed 10 graduate students about their engagement activities, students reported that they viewed graduate engagement as more purposeful, career driven, and goal oriented when compared to their undergraduate experiences. When analyzing the interviews, graduate students who report a high level of involvement networking described three major areas of engagement: connecting the classroom to the community, networking, and professional development. Even though elements such as social connections were important to the participants as both undergraduate and graduates, the theme of social connections as a means of obtaining professional development emerged only when describing graduate studies. This was emphasized by the fact that the participants' membership in field related national organizations and presenting at conferences was more important to them in their graduate studies (Garner \& Barnes, 2007).

Another study of graduate engagement used items derived from the Graduate Student Survey to analyze levels of graduate student involvement across a campus. As in the Garner and Barnes (2007) study, Wang (2003) found that graduate students' career goals and professional development were some of the highest rated aspects of their academic experience. Other important findings included differences between the levels of engagement between students who were completing their coursework versus students who were in their thesis or dissertation stage. The main differences indicated that 
graduate students completing their dissertations reported higher levels of faculty interactions, academic development, and personal development. Some of the lowest rated items centered on social support within graduate school. These findings provide a general view of some of the involvement characteristic of students, but are limited by the subset of items selected from the Graduate Student Survey and thus are not properly validated measures of graduate student involvement. This research on involvement may be a critical part of understanding graduate student success and thus may provide information about applicants and students that extends beyond the predictive validity of the GRE.

\section{Predictors of Graduate Success}

Understanding what predictors most accurately predict student success is important for all potential and current graduate students as well as faculty members responsible for admitting and guiding graduate students. The literature suggests that the predictive validity of the GRE may not be the best predictors of success for some students and other predictors of success (such as student characteristics) should also be taken into account when selecting and supervising graduate students. In summarizing the major studies, the highest percentage of variance predicted by the GRE is $16 \%$ (Kuncel et al., 2001). However, there are many inconsistencies and gaps in the data. For instance, while some studies conclude that the GRE is a good predictor of graduate success (ranging from GRE Total $r=.53$ to $r=.24$ ), other studies conclude the correlations to be much lower (ranging from $r=.08$ to $r=.15$; Chernyshenko \& Ones, 1999; Nilsson, 1995; Kuncel et al., 2001; Powers, 2004, and Smabyet al, 2005). 
Furthermore, there are no consistencies in the type of measure used for graduate student success. Most studies focus on measuring GPA exclusively and therefore expose a narrow scope of student success (Luthy, 1996; Nilsson, 1995; Powers, 2004). Since GPA is so restricted in range for graduate studies, it should not be used as the sole predictor of graduate success. Another, inconsistency stems from the different correlational values of the GRE Verbal and GRE Quantitative across disciplines. The few studies that address this difference demonstrate that both portions of the GRE may vary greatly. For the Verbal section the range was from $r=.40$ for humanities related disciplines to $r=.09$ for psychology. For the quantitative, the range was from $r=.37$ for math/science and social sciences to $r=.09$ for educational administration (Kuncel et al., 2001; Luthy, 2001).

There are additional difficulties for using the GRE to predict student success across difference minority, sex, and age groups. Various studies concluded that stereotype threat may influence test performance since minorities tend to score better on standardized test if told that the test was non-diagnostic and would not be an indicator of their aptitude (Nguyen \& Ryan, 2008; Steele \& Aronson, 1995). Similar issues have been investigated in research pertaining to women and the GRE. Luthy (1996) concluded that female graduate GPA was consistently higher than predicted by the GRE for some disciplines. The last population examined in this chapter is older graduate students. Studies have demonstrated that GRE score is inversely related to age (Educational Testing Services, 2008b; Luthy, 1996). However, studies on all of these groups have possible confounding variables, inconsistent findings, and sometimes inadequate measure of success that may alter the validity of their results. 
The review of the literature has shown that a variety of other characteristics may mediate the predictability of graduate student success. It is pertinent to study proximal facilitators such as mentorship relationships, academic environment, and involvement behaviors to gain a deeper understanding of the characteristics that may provide students with resiliency to failure as predicted by distal facilitators such as the GRE. The rationale for this stems from the literature relating positive mentorship experiences to persistence and productivity for a variety of graduate level students including ethnic and racial minority students (Paglis, Green, \& Bauer, 2006; Quarterman, 2008; Young \& Brooks, 2008). Furthermore, theorists such as Astin (1984), Lewin (1935), and Tinto (1975) supported the theory that the degree of involvement and of interactions with the academic environment is related to academic behaviors and persistence. Though theories of involvement have largely been investigated at the undergraduate level, a few researchers have begun to investigate the relationship of student involvement theory with graduate students (Garner \& Barnes, 2007; Wang, 2003). Their findings indicate that though involvement is important in the graduate level, it is important more for professional development than for social interactions (as is the case for undergraduates). Therefore, this study, while focusing on the GRE, also addressed other characteristics that may influence graduate student success.

\section{Summary}

Contradictory evidence and gaps in the methods by which the GRE has been measured as an assessment tool generate the need for further study. Additional factors, such as the prevalence of only using one criterion for measuring student success and the lack of a comprehensive analysis of predictive validity of the GRE in Minority Serving 
Institutions further emphasize the need for generating empirical data about this topic. The intention of the current study was to broaden our knowledge of the predictive validity of the GRE across disciplines in a Hispanic Serving Institution and to explore whether the predictive validity differs across diverse racial/ethnic, sex, and age groups.

Furthermore, though student psychosocial characteristics have been measured in relation to student success in prior research, this study attempts to examine the relationship between characteristics using the concept of proximal and distal facilitators of success. The research involved in understanding proximal facilitators includes mentoring, environmental factors, and student involvement theories. Mentoring and environmental factors have been widely supported by literature on graduate students. However, no studies related to the GRE have analyzed these two factors as characteristics that may relate to graduate student success. As for student involvement factors, few studies have investigated this phenomenon in the graduate years (Garner \& Barnes, 2007; Sweitzer, 2009). Therefore, since all of these factors need further analysis and exploration in relation to the GRE and graduate students, this study was undertaken to provide a richer context of how factors pertain to graduate student success. In efforts of gaining a more comprehensive understanding of student success by both exploring the predictive validity of the GRE and understanding the characteristics of graduate student who are under-predicted or over-predicted by the GRE, various gaps in the current literature will be addressed. The next chapter will describe the methods by which this study attempted to answer some of the questions that remain about the validity of the GRE and to provide information that may fill in some of the gaps in the literature. 


\section{CHAPTER III}

\section{METHODS}

The two principle purposes of this study were to investigate the predictive validity of the GRE General Test across disciplines and diverse populations and understand the characteristics of graduate students who are successful in graduate school. The methods described in this chapter were employed to address the following research questions:

1. How well does the GRE predict graduate student success in a minority serving institution across academic disciplines?

2. Does the GRE predict graduate student success when controlling for academic discipline, race/ethnicity, sex, and age?

3. What are the facilitators and detractors of achievement for successful graduate students?

\section{Research Design}

A mixed methods design was used to explore the questions above. The type of mixed methods design used in this study is sequential explanatory mixed design. This specific design was chosen for a variety of reasons. The first is that a typical single method design would not provide the breadth and depth that is necessary to thoroughly examine all of the research questions (Greene, Caracelli, \& Graham, 1989). As described by Tashakkori and Teddlie (2003), mixed methods approaches use quantitative and qualitative methods to complement one another and provide a more comprehensive view of the topic that is being studied. By conducting this thorough examination, I hoped to expand the foundations set by prior research that focused mainly on quantitative analysis by adding qualitative data and analysis that will help broaden our understanding of which 
graduate student characteristics are related to academic success. The second reason is that mixed methods allows for one phase to inform the other (Greene et al., 1989;

Tashakkori \& Teddlie, 2003). In this study, the quantitative phase was conducted first and was then followed by the qualitative phase. The qualitative phase served to broaden the information generated in the quantitative phase by allowing the researcher to explore a greater variety of student characteristics, not available in the student records, through open-ended questions during interviews. Together, these two phases allowed for the study to provide a more comprehensive understanding of graduate student success when compared to GRE studies with only a quantitative phase and served as a method of triangulating the results by comparing both phases. Figure 2 illustrates the mixed methods model used in this study.

\section{PHASE 1 Quantitative Analysis}

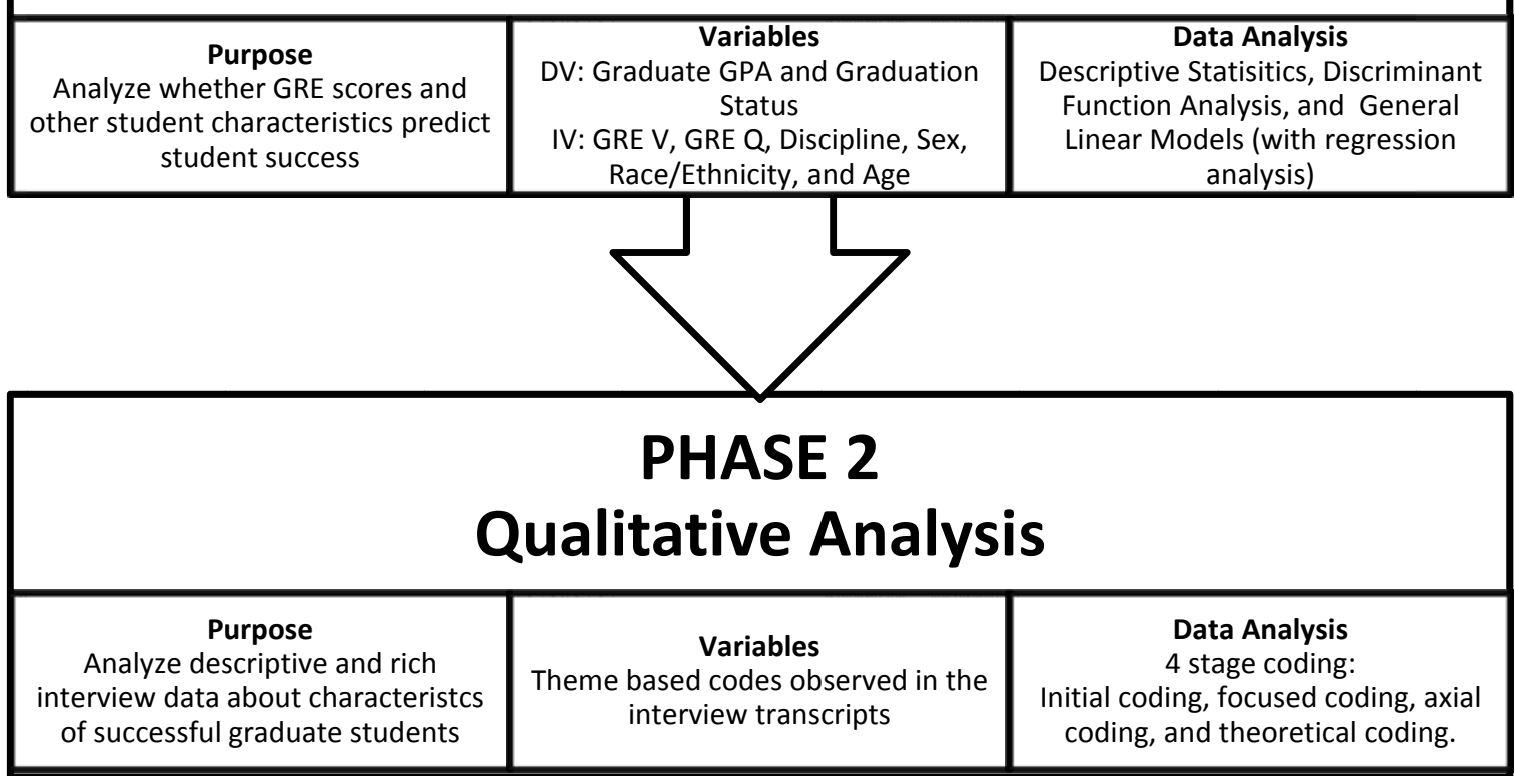

Figure 2. Sequential mixed methods model. 
To summarize Figure 2: The first phase of the sequential mixed methods design used a quantitative approach and consisted of analyzing data derived from student records databases using statistical analysis. This phase is defined as the dominant phase in this study since it contributed to answering all three of the research questions. In Phase II, a qualitative approach was used to answer the third research question by exploring additional graduate student characteristics through interviewing a sample of academically successful individuals who had either graduated or were currently graduate students maintaining high academic standing. The symbols used to denote this sequential mixed methods approach with a dominant quantitative phase are: QUAN $\rightarrow$ qual (Teddlie \& Tashakkori, 2009; Teddlie \& Yu, 2008). Each of these phases is thoroughly explained in the subsequent portions of this chapter.

\section{Phase I: Quantitative}

The first phase of this study focused on three goals that could be met by answering the research questions. The first goal was to understand whether the GRE was a predictor of graduate student graduation using discriminant function analysis. The second goal was to determine whether the GRE was a predictor of graduate student success, as measured by students' grade point averages, over and above all other student characteristics including: discipline, race/ethnicity, sex, and age using regression analysis. The third goal was to analyze all of the variables included in the study by testing whether they were positively or negatively related to graduate student success. These three goals address all three questions explored in this study.

The research design of this phase of the study is ex post facto design. As is characteristic of ex post facto design, the independent (or predictor) variable cannot be 
manipulated because it has already occurred. This type of design is appropriate when the independent variable cannot be manipulated because such manipulation would be unethical in nature or because it is simply not possible to manipulate the independent variable. Furthermore, an ex post facto design is weaker than a true experimental design because the participants cannot be randomly assigned to treatment conditions (Cohen, Manion, \& Morrison, 2000). However, the current study necessitated this design since the GRE scores of students cannot be manipulated since they took the GRE long before the data were collected and students cannot be randomly assigned GRE scores. Newman and Newman (1994) noted that the type of design used in this study used a more robust type of ex post facto research: ex post facto design with hypotheses. In this phase of the study, statistical methods were used to test the hypothesis that the GRE is a predictor of graduate student success. Student demographic and academic characteristics were the control variables. Thus, though causation cannot be inferred through ex post facto research, the study was guided by a hypothesis in order to increase internal validity.

\section{Participants}

The sample was derived from two databases maintained by the university's institutional research office. These two databases contain information from all Florida International University master's and doctoral students enrolled from the fall of 1998 to the spring of $2009(N \sim 20,000)$. A sample of master's and doctoral students was selected from the total number of students in these databases. The sample selection was based on various factors. The first factor is year of initial enrollment in the master's or doctoral program. Since the FIU graduate school gives students a specific number of years to graduate and some of the measures of success in this study are based on degree 
completion, only students who reached the deadline for completion were selected. In other words, only master's students who first enrolled in their programs 6 or more years ago were selected and only doctoral students who first enrolled 9 years or more years ago were selected.

These selection criteria were implemented in order to prevent erroneous data analysis since it is not appropriate to calculate degree completion for students who have not had the allotted amount of time in their programs. It is also important to note that on rare occasions, students are granted extensions and take longer than the allotted time to complete their degrees as determined by the university graduate school and the dean of their college. The sample used in this study included students who were in that situation and had not yet graduated despite surpassing the time limits. Another selection criterion was that the data set had to be complete for all of the variables analyzed in this study. Thus, all student records with at least one missing variable were eliminated. For this study, the number of master's students who have been enrolled for at least 6 years (i.e., enrolled from fall 1998 to spring 2004) and met all selection criteria was $N=4,271$ and the number of doctoral students who have been enrolled for at least 9 years (i.e., enrolled from fall 1998 to spring 2001) and met all selection criteria was $N=438$.

An analysis of the demographic composition of FIU graduate students revealed the following demographic characteristics. First, the sample of master's students included in the study was comprised of $31.5 \%$ men and $68.5 \%$ women. Furthermore, the sample was composed of the following racial/ethnic distribution: $34 \%$ of the students reported themselves as White, $16 \%$ as African American, $46 \%$ as Hispanic, $4 \%$ as Asian, and $.1 \%$ as Native American. Second, the data for the doctoral students indicated that 
$40 \%$ were men and $60 \%$ were women. Of all the doctoral students, $54 \%$ reported that they were White, 13\% African American, 31\% Hispanic, 2\% Asian, and .2\% Native American.

\section{Variables}

In this study, several variables were analyzed. The dependent variables were measures of graduate student success and the independent variables were demographic and academic characteristics of all of the graduate students included in the study.

Dependent (criterion) variables. The dependent variables for this study were graduate success as measured by degree completion rate and graduate GPA. Degree completion rate was based on the standards set by the University Graduate School, whereby all master's students should have graduated within 6 years and all doctoral students within 9 years. Within the given time limits, students would fall into one of two categories: graduated and not graduated. The not graduated status includes both drop outs and students still enrolled in the university who were granted extensions past the standard 6 and 9 year time limits for completing their master's and doctoral programs. The second variable, graduate GPA scores, was measured as the last recorded cumulative GPA score for each student. For data analysis, graduation status was dummy coded $(0=$ not graduated and $1=$ graduated) and graduate GPA was used as a continuous variable with a maximum of 4.0 .

Independent (predictor) variables. The primary independent variables in this study were the GRE Verbal and the GRE Quantitative scores. The GRE scores for each section of the test range from 200 to 800 points. The four other predictor variables used in this study were race/ethnicity, sex, age, and discipline group. Discipline group was 
defined by five major groups: education, humanities, life sciences, math/physical sciences, and social sciences. These categories were chosen following the trends of previous research (Educational Testing Service, 2008a; Kuncel et al., 2001). All of these predictor variables except for GRE scores and age were dummy coded so that 1 represents that a participant is a member of that category or group and 0 represents that a participant is not a member of that category or group.

\section{Data Sources}

The data used in the quantitative analysis were obtained from two data bases maintained by FIU's Office of Institutional Research. These are (a) the admissions file, and (b) the student data course file.

Admissions file. The admission file is a database containing all of the information from the applications submitted by the students at the university. The database was sorted in order to obtain only graduate students in the report.

Student data course file. The data course file contains the retention, degree completion, and attrition data from all students in the graduate programs at FIU. The students are grouped by cohorts according to admission date and discipline.

\section{Procedures}

The procedures for the first phase focused on collecting, compiling, and sorting the data that were used for data analysis. All of the data necessary for this segment of the study were accessible through the institutional research office. First, data from the admission file and the data course file were joined into one database in order to obtain a more complete data profile for each student. Then, before running the data through SPSS for data analysis, both master's and doctoral level students were separated into two files, 
all records with missing variables were eliminated, and all variables were sorted and dummy coded as specified in the earlier section describing the variables.

\section{Data Analysis}

Two programs were used to input, code, and analyze the relevant data collected. Initially, Microsoft Excel 2007 was used to record and organize the data that were gathered. Then, the data were transferred to SPSS 17 in order to conduct statistical analysis. At first, simple descriptive statistics were calculated for understanding the distribution of the student characteristics of the sample (including demographic information, degree level, discipline, GRE scores, and success measures). Then two statistical tests aimed at testing hypotheses about the two dependent variables (graduation status and graduate GPA) were carried out.

Analyzing graduation status as a predictor of success. The first statistical test that was conducted was a discriminant function analysis (DFA). This type of analysis is used in order to be able to predict group membership of a case when a case might belong to any one of a number of groups. In this study, discriminant function analysis was used to determine how accurately the independent variables could predict whether students graduate or do not graduate. This statistical procedure was selected because it allows for the analysis of a singular categorical dependent variable (graduation status) and multiple interval and/or categorical independent variables (Duarte, Silva \& Stam, 1995).

This study used a two group (graduation status) DFA to explore which of the independent variables (also referred to as attributes in this type of analysis) predict group membership. In order to assess prediction value for these variables, standardized 
discriminant function coefficients were obtained and tested for significance in the analysis. Alpha levels for all tests were set at the .05 level.

Analyzing GPA as a predictor of success. For the third statistical procedure, the data were analyzed using the General Linear Model with multiple regression analysis. The analysis utilized $F$ tests because this type of analysis is robust for violations such as lack of normal distribution or homogeneity of variance (McNeil, Newman, \& Kelley, 1996). Specifically, multiple linear regression (MLR) procedures were used due to the facility by which the statistical analysis can be structured by the research questions (Newman, Fraas, \& Newman, 2002). Additionally, MLR is one of the two appropriate tests to use when analyzing multiple independent variables that can be either categorical or continuous while using a single interval dependent variable. Data for doctoral and master's level students were analyzed separately. In order to examine the predictive validity of the GRE when controlling for discipline, race/ethnicity, sex, and age, a regression analyses was performed. The regression models for this stage of statistically analyzing the data were as described below:

- Full model: $y($ Graduate GPA $)=\mathrm{a}_{0} \mathrm{u}+\mathrm{a}_{1}\left(\right.$ GRE V) $+\mathrm{a}_{2}\left(\right.$ GRE Q) $+\mathrm{a}_{3}($ education $)+$ $\mathrm{a}_{4}($ humanities $)+\mathrm{a}_{5}($ life sciences $)+\mathrm{a}_{6}($ math $/$ physical sciences $)+\mathrm{a}_{7}($ social sciences $)+\mathrm{a}_{8}($ African American $)+\mathrm{a}_{9}($ Asian $)+\mathrm{a}_{10}($ Native American $)+$ $a_{11}($ Hispanic $)+a_{12}($ White $)+a_{13}($ sex $)+a_{14}($ age $)+E_{1}$

- $\quad$ Restricted model: $\mathrm{y}($ Graduate GPA $)=\mathrm{a}_{0} \mathrm{u}+\mathrm{a}_{15}($ education $)+\mathrm{a}_{16}($ humanities $)+$ $\mathrm{a}_{17}($ life sciences $)+\mathrm{a}_{18}($ math $/$ physical sciences $)+\mathrm{a}_{19}($ African American $)+$ $\mathrm{a}_{20}($ Asian $)+\mathrm{a}_{21}($ Native American $)+\mathrm{a}_{22}($ Hispanic $)+\mathrm{a}_{23}($ White $)+\mathrm{a}_{24}(\mathrm{sex})+$ $\mathrm{a}_{25}($ age $)+\mathrm{E}_{2}$ 
Since it was hypothesized that a difference exists between these groups, a one-tailed test of significance was conducted while controlling for disciplinary areas (i.e., education, humanities, life sciences, math/physical sciences, and social sciences) and demographic characteristics. All of the alpha levels in this study were set at .05.

Another regression analysis was conducted to answer the first research question pertaining to the prediction validity of the GRE across disciplines. To test this question, the following regression models were used:

- Full model: $\mathrm{y}($ Graduate GPA $)=\mathrm{a}_{0} \mathrm{u}+\mathrm{a}_{1}($ GRE V $)+\mathrm{a}_{2}($ GRE Q $)+\mathrm{a}_{3}($ education $)+$ $\mathrm{a}_{4}($ humanities $)+\mathrm{a}_{5}($ life sciences $)+\mathrm{a}_{6}($ math $/$ physical sciences $)+\mathrm{a}_{7}($ social sciences) $+\mathrm{E}_{1}$

- Restricted model: $\mathrm{y}($ Graduate GPA $)=\mathrm{a}_{0} \mathrm{u}+\mathrm{a}_{8}$ (education) $+\mathrm{a}_{9}$ (humanities) $+\mathrm{a}_{10}$ (life sciences) $+\mathrm{a}_{11}($ math $/$ physical sciences $)+\mathrm{a}_{12}($ social sciences $)+\mathrm{E}_{2}$

Similar to the first regression analysis, this model was tested using a one-tailed test of significance with the alpha levels set at the .05 level.

\section{Phase II: Qualitative}

In order to complement the conclusions drawn from the quantitative phase, the qualitative phase focused on gathering data that provided a deeper and richer understanding of characteristics associated with graduate student success. This second phase of the study served to understand specific graduate student characteristics that contribute to success and expand the number and breadth of characteristics explored in this study to complement the student data analyzed in Phase I. The qualitative research framework used to design this phase of the study is based on naturalistic inquiry with a focus on principles derived from grounded theory. As described by Lincoln and Guba 
(1984), naturalistic inquiry is founded on the concept that the researcher is the primary instrument for collecting data and the participants of the study are the primary sources of the data. It is essential that the researcher be able to gain entrance to the participants' environment, contact gatekeepers, contact and select participants, obtain consent and preliminary information, and build/maintain trust. This study employed these basic strategies of naturalistic inquiry as described in the data analysis segment of this phase. The current study also used concepts from grounded theory design. This design lends itself to the generation of theories after the data are analyzed (Strauss \& Corbin, 1990). These theories could inform graduate admission policies, which was one of the main goals of this study as outlined in Chapter 1.

As defined by Glaser and Strauss (1967), grounded theory is a systematic approach of analyzing and coding all of the data collected in a study and developing a theory from the emerging themes identified. A primary characteristic of grounded theory is that it approaches research in a way that is inductive rather than deductive. Glaser (1998) and Strauss and Corbin (1990) have approached grounded theory from a positivistic perspective while Charmaz (2006) has approached grounded theory from a constructivist perspective. From this perspective, Charmaz views grounded theory as way of analyzing the world through interpretation. Her perspective emphasizes the concept that the researcher cannot be a separate and neutral agent gathering evidence, but rather the researcher is an essential part of the collection and interpretation of the data. This approach is aligned with the current study for two reasons. First, the goal of the qualitative phase is to go beyond the variables typically analyzed in traditional studies about the GRE and to use the rich narrative provided by the participants to explore a 
greater range of student characteristics not available in university databases. Charmaz's perspective of grounded theory lends itself to fulfill this goal by using a systematic method of analyzing rich data and generating fresh theories without overlooking the researcher's role in interpreting the data that are collected. The second reason stems from the alignment of Charmaz's perspective to my own perspectives about human behavior and learning. Covered more broadly in the next segment, I believe that the researcher is the primary lens through which data are collected, analyzed, and interpreted. Being transparent about this perspective and choosing an approach to grounded theory that closely mirrors this perspective, allowed for me to approach the data with more clarity and consistency.

\section{Researcher Subjectivity}

Throughout Phase II, various steps were taken to improve the integrity of the study. One of the major steps to improve transparency is to describe the researcher's subjectivity and perspectives relevant to this study (other steps will be described in the section concerning transparency in this chapter). As previously described, Charmaz (2006) believes that researchers and their perspectives cannot be separated from the data that are being analyzed since these individuals are integral to the process of collecting and interpreting the data. Thus, in this section, I describe two of the major influences that guided me in conducting and influenced my perspectives throughout this study. The first influence pertains to my current circumstances. I am a Hispanic graduate student at FIU who has strived to balance school, work, and family and who has observed fellow classmates attempting to do the same. Often, I found myself wondering why some of us were able to persist and succeed while others did not. This question as well as my 
interest in the validity of assessment drove me to research this phenomenon. As a Hispanic woman in a majority minority university and city, I was particularly interested in investigating why most of the research I read indicated that individuals of racial/ethnic minorities often did not perform well on high stakes admission tests.

The second influence centers on my assumptions about learning and development. My perspectives of how people develop, interact with their environment, and achieve success most closely align with the constructivist theoretical framework. One of my fundamental principles is that learning is not something that occurs in isolation from the context of the environment, from the background of the learner, or from the type of interaction that occurs between the environment and the learner. This notion closely aligns with the frameworks used to gather and interpret the interview data in this study and closely aligns with Charmaz's (2006) perspective on grounded theory. For instance, according to Charmaz's view on grounded theory methods, they provide a systematic yet flexible way by which a researcher can interact with data and codes throughout the entire process. In other words, data collection is an engaging process that evolves much like my concept of learning. The literature on graduate student success is also closely aligned to this concept of the influences of the environment on learning. While this conception is similar to that of most qualitative analysis researchers, it differs from Glaser's more positivistic conception of grounded theory, which viewed the interpretation of data as a process that can derive information directly from the source and does not consider the role of the observer/researcher. In contrast, Charmaz's perspective was that "the viewer creates the data and ensuing analysis through interaction with the viewed" (Charmaz, 2000, p. 523). 
An example of the interaction of the environment with learning is that research on graduate student success has found that graduate students who were highly involved were more likely to succeed (key aspects include experiences with mentoring and peers; Garner \& Barnes, 2007; Young \& Brooks, 2008). Furthermore, Astin's (1984) theory of involvement makes very similar assumptions about the learner and the importance of interacting with the academic environment to increase students' persistence and level of investment.

\section{Participants}

The current study used purposeful sampling to gather the sample of graduate students who participated in this phase of the study. This sampling technique is focused on gathering participants who can provide a rich source of data (Patton 1990). Two methods were used to obtain the sample of graduate students. At first, the researcher used gatekeepers from around the university to contact the students who were recruited for interviews. These gatekeepers consisted of various faculty and administrators who have direct contact with graduate students and were willing to reach out to these students to ask them to participate in the study. The second method used was snowball sampling. Participants who volunteered to participate in the study were asked to contact any other students who met the sampling criteria described below.

In order to be a participant in the study, students had to fit certain criteria. The first criterion was that the student had to be enrolled in a graduate program that required a given GRE score as one of the criteria for admission. These students could be either currently enrolled or graduated. Another criterion was that the students had to be in high academic standing if they were currently enrolled. High academic standing was defined 
by having the minimum required GPA for graduate students (i.e., at least a 3.0 GPA). All of the students in the Phase II sample met these criteria. Furthermore, all students appeared to meet the minimum GRE score required for their major. The final criterion was that there had to be a minimum of two students from each of the five disciplinary groups in the study.

In total, 11 graduate students participated in the interviews. Humanities had the largest number of participants with a total of three students. In terms of degree type, six of the students were master's students/graduates and five doctoral students/graduates. Furthermore, although several men were contacted to participate in the study, only one of the participants was male. The rest of the men did not respond to follow-up emails and no other men were referred to me for participation by either my gatekeepers or by the other participants I interviewed. These gatekeepers and participants referred through snowball sampling were the only means I used to recruit participants and therefore, no other men were contacted after the first set. For all participants, the ages ranged from 25 to 45 years old. Two of the participants omitted their GRE scores because they reported having forgotten the exact score. However, they each stated they had met the minimum requirement for their program. More detailed information about each of the participants as identified by their self chosen pseudonym is included in Table 3 below. In the table, the participants in the table are grouped by discipline first and then in alphabetical order.

As can be observed from the table, some disciplinary areas only include doctoral students or master's students. In the case of education, this selection was purposeful since only doctoral degrees require the GRE as an admission criterion. Overall, however, 
no differences were evident from the interview data between master's and doctoral level students across majors.

Table 3

Characteristics of the Sample of Interview Participants

\begin{tabular}{|c|c|c|c|c|c|c|c|c|}
\hline Pseudonym & Sex & Age & $\begin{array}{l}\text { Race/ } \\
\text { Ethnicity }\end{array}$ & Discipline & $\begin{array}{l}\text { Degree } \\
\text { Type }\end{array}$ & $\begin{array}{l}\text { GRE } \\
\text { Score }\end{array}$ & $\begin{array}{l}\text { Student } \\
\text { Status }\end{array}$ & $\begin{array}{l}\text { Work } \\
\text { Status }\end{array}$ \\
\hline Fabiola & $\mathrm{F}$ & 29 & Hispanic & Education & Ed.D. & 1070 & $\begin{array}{l}\text { Full- } \\
\text { time }\end{array}$ & GA \\
\hline Lupe & $\mathrm{F}$ & 37 & Hispanic & Education & Ed.D. & 1200 & $\begin{array}{l}\text { Full- } \\
\text { time }\end{array}$ & GA \\
\hline Gabby & $\mathrm{F}$ & 28 & White & Humanities & M.F.A. & 1030 & $\begin{array}{l}\text { Full- } \\
\text { time }\end{array}$ & GA \\
\hline Katelin & $\mathrm{F}$ & 27 & Hispanic & Humanities & M.F.A. & 1100 & $\begin{array}{l}\text { Full- } \\
\text { time }\end{array}$ & GA \\
\hline Rick & M & 29 & White & Humanities & M.F.A. & 1120 & $\begin{array}{l}\text { Full- } \\
\text { time }\end{array}$ & GA \\
\hline Nancy & $\mathrm{F}$ & 45 & Black & $\begin{array}{l}\text { Life } \\
\text { Science }\end{array}$ & Ph.D. & * & $\begin{array}{l}\text { Full- } \\
\text { time }\end{array}$ & GA \\
\hline Nessie & $\mathrm{F}$ & 29 & Black & $\begin{array}{l}\text { Life } \\
\text { Science }\end{array}$ & Ph.D. & 1130 & $\begin{array}{l}\text { Full- } \\
\text { time }\end{array}$ & GA \\
\hline Ava & $\mathrm{F}$ & 35 & Hispanic & $\begin{array}{l}\text { Physical } \\
\text { Sciences }\end{array}$ & M.S. & * & $\begin{array}{l}\text { Part- } \\
\text { time }\end{array}$ & $\begin{array}{l}\text { Full- } \\
\text { time }\end{array}$ \\
\hline Marilyn & $\mathrm{F}$ & 38 & Hispanic & $\begin{array}{l}\text { Physical } \\
\text { Sciences }\end{array}$ & M.S. & 1100 & $\begin{array}{l}\text { Part- } \\
\text { time }\end{array}$ & $\begin{array}{l}\text { Full- } \\
\text { time }\end{array}$ \\
\hline Charlotte & $\mathrm{F}$ & 38 & White & $\begin{array}{l}\text { Social } \\
\text { Sciences }\end{array}$ & Ph.D. & 1400 & $\begin{array}{l}\text { Full- } \\
\text { time }\end{array}$ & GA \\
\hline Lulu & $\mathrm{F}$ & 25 & Hispanic & $\begin{array}{l}\text { Social } \\
\text { Sciences }\end{array}$ & M.S. & 1050 & $\begin{array}{l}\text { Part- } \\
\text { time }\end{array}$ & $\begin{array}{l}\text { Full- } \\
\text { time }\end{array}$ \\
\hline
\end{tabular}

Notes: * denotes not reported. GA is the acronym for Graduate Assistant (this categories includes teaching assistants and research assistants).

Thus, as the interviews progressed and there were no selection criteria added to have a predetermined ratio of master's and doctoral students within the sample.

\section{Data Collection}

All of the participants received two forms before being interviewed: the informed consent form and the demographic survey (see appendices). The consent form was the 
first form given to all participants. It served to inform them of their right to leave the study at any point and of some basic information about the study and the researcher. The second form was the demographic survey that served to collect basic information about each participant. This demographic survey as well as the interview protocol served as the primary sources of data for this phase of the study. Below are more detailed descriptions of each data source.

Demographic survey. The second phase of the study used a short survey asking the students to provide basic demographic information and GRE test scores. This survey served to supply additional information about the students' characteristics that might be relevant to the interpretation of the data. The information collected by the survey was used to help provide quick facts about the participants in the study.

Interview protocol. The interview protocol consisted of several open ended questions. The questions focused on addressing various aspects of student life, including involvement with academics, interactions with peers/faculty, and other relevant topics. This focus was determined by previous research on factors that contributed to student success. All interviews were conducted by the researcher. Each participant was interviewed separately for at least 1 hour in a conference room. The following are examples of the open ended questions from the interview protocol that were asked:

- How would you describe yourself and your life as a graduate student?

- What do you think of the GRE?

- How would you define the academic environment in your program?

The entire interview protocol is included in the appendices. In addition to the questions included in the protocol, follow-up questions were also asked when further information 
or clarifications were needed. These follow-up questions emerged spontaneously during the interview and were not scripted. Derived from the transcripts, some examples of follow-up questions include:

- Why do you think some students were unsuccessful in your program?

- How does the GRE relate to your discipline?

- Which of the admission criteria for your program do you think are most relevant for predicting student success?

These follow-up questions served to increase the richness of the data gathered and to adapt the interview to gather as much data as possible. The interviews were transcribed throughout the interviewing process. This allowed the researcher to also base follow-up questions on the experiences and data gathered from the previous interviews.

\section{Procedures}

After Phase I was completed, various gatekeepers were identified and contacted within colleges across disciplinary groups. The gatekeepers are individuals who are highly involved with graduate programs in their college and have the ability to reach out to graduate students. Each of the gatekeepers was informed of the purpose of the study and the selection criteria required for the participants. Various students were contacted by the gatekeepers and out of these some contacted the researcher to indicate their interested in participating. When the interviews started, more students were identified as participants by those who had been interviewed. Out of all of these, some did not meet the minimum criteria and some never replied to follow up e-mails from the researcher. The interview period lasted from June to the end of August 2010 and a total of 11 participants were interviewed. Each of the students was asked to sign a consent form and 
asked to complete a short demographic survey. Afterwards, each participant was interviewed separately by the researcher for at least 1 hour using open-ended questions in a semi-structured interview format. All interviews took place on campus in either the library or in a prearranged meeting room. The interviews were designed to be semistructured in order to allow participants to describe circumstances not specifically outlined in the interview protocol. A digital recorder was used to document the dialogue and some field notes were taken by the researcher to support the information being collected via digital recorder. These field notes described a wide range of topics within the context of the interviews including potential codes, comments about topics the students discussed, and notes about ideas that needed to be further addressed. The following are a few examples of some of the comments that were generated during the interviews:

- GRE parts more related to the fields than the whole test

- Faculty support important inside and outside of the academic arena

- Need to address more specific information about the GRE and how it predicts success

\section{Data Analysis}

The interview data were recorded, transcribed, and coded in accordance with the grounded theory data analyses methodology. As defined by Charmaz (2006), the data were coded in four stages: initial coding, focused coding, axial coding, and theoretical coding. In the first stage, initial coding, all of the transcribed interview data were analyzed using the line-by-line interpretation and coding. The focus of this stage of 
coding was to break down the large quantity of interview data and to identify common categories.

During the second stage of coding, focused coding, another more directed round of coding was conducted whereby categories from the initial coding stage were reanalyzed in relation to the data and were merged or modified according to their relevance and significance. This stage of coding required a more critical interpretation of the interview data and the categories from the initial coding stage. The major goal of this stage was to condense and synthesize similar codes and discard inappropriate or synonymous codes. For example, during the initial coding stage, I identified a category I called "relevance to coursework" as one of the factors students mentioned when they spoke of their perception of the GRE. During the focused coding stage, I was able to merge that category into another category called "validity" so that a single category emerged that I labeled "prediction value".

In the third stage, axial coding, the coding of the previous stage was used to identify emergent themes. These emergent themes were derived by grouping related minor categories from the focused coding stage into major categories. For instance, when looking at the categories persistence/dedication, time on task, and involvement, all of these categories were related and in many cases were often mentioned in conjunction by the participants. Thus, these three categories were grouped into one theme that I labeled "personal traits." The purpose of this stage was to bring together the data that were previously broken down in order to form a more cohesive interpretation of the interview data. 
The final stage, theoretical coding, was conducted to derive a central theme from the third stage of coding and generate theories. The goal of this stage was to integrate the previous codes into a theory aimed to answer the research question. When theories were developed for this stage of the study, the previous themes and codes were interpreted to make various theories related to the characteristics and traits associated to graduate student success among the 11 students interviewed.

All of the themes and categories were analyzed so that all classifications were mutually exclusive, exhaustive, and meaningful (Patton, 1990). After the first two interviews were conducted, the data were recorded and a preliminary analysis was conducted. Throughout the process of interviewing, this ongoing analysis and recording of the data helped shape the probes asked during the interviews, the interpretation of the data, and the codes and categories derived from the data. This supports Charmaz's (2006) view that the data should be analyzed as an integrated rather than sequential step in the research process. A coding map was created to categorize and organize the codes, categories, and themes. This coding map is illustrated in the next chapter along with the results.

\section{Trustworthiness}

Several processes were used to enhance the trustworthiness of this study (Guba \& Lincoln, 1985). Three methods were used to improve credibility, transferability, dependability, and conformability. The first method to increase credibility and dependability was methodology triangulation. This type of triangulation states that using multiple research methods to address research question improves the credibility and dependability of a study. In this study, mixed methods research design was used so that 
quantitative and qualitative methods complement one another as demonstrated in Chapter 5. This allowed me to provide enough evidence for my "claims to allow the reader to form an independent assessment - and agree with [my] claims" (Charmaz, 2006, p. 182). In addition, it should be noted that as another strategy to enhance the credibility of the study, the qualitative interview data were systematically compared to the categories, themes, and theories that were developed in this study and were consistently provided in the results as direct evidence for my analysis.

Another method used to increase credibility and confirmability was expert review. A summary of the research, including background information, purpose statements, research questions, methods, and findings, were submitted to researchers who are employed by the university and are involved in reviewing graduate student data. These researchers provided feedback and critique based on their expertise in the field. In the beginning stages, when I did not have findings and was still calibrating my methods, they made suggestions about the variables that were available for analysis and provided examples of databases they had generated for retention studies. This feedback helped in the process of making the research questions more specific and helped in identifying the variables that would be included in the statistical analysis. When the findings were presented to them, these experts provided feedback on whether they would draw similar conclusions with the given data. For the qualitative phase, they provided me with suggestions about defining the themes and categories. This feedback was integrated into the findings.

To further improve the credibility of the study, the findings are reported using rich description to provide a more comprehensive representation of characteristics related to 
graduate student success or failure. This rich description was present when displaying the results in the form of direct quotes from the participants that allow the reader to gain a deeper understanding of both their views and the interpretation of the researcher. Moreover, rich descriptions served to increase transparency across the study. In-depth descriptions of the methodology served to improve dependability and conformability while disclosure of the researcher's perceptions served to improve confirmability. Additionally, all of these instances of including rich description functioned as a means to allow readers to understand the background and context of the study and of the participants in order to increase the possibility of transferability.

Two other criteria Charmaz (2006) has for evaluating grounded theory are originality and usefulness. By including a qualitative phase, specifically with a grounded theory lens, I was able to provide a fresh perspective on how the GRE and other predictors of success are relevant to graduate students. Charmaz's last criterion is usefulness. This study has the potential for being applied in admission policies and for generating further research in graduate student success and the GRE.

\section{Summary}

This study used a sequential explanatory mixed methods approach whereby the quantitative and qualitative phases serve to complement one another by providing a deeper understanding of predictors of graduate student success, and by having one phase inform the other. The research questions in this study were best answered by this complementary approach to inquiry. In Phase I, data from the graduate student records was statistically analyzed using discriminant function analysis and general linear models. 
This analysis served to predict graduate student success from verbal and quantitative scores on the GRE, along with various demographic and academic predictors.

Phase II focused on gathering richer and more descriptive information about the characteristics that were perceived as factors that facilitate or hinder graduate student success at a Hispanic Serving Institution. The results of Phase I were complemented by the data collected from graduate students who were interviewed in Phase II because they offered more insight into concepts and themes that were not available through the student records databases. Purposeful sampling techniques were used to gather the 11 participants. Using a grounded theory approach, data were analyzed through open/initial, focused, axial, and theoretical coding for the purpose of generating potential theories. The next chapter reports all data generated from implementing the methods described in this chapter. 


\section{CHAPTER IV \\ RESULTS}

In this chapter, the results of the data analysis conducted for the quantitative and the qualitative phases of this study will be presented. The chapter is divided into two sections: Phase I - Quantitative Results and Phase II - Qualitative Results. The first segment contains descriptive statistics on the characteristics of the samples of master's

and doctoral level students in the database as well as the results of the statistical analysis as they relate to the research questions. The second segment contains the analysis of the interviews conducted during this study and is divided by the major and minor themes found within the data.

\section{Phase I: Quantitative Results}

\section{Student Characteristics}

The independent variables in this study describe various dimensions of the graduate students' demographic and academic characteristics. These characteristics include: age, sex, race/ethnicity, graduate academic discipline, GRE verbal score, and GRE quantitative score. In terms of age, the mean age for master's students was 30 years with range of 20 to 71 years and the mean age for doctoral students was 36 years with range of 20 to 71 years. Amongst master's students, $68.5 \%$ of the students in the database were women $(\mathrm{N}=2,927)$ and $31.5 \%(\mathrm{~N}=1,344)$ were men out of a total of 4,271 students. For doctoral students, 59.8\% $(\mathrm{N}=262)$ of the students were women and $40.2 \%(\mathrm{~N}=176)$ were men out of a total of 438 students. Table 4 describes the racial/ethnic characteristics of the master's and doctoral students included within this phase of the study. The majority of the students classified themselves as Hispanic 
(46.5\%) for the master's level and White (54.3\%) for the doctoral level. For both master's and doctoral levels, Native Americans were the smallest group, accounting for only . $1 \%$ and $.2 \%$ of the sample, respectively.

Table 4

Number of Master's and Doctoral Level Students by Racial/Ethnic Group

\begin{tabular}{lrr}
\hline Race/Ethnicity & $\mathrm{N}$ & Percent \\
\hline Master's Students & 1460 & $34.2 \%$ \\
$\quad$ White & 667 & $15.6 \%$ \\
African American & 1987 & $46.5 \%$ \\
Hispanic & 151 & $3.5 \%$ \\
Asian & 6 & $.1 \%$ \\
Native American & & \\
Doctoral Students & 238 & $54.3 \%$ \\
White & 55 & $12.6 \%$ \\
African American & 135 & $30.8 \%$ \\
Hispanic & 9 & $2.1 \%$ \\
Asian & 1 & $.2 \%$ \\
Native American & & \\
\hline
\end{tabular}

As for academic characteristics, the mean GRE score for master's students was $434.53(S D=99.24)$ for GRE V and $493.36(S D=125.99)$ for GRE Q with a range of 200 to 800 for each scale. The mean GRE scores for doctoral students were 509.93 (SD $=93.46)$ a range of 280 to 800 for GRE $\mathrm{V}$ with and $539.59(S D=109.17)$ with a range of 210 to 800 for GRE Q. In Table 5, the distribution of graduate students is described as sorted by disciplinary area. The largest proportions of both master's and doctoral students majored in education ( $30.7 \%$ and $40.4 \%$, respectively). The smallest 
proportions of master's students majored in humanities $(8.9 \%)$ and there was a tie at the doctoral level between humanities $(8.7 \%)$ and physical sciences $(8.7 \%)$.

Table 5

Number of Master's and Doctoral Level Students by Major

\begin{tabular}{lrc}
\hline Discipline & $\mathrm{N}$ & Percent \\
\hline Master's Students & 1312 & $30.7 \%$ \\
Education & 380 & $8.9 \%$ \\
Humanities & 1157 & $27.1 \%$ \\
Life Sciences & 547 & $12.8 \%$ \\
Physical Sciences & 875 & $20.5 \%$ \\
Social Sciences & & \\
Doctoral Students & 177 & $40.4 \%$ \\
Education & 38 & $8.7 \%$ \\
Humanities & 41 & $9.4 \%$ \\
Life Sciences & 38 & $8.7 \%$ \\
Physical Sciences & 144 & $32.9 \%$ \\
Social Sciences & & \\
\hline
\end{tabular}

The two dependent variables used to measure student success in this study were graduate GPA and graduation status within 6 years of enrollment for master's students or 9 years of enrollment for doctoral students. The mean GPA was 3.54 for master's students and 3.61 for doctoral students. As for graduation rates, $69 \%(\mathrm{~N}=2,945)$ of the Master's students graduated within 6 years of enrolling into their program, while only $34 \%(\mathrm{~N}=150)$ of doctoral students graduated within 9 years of enrolling into their program. 


\section{GPA as a Measure of Success}

A multiple regression analysis was used to predict whether GPA could be predicted by GRE score when controlling for disciplinary area, race, sex, and age. The results of the first analysis indicated that disciplinary area, race, sex, and age were significant predictors of GPA for master's students, $R^{2}=.09 ; F(10,4260)=42.395, p<$ .05 (see Table 6).

Table 6

GRE as a Predictor of GPA for Master's Students Controlling for Student Characteristics

\begin{tabular}{|c|c|c|c|c|c|c|}
\hline \multirow[b]{3}{*}{ Variables } & \multicolumn{6}{|c|}{ Graduate GPA } \\
\hline & \multicolumn{3}{|c|}{ Model 1} & \multicolumn{3}{|c|}{ Model 2} \\
\hline & $B$ & $t$ & $p$ & $B$ & $t$ & $p$ \\
\hline Constant & & 119.757 & .000 & & 68.737 & .000 \\
\hline Age & $.039 *$ & 2.640 & .004 & $.051 * *$ & 3.329 & .001 \\
\hline Sex & $.142 * *$ & 9.003 & .000 & $.161 * *$ & 10.067 & .000 \\
\hline African American & $.083 * *$ & 5.167 & .000 & $.047 *$ & 2.811 & .003 \\
\hline Hispanic & $-.170 * *$ & -10.785 & .000 & $-.160 * *$ & -10.146 & .000 \\
\hline Asian & -.012 & -.771 & .221 & -.018 & -1.217 & .112 \\
\hline Native American & $-.057 * *$ & -3.916 & .000 & $-.060 * *$ & -4.095 & .000 \\
\hline Humanities & .009 & .536 & .296 & -.015 & -.909 & .182 \\
\hline Life Sciences & .013 & .776 & .219 & .000 & -.025 & .490 \\
\hline Physical Sciences & $-.111 * *$ & -6.350 & .000 & $-.136^{* *}$ & -7.173 & .000 \\
\hline Social Sciences & $-.047 *$ & -2.786 & .003 & $-.047 *$ & -2.788 & .003 \\
\hline GRE Verbal & & & & $.074 * *$ & 4.104 & .000 \\
\hline GRE Quantitative & & & & $.068 * *$ & 3.454 & .001 \\
\hline$R^{2}$ & .091 & & & .102 & & \\
\hline$F$ & $42.395^{* *}$ & & & $40.189 * *$ & & \\
\hline$\Delta R^{2}$ & & & & .011 & & \\
\hline$\Delta F$ & & & & 26.607 & & \\
\hline
\end{tabular}


Similar results were calculated for the doctoral students whereby the analysis demonstrated that these variables were also significant predictors of GPA, $R^{2}=.04 ; F$ $(10,427)=1.87, p<.05($ see Table 6$)$

GRE V and GRE Q score were added to assess whether these variables accounted for variance beyond that of the variables included in the previous analysis (i.e., disciplinary area, race/ethnicity, sex, and age). Analysis of both master's and doctoral level student data revealed that GRE scores increase the predictive power after controlling for the other independent variables (master's students: $R^{2}$ change $=.01 ; F(2$, $4258)=26.61, p<.05$ and doctoral students: $R^{2}$ change $\left.=.03 ; F(2,425)=6.25, p<.05\right)$. In Table 5, the standardized coefficients are listed for each variable for the master's students. As expected, most of the variables in the first analysis were significant and in the second analysis GRE V and GRE Q were also significant at $p<.05$.

The results for doctoral students are included in Table 7. For these students, only sex and the humanities disciplinary area were significant in the first analysis, while GRE V, GRE Q, humanities, and sex were significant in the second analysis. As stated in Chapter 3, a one-tailed test of significance was conducted for all of the regression analysis conducted in this study. Also, both in both of the analysis in Table 5 and Table 6 , the sex variable was dummy coded so that men were represented be the number 0 and women were represented be the number 1 . Note that in Table 5 and Table 6 , one value of the independent variables race/ethnicity and discipline were not reported in the output of the hierarchical multiple regression (White and education, respectively). This was a function of the algorithm used by SPSS to calculate the output of the analysis which requires orthogonal matrices when using dummy coded data. 
Table 7

GRE as a Predictor of GPA for Doctoral Students Controlling for Student Characteristics

\begin{tabular}{|c|c|c|c|c|c|c|}
\hline \multirow[b]{3}{*}{ Variables } & \multicolumn{6}{|c|}{ Graduate GPA } \\
\hline & \multicolumn{3}{|c|}{ Model 1} & \multicolumn{3}{|c|}{ Model 2} \\
\hline & $B$ & $t$ & $p$ & $B$ & $t$ & $p$ \\
\hline Constant & & 27.661 & .000 & & 12.953 & .000 \\
\hline Age & .049 & .923 & .178 & .047 & .880 & .190 \\
\hline Sex & $.112 *$ & 2.286 & .012 & $.120^{*}$ & 2.444 & .008 \\
\hline African American & -.087 & -1.724 & .043 & -.024 & -.453 & .326 \\
\hline Hispanic & -.004 & -.087 & .466 & .050 & .936 & .175 \\
\hline Asian & .036 & .749 & .227 & .038 & .779 & .436 \\
\hline Native American & -.027 & -.563 & .287 & -.035 & -.738 & .231 \\
\hline Humanities & $.092 *$ & 1.759 &. .040 & $.109 *$ & 2.065 & .020 \\
\hline Life Sciences & .051 & .968 & .167 & .019 & .359 & .360 \\
\hline Physical Sciences & -.064 & -1.217 & .112 & -.088 & -1.621 & .053 \\
\hline Social Sciences & .009 & .160 & .437 & -.023 & -.401 & .344 \\
\hline GRE Verbal & & & & $.114^{*}$ & 2.055 & .020 \\
\hline GRE Quantitative & & & & $.118^{*}$ & 1.987 & .024 \\
\hline$R^{2}$ & .042 & & & .069 & & \\
\hline$F$ & $1.870 *$ & & & $2.638^{*}$ & & \\
\hline$\Delta R^{2}$ & & & & .027 & & \\
\hline$\Delta F$ & & & & 6.249 & & \\
\hline
\end{tabular}

Note. ${ }^{*} p<.05$

Another set of multiple regression analyses were conducted to test whether GRE was predictive of GPA score across disciplines for master's and doctoral level students. For master's students, the results of the first analysis indicated that disciplinary area was a significant predictor of GPA, $R^{2}=.03 ; F(4,4266)=40.98, p<.05$. However, the 
analysis demonstrated that these variables were not significant predictors of GPA for doctoral students, $R^{2}=.05 ; F(4,433)=2.21, p>.05$.

The second analysis included the GRE V and GRE Q scores to determine if these variables accounted for variability beyond that of disciplinary area. Similar to the first set of regression analyses, GRE scores increase the predictive power both master's and doctoral level students after controlling for disciplinary area. Specifically, the results for the master's students indicated that $R^{2}$ change $=.02 ; F(2,4264)=40.74, p<.05$. Furthermore, the results for the doctoral students indicated that $R^{2}$ change $=.03 ; F(2$, $431)=6.77, p<.05$. In Table 8 , the standardized coefficients are listed for each variable for the master's students included in the study. In the first model, the two variables that were significant at $p<.05$ were physical sciences and social sciences. In the second model the same two disciplinary areas were also significant: physical sciences and social sciences. Additionally, the GRE V and GRE Q were significant predictors of GPA for master's students in the second model. Again, for this second set of regression analysis, a one-tailed test of significance was used to conduct the analysis. 
Table 8

GRE as a Predictor of GPA for Master's Students Controlling for Discipline

\begin{tabular}{|c|c|c|c|c|c|c|}
\hline \multirow[b]{3}{*}{ Variables } & \multicolumn{6}{|c|}{ Graduate GPA } \\
\hline & \multicolumn{3}{|c|}{ Model 1} & \multicolumn{3}{|c|}{ Model 2} \\
\hline & $B$ & $t$ & $p$ & $B$ & $t$ & $p$ \\
\hline Constant & & 119.757 & .000 & & 100.957 & .000 \\
\hline Humanities & .011 & .655 & .512 & -.025 & -1.515 & .130 \\
\hline Life Sciences & -.005 & .776 & .773 & -.023 & -1.305 & .192 \\
\hline Physical Sciences & $-.167 * *$ & -9.932 & .000 & $-.194 * *$ & -10.329 & .000 \\
\hline Social Sciences & $-.069 * *$ & -3.946 & .000 & $-.072 * *$ & -4.207 & .000 \\
\hline GRE Verbal & & & & $.107 * *$ & 6.003 & .000 \\
\hline GRE Quantitative & & & & $.055^{*}$ & 2.890 & .004 \\
\hline$R^{2}$ & .028 & & & .046 & & \\
\hline$F$ & $30.979 * *$ & & & $34.615 * *$ & & \\
\hline$\Delta R^{2}$ & & & & .018 & & \\
\hline$\Delta F$ & & & & 40.735 & & \\
\hline
\end{tabular}

Note. $* p<.05 * * p<.001$

As Table 9 illustrates, a regression analysis was also conducted to test whether the

GRE was a significant predictor of graduate student GPA while controlling for disciplinary area for doctoral students. The results for this analysis indicated that no variables were significant in the first model at $p<.05$. However, for the second model, there were two disciplinary areas that were significant: humanities and physical sciences. Additionally, the GRE V was also significant in the second model. This regression analysis was the last test that was conducted to test the significance of the GRE in predicting graduate student GPA. The next section focuses on analyzing how well the GRE and the other variables in this study can be used to correctly predict whether a student will be classified as graduated or non-graduated. 
Table 9

GRE as a Predictor of GPA for Doctoral Students Controlling for Discipline

\begin{tabular}{|c|c|c|c|c|c|c|}
\hline \multirow[b]{3}{*}{ Variables } & \multicolumn{6}{|c|}{ Graduate GPA } \\
\hline & \multicolumn{3}{|c|}{ Model 1} & \multicolumn{3}{|c|}{ Model 2} \\
\hline & $B$ & $t$ & $p$ & $B$ & $t$ & $p$ \\
\hline Constant & & 94.654 & .000 & & 19.234 & .000 \\
\hline Humanities & $.090 *$ & 1.803 & .036 & $.104 *$ & 2.056 & .020 \\
\hline Life Sciences & .042 & .835 & .202 & .006 & .123 & .451 \\
\hline Physical Sciences & $-.090 *$ & -1.805 & .036 & $-.108 *$ & -2.071 & .020 \\
\hline Social Sciences & -.012 & -.226 & .411 & -.051 & -.961 & .169 \\
\hline GRE Verbal & & & & $.126^{*}$ & 2.460 & .007 \\
\hline GRE Quantitative & & & & .092 & 1.644 & .051 \\
\hline$R^{2}$ & .020 & & & .050 & & \\
\hline$F$ & 2.212 & & & $3.770^{*}$ & & \\
\hline$\Delta R^{2}$ & & & & .030 & & \\
\hline$\Delta F$ & & & & 6.768 & & \\
\hline
\end{tabular}

Note. ${ }^{*} p<.05$

\section{Graduation Status as a Measure of Success}

A discriminant function analysis was conducted to analyze to predict whether student success as measured by graduation status could be predicted by student characteristics. Predictor variables include GRE V, GRE Q, disciplinary area, age, sex, and race/ethnicity. For this study, one discriminant function was calculated and the Wilks' lambda test was significant, $\Lambda=.95, \chi^{2}(12)=24.08, p=.02$. In the analysis, graduation status after 6 years for master's students and 9 years for doctoral students was dummy coded whereby $0=$ not graduated and $1=$ graduated. Furthermore, as described in Table 10, standardized canonical coefficients were strongest for three variables related to race/ethnicity for both master's and doctoral students. Specifically, these variables 
were: White (.562 master's and 1.410 doctoral), African American (.775 master's and 1.034 doctoral), and Hispanic (.879 master's and 1.032 doctoral).

Table 10

Standardized Canonical Coefficients for Master's and Doctoral Students' Graduation Status

\begin{tabular}{lll}
\hline Variable & $\begin{array}{l}\text { Master's Students' } \\
\text { Coefficients }\end{array}$ & $\begin{array}{l}\text { Doctoral Students' } \\
\text { Coefficients }\end{array}$ \\
\hline GRE V & .319 & .433 \\
GRE Q & .184 & .290 \\
Age & .247 & -.170 \\
Sex & -.310 & .336 \\
White & .562 & 1.410 \\
African American & .775 & 1.034 \\
Hispanic & .879 & 1.032 \\
Asian & .257 & .320 \\
Education & -.207 & -.415 \\
Humanities & .451 & .395 \\
Life Sciences & -.354 & .075 \\
Physical Sciences & .139 & -.138 \\
\hline
\end{tabular}

In Table 11, the variables that significantly discriminated for graduation status were GRE V, GRE Q, age, sex, and all four disciplines with the exception of social sciences for the master's students. For doctoral students, the variables that significantly discriminated for graduation status were GRE V, GRE Q, White, and education. Overall, the cross validation classification demonstrated that $61.5 \%$ of master's students would be correctly classified into the appropriate graduation status, which exceeds the probability based on chance. At the individual level, $50.4 \%$ of the master's students would be 
correctly classified into the non-graduating group and $66.5 \%$ of the master's students would be correctly classified into the graduated status.

Table 11

Test of Equality for Group Means for Master's and Doctoral Students' Graduation Status

\begin{tabular}{|c|c|c|c|c|c|c|}
\hline \multirow[b]{2}{*}{ Variable } & \multicolumn{3}{|c|}{ Master's Students } & \multicolumn{3}{|c|}{ Doctoral Students } \\
\hline & $\Lambda$ & $F$ & $p$ & $\Lambda$ & $F$ & $p$ \\
\hline GRE V & $.991 * * *$ & 39.243 & $<.001$ & $.979 * *$ & 9.206 & .003 \\
\hline GRE Q & $.994 * * *$ & 27.160 & $<.001$ & .991 & 3.818 & .051 \\
\hline Age & $.997 * *$ & 11.953 & .001 & .996 & 1.624 & .203 \\
\hline Sex & $.989 * * *$ & 48.303 & $<.001$ & .996 & 1.659 & .198 \\
\hline White & 1.000 & 1.744 & .187 & $.990 *$ & 4.525 & .034 \\
\hline $\begin{array}{l}\text { African } \\
\text { American }\end{array}$ & 1.000 & .843 & .359 & .999 & .310 & .578 \\
\hline Hispanic & 1.000 & .491 & .483 & .994 & 2.490 & .115 \\
\hline $\begin{array}{l}\text { Asian } \\
\text { Native }\end{array}$ & 1.000 & .023 & .880 & .999 & .588 & .444 \\
\hline American & 1.000 & .579 & .447 & .999 & .520 & .471 \\
\hline Education & $.996 * * *$ & 16.190 & $<.001$ & $.982 * *$ & 7.912 & .005 \\
\hline Humanities & $.984 * * *$ & 71.335 & $<.001$ & .995 & 2.034 & .155 \\
\hline Life Sciences & $.993 * * *$ & 31.323 & $<.001$ & .996 & 1.872 & .172 \\
\hline $\begin{array}{l}\text { Physical } \\
\text { Sciences }\end{array}$ & $.993 * * *$ & 28.008 & $<.001$ & .999 & .512 & .472 \\
\hline Social Science & 1.000 & .843 & .649 & .994 & 2.718 & .100 \\
\hline
\end{tabular}

For doctoral students, the overall cross validation classification showed a smaller proportion of correctly classified students at 56.8\%. When individually analyzed, $59.7 \%$ 
of doctoral students would be correctly classified as not graduated and $51.3 \%$ as graduated.

The statistical analyses for Phase I served to answer the three research questions of this study. First multiple regression analysis was used to analyze how well the variables used in this study predicted graduate student GPA. The first research question was answered by analyzing GRE V and GRE Q while controlling for discipline and the second research question was answered by controlling for all demographic and academic student characteristic available in the study. In order to analyze graduation as another success variable, a discriminant function analysis was conducted whereby all of the variables were used to determine whether they would be correctly classified into the graduated or non-graduated groups. This analysis served to address both the first and the second research questions. Furthermore, the third research question, which aimed to explore what characteristics are associated with students who succeed, was answered in the discriminant function statistical analysis in this study. The next section of this chapter describes the results derived from the qualitative analysis of student interviews in Phase II of the study.

\section{Phase II: Qualitative Results}

This segment of the results focuses on describing the data collected from the 11 participants who were interviewed in the study. Each of the interviews included two forms of data sources. The first being a demographic survey and the second being the actual transcribed interviews. The interviews focused on several central issues relating to 
the research questions such as perceptions on the validity of the GRE within their program, characteristics of graduate student success, and motivational factors. Each of these areas served to add more rich detail to the variables and conclusions from Phase I of this study. The principle purpose, however, was to triangulate data sources and to answer the third research question of this study: What are the facilitators and detractors of achievement for successful graduate students? The data collected contained what is classified according to the theoretical framework as both facilitators that had a positive impact on students' perceptions of success and detractors that had a negative impact on students' perceptions of success. Where these differences were present within the categories and themes, they are described in this chapter. A summary of the basic demographic data can be found in Table 3 located in Chapter 3.

As explained in Chapter 3, various categories emerged from the data that were analyzed from the transcripts using initial and then focused coding. Through axial coding these categories were then grouped into distinct themes. Table 12 illustrates the main themes and the focused categories that formed these themes. The predominant themes were: (a) Program Structure, (b) Importance of Admission Criteria, (c) Motivators, (d) Personal Traits, (e) Peer Interaction, and (f) Faculty Interaction. This section of the results is organized by major theme, which is then divided by each of the categories that formed each particular theme. In the table, the categories are prioritized by the frequency with which they emerged in the interview data (to see the interview protocol see appendices). 
Table 12

Coding Map for Major Themes and Categories

\begin{tabular}{|c|c|c|c|}
\hline \multirow[b]{2}{*}{ Themes } & \multicolumn{3}{|c|}{ Categories } \\
\hline & 1 & 2 & 3 \\
\hline Program Structure & $\begin{array}{l}\text { Curriculum and } \\
\text { Resources }\end{array}$ & $\begin{array}{l}\text { Organization/ } \\
\text { Structure }\end{array}$ & \\
\hline $\begin{array}{l}\text { Importance of } \\
\text { Admission Criteria }\end{array}$ & Prediction Value & Academic Access & $\begin{array}{l}\text { Language/ } \\
\text { Academic Culture }\end{array}$ \\
\hline Motivators & Family/ Friends & $\begin{array}{l}\text { Financial/ } \\
\text { Opportunities }\end{array}$ & Love of Field \\
\hline Personal Traits & Involvement & $\begin{array}{l}\text { Persistence/ } \\
\text { Dedication }\end{array}$ & Time on Task \\
\hline Peer Interaction & $\begin{array}{l}\text { Support/ } \\
\text { Belonging }\end{array}$ & Competition & \\
\hline Faculty Interaction & $\begin{array}{l}\text { Academic and } \\
\text { Personal Support }\end{array}$ & Availability & \\
\hline
\end{tabular}

\section{Program Structure}

The theme program structure was divided into two categories involving some of the topics that students addressed when referring to the benefits and challenges of their graduate experience. The first category was curriculum and resources. In this category, academic issues including their department's structure were discussed. In the second category, organization/structure, students discussed their program's administrative issues that did not relate specifically to academics.

Curriculum and resources. The participants in this study mentioned the importance of having adequate courses and resources available for them as they were completing their programs. Some of these comments were extremely positive and described how course selection was better than in other programs and how different resources were available for the students. For instance, Rick described how his program required for all students to take courses within areas outside of their field of specialty and 
how that helped him professionally. He contrasted these opportunities with similar programs in other universities that prohibit students from taking courses outside of their specialty. In another example, Marilyn specified how her degree program provided a computer lab that housed software that was unaffordable for the majority of the students in her program. This lab was often crowded and noisy, but allowed for students to have a place to work on projects without having to purchase their own software.

Contrasting with the positive comments, some students also noted that certain aspects of their curriculum were poorly planned and/or there was a lack of adequate resources for their program. For example, both Charlotte and Nancy experienced delays in completing their coursework because several of their required courses were not available at the right time or because they were unclear as to which courses additional courses would complement their area of study. As Charlotte described,

I think I took a lot of classes. I didn't take the right classes. And part of that is because I came out with a bachelor's and didn't know what I was doing. But I think a big part of that was the classes were offered and the order I took them.

Lupe described a similar experience with the limited number of faculty available in her program due to budget cuts. She explained how lack of resources affected her academically,

That has been a limitation. A big humongous limitation there is that, whether it is because of budgets cuts, which we just don't have the manpower in that program, and it has limited my opportunities for interactions and dialogue. I can only work with one person and that's very limiting so either have more people, or integrated into some other discipline, some other area that would allow for expansion of faculty, you know. 
Lack of resources also restricted Lupe's ability to interact more with faculty. This concept also was coded under the theme of faculty interaction since both resources and faculty interactions were involved in Lupe's experience.

Organization/structure. Sometimes students felt discouraged and frustrated from other aspects of their departments that were not related to academic issues such as curriculum and academic resources. These students encountered difficulties in minor administrative issues such as getting themselves set-up in their programs or getting appropriate guidance for completing paperwork. In one example, Fabiola discussed one her biggest administrative challenges, "it has been disorganized and a little bit impersonal...like they lost my grades of the last 2 years." Gabby discussed a series of other administrative challenges that she encountered as she progressed through her degree,

There were a lot of frustrations of, like, "Oh I almost missed another deadline because of I had no idea where to go to find that deadline, and nobody told me." And so you know that I've known other students in the program who had to delay their graduation just because of the logistics of it... Systems were different, half the stuff changed, you know, the email. Even just getting to my email I didn't know I had email address, and then I have like five different ones, and then payroll. That sort of stuff, I mean, really, they made the entry into the graduate program really difficult. And like, I got used to it, you know, as the years went on, but it was still a huge stressor and it really had nothing to do with my academics and whatever I was trying to study, but rather, you know, so I guess if I could've had more guidance that way would've been really helpful.

These challenges and frustrations affected students' perceptions of their programs and also made completing their degrees more difficult in areas that they were not expecting to encounter any challenges. 


\section{Importance of Admission Criteria}

The importance of admission criteria for graduate programs was a fundamental part of each of the interviews in this study. Students extensively spoke about the impact that the GRE and other admission criteria had on their access to certain graduate programs. They also discussed the predictive value and/or relevance of each of these admission criteria to the competencies required by their graduate programs. Issues related to the perceived impact of language and culture on performance in the GRE is also covered under this broader theme. Thus, the three main focused categories forming this theme are: academic access, prediction value, and language/culture. Each of these categories is discussed in broader detail in the following sections.

Prediction value. The prediction value of graduate programs admission criteria was one of the major categories in this phase of the study. To summarize the findings, most of the students believed that the GRE had very poor prediction value for graduate success. Some students cited cases in which high GRE scores did not equate success in graduate school. Fabiola described one such instance where a student who borrowed her study guide for a week and got a really high score on the GRE, got expelled shortly after admission to his program due to low academic performance. She further explained that,

The GRE or a standardized test in general cannot really take out of your head what you really, really know and what you can do. I can tell you, I know people that scored really, really high on the GRE, but cannot put their act together to complete a good paper... The exam is just a test and it depends on your test taking abilities, on your emotional precision, I don't even know what to call it, but you cannot use the score to just tell somebody, you are not allowed in here. 
Other students mentioned that GRE scores did not reflect their graduate GPA or their success in their programs. Two examples of this come from Marilyn and Lulu, as they described their thoughts,

Marilyn: I don't think it is related at all because it isn't what I thought was pretty terrible in the exam and I did pretty decently in the program. In all my classes, I got good grades and I don't think it would have helped me if I would have prepared better for the GRE exam. I don't think I would have been better prepared for the program by having prepared way well for the GRE exam.

Lulu: I definitely when I think what has helped me the last thing that I think of is my GPA and my GRE. I think that if I did well at the GRE, and I didn't do more than I got a 1050. I just barely made the minimum which was 1000 for my program. If I did okay in the GRE, it is because I worked hard and studied for the exam.

In another cases, students described that they questioned the validity of the GRE because they believed it was a test that was coachable. As Katelin stated,

Studies have shown, that the tests is not supposed to be about coaching because it's supposed to be an equalizer. But people who have got money to pay for the coaching tend to score lot higher than people who don't. They teach you the tricks. My sister actually taught the SAT tricks for high school students, so I know there are tricks, but yeah, it's not about smarts, it's about tricks.

Those students who believed the GRE had some predictive validity only focused on a specific portion of the GRE instead of the GRE as a whole. For example, both Katelin and Charlotte thought that the GRE's writing section was the best predictor of success for graduate school. As Charlotte described, "It's just writing section which I think it's really good. But I have really high reasoning skills, really high logic skills, and really bad math skills, and I think the GRE skips that.” The other students who also believed that a part of the GRE may be a good predictor chose the part that most related to their field and the part that they tended to be most proficient in as well (e.g., those in the physical sciences chose the quantitative piece as the best predictor and also scored 
highest in that portion of the test). Other students perceived that the predictive validity of the GRE was diminished because both the verbal and the quantitative pieces were given equal value even though many majors tend to be more focused on only one of these competencies. When Nancy mentioned this issue, she the described the GRE as,

It doesn't have anything to do with your Ph.D. It has nothing to do with that. So I wouldn't really say it's testing that because okay you do math for the GRE, you do the reading the verbal and if you are not really into the sciences your math is softer. And if you are in the sciences, that will help. So that's why I'm thinking it doesn't, it doesn't really have anything to do with your Ph.D. because for me I would say it's the math - because my area we need the math.

All of the students mentioned alternative measures of success, some of which they stated, were better indicators of success within their disciplines than the GRE. Most students placed a higher value on previous GPA or previous coursework, than on the GRE for predicting success at the point of admission. An example of this was when Nancy stated that she would rather,

Place value on your GPA, on courses that you've taken, and I think, okay another thing that I think is important when you're admitting students the program is: see how the courses they are going to be taking here is related to what they've taken before. Admitting someone who has never learned science into the sciences... is not going to help.

Another example was illustrated by Rick and several other students in the fields of education, humanities and social sciences, who believed that the truest indicator of success was the writing samples and the portfolios. As Rick described,

I guess the main thing I would be looking at would be the portfolio and the quality of the work you know. That's probably the main thing. And then I'll probably be curious about the applicant's attitude towards their work and also curious about what they wanted the degree for, why they were pursuing it.

Lupe also agreed that writing samples were the best measures of students' true writing skills "because the verbal doesn't tell me anything about what they are capable of doing 
in writing." Overall, the participants agreed that the GRE should not be the main determinant for graduate school admission or the main tool for predicting graduate student success.

Academic access. The topic of the GRE as a criterion for admission into graduate programs sometime generated conversations about the limitations that the GRE had on students' access into programs or universities of their choice. In the case of Katelin, she applied to various Ph.D. programs, but was not accepted to these programs with a scholarship due to her low GRE score and decided to settle for a master's degree instead. She described how the low GRE score not only affected her immediate choice of graduate school, but also had long term effects. As opposed to going to school for 7 years to obtain her doctorate, as she would have to do now, she could have been able to finish in 5 years at the University of Miami if her GRE score had been higher.

Furthermore, Katelin expressed other ways in which the low GRE scores impacted her education,

If UM had given me a scholarship, I probably would've taken the scholarship because as much as I love the professors here and I was in between my element because I'm used to those classes, I would've liked the option to continue with the $\mathrm{Ph}$.D. without having to worry about where am I going to find the funding at this point.

For the two students in education, the impact of GRE scores affected their choice of program rather than their choice of school. They both opted to complete the Ed.D. instead of the Ph.D. due to the higher GRE scores required for admission into the Ph.D. program. Fabiola related her frustrations at not being able to be admitted into the Ph.D. after taking the test three times, paying for expensive courses to master some strategies 
for taking the test, and still missing the cut off score for Ph.D. admission by 30 points.

When telling her story, she explained,

So basically, that's what was the difference between pursuing a Ph.D. and an Ed.D. was 30 points. And you know my advisor was "go for a fourth time." I could just not do it and said "forget it." I rather do the Ed.D. and just be a happy Ed.D. and not a depressed Ph.D. ... So really, I really wanted to pursue my Ph.D., but for 30 points I'm like "forget it, that's it." I rather people look at my work than my cherished score. So I think as in every standardized test, the GRE has its good aspects and its bad aspects. I do understand, you know, philosophically what we want to get out of standardized test and what level of field and allow everybody to compete, or to perform without other hindrances, but I also see that not every test taker is the same.

Whether it is because of limitations to choice in school or in program, these examples demonstrate of the common categories derived from the interview data.

Language/academic culture. When describing the GRE, many students also described issues of language or academic culture as a barrier in adequately demonstrating their academic capacity through this type of measure. Several of the participants were from other countries where the native language is not English and where multiple choice exams do not commonly exist. These student felt at a disadvantage when taking the GRE because of the extensive and rarely used vocabulary in the verbal section and because of the modality by which they had to answer the questions. One of the students from social sciences, Lulu, described her experience as,

My first impression is I was intimidated especially by the English component because English, my vocabulary isn't that good so that was the hardest part for me. For math, math has always been like an easy subject for me, well not easy, but I get it.... It was different with English, I guess since it wasn't my first language.

Nessie, also described her difficulties with the GRE in relation to differences in academic culture. She stated, 
And that is just because, if students are coming from the U.S. then they know how to take tests like that. When students are not accustomed to the U.S. education, the multiple choice, and ...that kind of critical thinking, those kinds of questions are not what I am used to, I was used to writing essays.

On the other hand, two other students, Ava and Nancy, related stories that contradicted these previously described barriers. They spoke of foreign students who were very good at memorizing large amounts of information because of their countries' academic polices and scored very well on the GRE. However, in the case of the student Nancy spoke of, he had to drop the doctoral program due to lack of English skills and was instead moved to the master's program until he was capable of demonstrating proficiency in the language.

\section{Motivators}

When responding to questions about motivators, graduate students often spoke of the things that inspired them to pursue a graduate degree and that kept them in their programs after they were enrolled. These motivators were classified under three primary categories: family and friends, financial gains or career opportunities, and the love for their field. These categories were also interrelated in the interviews. Student who described financial gains as their motivators also described that entering a graduate program required more than just financial incentives. Furthermore, those who stated their family was a primary motivator also stated that they wanted the degree to provide better financial perspectives for their family. Each of these categories is explained in the next sections.

Family/friends. Family and friends were often cited as a source of motivation for entering a graduate program. Most of the participants mentioned their families during the 
interviews. Lulu described that she felt that her family inspired her to get a master's degree because she was the first person in her family to go to college and that her "motivation is to set an example" for her two younger brothers. Katelin also mentioned her family as a primary source of motivation because of their expectation that she would reach the doctoral level of education at some point. As she described, "Family is a big part of why I continue studying because my family was at first 'Oh get your bachelor's ... and then they go 'Where's your Ph.D?'."

Family and friends were often simultaneously referred to as a source of motivation and as a great source of support. Nancy, who had a husband and three young children, said that her husband agreed with her decision to pursue her doctorate even though she already had master's degree. She described his support and the inspiration her children gave her,

And he was always there even though I wasn't working and there are four of us, there is never a time that he would complain that oh no because you're doing this, this was this. You know even when things were really, really tough he was still there and my kids. Oh God bless them. Because if not for them. Like when I get home sometimes and they are there I forget about everything else. People would say, "Oh you have these young kids, how do you manage?" But they are part of what motivates me to go on because with all of the pressure with everything, when they are there that clears my head.

While enrolled in her doctorate program, Nessie also discussed the role of family and friends in motivating her and supporting her throughout her studies. Even though most of her family was living abroad or on the other side of the country, she found a close circle of friends from church that she considered family. Thus, she often referred to how she would depend on her real family for support over the phone, but would depend on her new "brothers and sisters" from church for support while living in Miami. 
Financial/opportunities. Having access to more job opportunities or to higher wages was a primary motivator for most students. Several of the students indicated that they entered the graduate program because they wanted the opportunities to gain higher wages and have the type job they desired. For instance, Ava and Marilyn, the two students in the physical science disciplines expressed that getting a higher salary was a primary motivator for applying to graduate programs since they were already employed in the field. Similarly, Charlotte described: "I'm tired of being poor and my student loans are building up and I need to get a job. I'm getting old, and that's a big one. I mean, I need to get paid for doing this." The notion of getting "too old" to be in school and not getting the job or money that they desired without the degree was also echoed in Lupe's and Nancy's interviews. For instance, in Lupe's interview, she stated: "My age, I'm getting too old for school. Umm..I need a job.” In Nancy’s experience, her main motivator for getting a Ph.D. was because she wanted a job in academia. As she described, "I'll want to get a job in academia. That was my main reason. Because I can have time with my kids. Because it's more flexible."

Moreover, some students described that a graduate degree was the minimum requirement for most of the jobs in their field. Lulu had an undergraduate degree in psychology and found that most jobs required at least a master's degree. In another example, Nessie stated,

And after I did my master's, I wanted to do interventions. And when I started looking for intervention jobs, all of them required a Ph.D., so I decided to get a Ph.D.. However, when I was looking for a Ph.D., so looking at the schools, FIU was the only school that had the department, a department [dedicated to my area]. 
Opportunities for work in a more specialized and skilled workforce seemed to be a very relevant source of motivation for the students interviewed.

Love of field. One of the frequently cited reasons they entered a particular graduate program was because they truly liked the field. Many of students said that they "love" their field and that they loved the things that they would be able to work on when they graduated. Lulu, for instance, said that she fell in love with her graduate studies field when she took a class in that area as an undergraduate student. Ava described that she needed to love the career in order to be able to persist because of the level of work needed to complete a graduate level engineering program. Students often found love of the career as pivotal for success. Two of the students in the humanities, Gabby and Rick, remarked that having a true passion for writing and for the creative process were essential to being successful and being motivated to enter into their graduate program. While completing their doctorates, Ava and Lulu also mentioned similar trends:

Ava: I started my program because I loved computers and I love engineering. Students should make sure that that is what they want to do. Because it's stressful and if it's just for the money, they wouldn't be able to make it because it is a tough degree. So [I advise them] to make sure that they themselves are motivated enough to accomplish it.

Lulu: In my undergrad, I, I learned [about my specialization] at my bachelor's, my bachelor's is in psychology. So while I was doing that, I took some [specialization specific] classes and I guess I fell in love with that field. I mean, at first I loved child psychology, but then when I took my [specialization's] classes it like opened a whole door to a different area.

As stated previously, this category of motivational factors emerged frequently from the data and served to support and in some ways contrast the students' perception that financial gains and future opportunities were also a concurrent motivator for completing their degrees. 


\section{Personal Traits}

The students interviewed often cited personal traits as important factors that either helped or hindered academic success in graduate school. These personal traits reflected several of the characteristics that students would display while enrolled in their academic programs such as high levels of involvement, degree of persistence, and time dedicated to academia in their program. Below all of these categories are described in greater detail.

Involvement. Most of the students in this study reported high levels of involvement while enrolled in their graduate programs. High levels of involvement were not only reported in the interviews, but also as a part of the demographic survey each of the students completed prior to the interview. As reported in this survey, only Lulu and Ava reported low levels of involvement outside of the classroom defined as "only attended classes and required events" in the survey. This was not surprising as they were they only full-time employees in the sample of students interviewed. Marilyn and Rick reported intermediate levels of involvement defined as "involved with a few activities; limited interactions with faculty/peers." The rest of the seven participants reported high levels of involvement defined as "publications; attending academic events/groups; interacting regularly with faculty/peers." During the interviews, most of the students also defined involvement as graduate or teaching assistanceships, independent research, social activities, belonging to professional associations or student association, and conducting workshops related to their field.

Most of the students viewed level of involvement as crucial to their academic progress and level of achievement. Both part-time and full-time students concurred that 
being involved was an important part of being a graduate student. Charlotte described

how involvement affected her professionally:

Networking is not my strong suit. But it's extremely important into getting a job. So, by being involved in the organization in different levels I was forced to, you know, become more communicative with the faculty, more communicative with the department, with GSO, that kind of thing. So I met I met a lot of people with a lot of connections, which I would not have otherwise.

Marilyn contrasted her experiences working outside of her department with her

experiences working in the department of her program. She explained:

I think it helped a lot working there. For one it was very convenient that we were in the same location as your classes are and the same location as your teachers are. Sometimes they have their office hours during the middle of the day and if I was working outside of campus, it would have been hard for me to take a break at work to drive here and ask them a question or whatever and go back to work. So being in the same location as were your teachers are helps a lot and also where your classes are was very convenient and also I got to interact with my teachers outside of the class rooms. Interactions related to other things some systems that we were implementing, but it makes you comfortable around that person and you feel that you can ask them anything so that helped me too.

I'm thinking of the other two people who were in my group who were in the same situation working and taking classes. But in my case I got experience in the same field where I was getting my degree in. Work experience because I was working in some of things that I was seeing in class sort of not exactly but sort of similar. I think that helped too. As opposed to working in a field totally unrelated as it was the case when I was doing my bachelor's.

It should also be noted that in Marilyn's experience, faculty interaction was also a theme that was associated to perceived success during graduate school. Though she was a parttime student and though she felt she had less overall interactions with faculty as stated later in this chapter, she also felt that the fact that she was involved with her program and her field by working in the department helped her succeed academically.

In contrast, some of the students also identified some negative aspects of being highly involved. Nessie was highly involved in teaching and in multiple organizations, in 
one of which she was a key member who advocated student concerns to the faculty and to the university. When describing these activities, she expressed how being involved gave her a sense of motivation and inspiration, but also described negative aspects such as noted below:

The associations and avocations take much of my time, so there were two semesters that I thought I was going to crash. I couldn't because those semesters I was taking classes and actually trying to do these other things at the same time.

Katelin was also highly involved in teaching and student organizations. In her case, teaching took more time away from writing her thesis than did student organizations. She explained:

The problem was that teaching took a lot of time. TA [Teaching Assistant] and the teaching took a lot of effort. If you actually were interested in the students and helping them succeed, then your focus wasn't on your thesis, but on the students.

The degree to which each of the students decided to get involved in their program beyond the basic academic requirements, was both a pivotal experience in their lives as students and as professionals and a time consuming factor which sometimes led to their participation in activities that would detract from their academic requirements. This contrast was especially evident with graduate students who were full-time students and who were highly involved in multiple areas of involvement rather than just a few. Students who were highly involved in student organizations and in teaching were the ones who most expressed this duality in which they both benefited and were hindered by getting involved.

Persistence/dedication. All students described the importance of persistence or dedication to academic activities when asked to list the primary factors that helped them succeed or when asked to list factors that contribute to student success in general. 
Students explained that a large part of their success was about having the willingness and the capacity to dedicate themselves to academia despite any barriers or outside pressures and distractions. As Charlotte and Rick stated,

Charlotte: You have to know what you are doing. And I think the biggest thing I mean, the absolutely have to want it with everything. You know, you have to want it the way, you know, an athlete at the Olympics wants it, you have to want it.

Rick: Self motivation. Yeah that's the main thing I think and some sort of perseverance. Yet generally I guess having this desire to make your work better. Because really there's not a lot of... and a degree in creative writing, it's not like you are going to practice law with it or anything like that. And there's not a lot of money at the end of the line, so it's really interest in the craft itself. So you have to be motivated. Money isn't the motivator so there has to be another motivator.

Other students also mentioned that from before even applying to a graduate program, students should already be disciplined and persistent. As these students described, incoming students should be dedicated to obtaining their degree for next few years of their lives. If they are not prepared to be dedicated, then they should not even consider graduate school until they were able to fully pursue that goal.

Time on task. The quantity of time that students were able to dedicate to their academic program was one of the factors that many students reported as important to completing their degrees. In this category, there were contrasts between experiences of full-time and of part-time students. While part time students described the lack of time to dedicate to school work as an obstacle to completing their degrees or achieving the highest level of academic performance, full-time students described that dedicating their time to mainly academic pursuits allowed them to focus more on completing their degrees. Lupe, one of the full-time students, even explained that all of the students she had seen fail were part time students in education. She stated that "to fully get, all the 
benefits in being graduate school, and all the benefits in having the academic growth you need to be [a] full time" student.

Also, under this category were comments that related to time management skill and work/life/home balance. Most of the participants indicated that time management skills and willingness to follow through on deadlines was extremely important to successfully completing their coursework. This was especially apparent for students who were completing their thesis, dissertation, or were part-time students. Ava described the difficulties she confronted when trying to balance a full job with the lengthy time required for completing all of the assignments and projects in her coursework. She stated that if she had more time to dedicate to school as a full-time student, she would:

Well basically I would've been able to ace all my classes, because I would've had more time to dedicate. I was juggling work which was 48 hours plus and also school which that in itself is a lot of work and a lack of understanding from the faculty in terms of that not everyone is a full-time student especially at FIU. So they had all these ridiculous assignments that were due every week or every 2 weeks, so technically it was it was do as much as you can to get by.

Charlotte was especially concerned with time management. She would have a strict schedule from morning until evening on weekdays and even engaged in what she referred to as "cross training," which involved combining simple academic activities such as highlighting main ideas in an article with non-academic activities such as watching TV. Time dedicated to academia also placed pressure on her relationship with her boyfriend. As she explained:

I gave myself a schedule where I work either till 5 or 7 , which gives me 2 hours of flexibility; sometimes I work, sometimes not. If I can't work past 4, I don't go past him, I had to do something else. So he knows I'm never available after 5. So after 5-7 on Fridays and I don't work on weekends ever. Yeah, and so he knows he can't say "you are always working." Because I don't work on the weekends. 
These types of strains and the importance of dedicating time to their academic pursuits were brought up in most of the interviews.

\section{Peer Interaction}

Out of all of the themes derived from the data in this study, peer interaction was the second most frequently discussed topic (the first being faculty/student interactions). Two main aspects of peer interactions were mentioned throughout the different interviews. The first was peer interaction that was characterized by extensive support and a sense of belonging and the second was peer interaction that was characterized by competition between peers. These opposing categories affected the perceptions and experiences of the students in their graduate studies.

Support/belonging. Along with support from the faculty, support from peers was one of the major factors that helped the students throughout their programs. Much as faculty interactions were divided into two main dimensions of support, peer interactions also were divided into two categories: personal support and academic support. Personal support was often mentioned to be crucial for adapting to life as a graduate student and provided students with a sense of belong that went beyond academic camaraderie.

Rick, Katelin, Gabby, and Charlotte spoke about how important their nonacademic interactions with their peers became as they began their graduate studies. These students described how they would go out to dinners and events and "not just because of academia, but because [they] were friends" as Katelin stated. All of these students except for Katelin were also new to the city. Many of the students interviewed had come from other cities when they first choose FIU as their graduate school. For these students, having an extensive social network who shared their academic 
experiences, but were also part of their personal lives was cited as being very important to them. Gabby stated that soon after she arrived from the Midwest, she was confronted with the challenge of preparing for a series of hurricanes her first semester. Through a friend she had made in the program, she was offered help in securing her apartment and was offered a place to stay throughout the hurricanes. Such interaction helped these students adapt to their new lives as graduate students and/or as new residents of Miami.

Academic support was also pivotal for students as they tried to make sense of the expectations that were required of them as graduate students. Most of students described how important it was to call fellow students who had gone through the same challenges as they did to find out answers to questions that they felt reluctant to ask a professor. Other students depended on older peers for information about day-to-day issues, such as which forms were needed to complete their proposals or which strategies to use when teaching an unfamiliar course. For example, Nancy found herself contacting several of her peers about such matters long after her friends had graduated. As Nancy described,

This other student, she graduated 2006 was still in charge and another one in Texas was so I wonder what the department did before me. So like the other thing we share is ideas or of taking this class of taking this class before, these are the things that you should do, these are the things that you should look out for. Give ideas of what kind of exam the professor gives and the things that happen and some cases we share books, the textbook. This is the textbook we used for that class and some other things that really helped. I'd say this particular person, she is in Maryland now, and we have developed a very good relationship that you know if there's anything. Like you know I've written this and I'm not sure I understand it what you think of this. You know. I'll call her up and we talk you know. Or I go over to her or she comes over. Sometimes she would keep my kids so you know, it was really helpful.

Even part-time students found value in finding support from their peers. On separate occasions throughout the interview, Marilyn mentioned her relations with a group of 
students in her program who helped her and motivated her to complete her coursework.

She talked about how this group of students coordinated themselves to work together,

Yes, for most of the program there were, let's say four or five friends that we always try to register for the same courses. There was one particular other guy that we would usually take the same course so we would try to be in the same group for homework and projects. The other guys because we were moving at a slow pace only taking one course at a time, so the other people move forward, so we stayed behind this other guy and me. And at the end we took separate courses, actually no we took one class together, but anyway because we knew each other every time that we would work on group projects he would stick together. But sometimes it was teacher who would sometimes designate the groups. And in that case they would try to adjust to a different pick. The reason why we would study together was because we knew each other and we knew everybody was going to do their part and that nobody was going to lean on each other for when we had to work with other people. I guess we try to do the best that we could and there's always people that you get upset with because you feel that they're not doing their part; that they have waiting for you to do as much as you can for free.

Marilyn found that group work with her friends helped her get assignments and projects done because they had set study time every week and they helped to answer each other's questions when they were confused about a topic. Overall, most of the interactions described were extremely positive with the exception of the aforementioned category, competition. Charlotte summarized the impact of these positive interactions when she said:

I think, staying in touch with the graduate students has been crucial, I kind touched on that a bit, but the kind of advice that I would give to graduate students. My first year, I felt overwhelmed like I couldn't hang out. Umm..like, you know, I'd go to these graduate student organization meetings and waste some time on it, "like, whoa, what are we doing?" But, to be around people who have gone through the same thing is huge, absolutely huge.

In a way, both the positive faculty and peer interactions also served as motivators to succeeding as graduate students. 
Competition. The category defined as competition was often described as a negative aspect of interacting with peers in graduate programs. Marilyn and Lulu, for instance, stated that some of their peers demonstrated behaviors to "show off" and to compete with other students. Marilyn related a story about a student in her class who often tried to appear more knowledgeable than his peers and professors. In her accounts, Marilyn described how negatively she felt when the student would embarrass others in front of her and how this student would treat people as if they were too incompetent to understand concepts covered in class. In another incident, Lulu explained how she felt that many of her peers were only trying to compete with her and others. This made her feel as if making mistakes or saying the wrong thing in class would immediately make her a target for these students. Lulu described one such incident that occurred during one of her presentations,

Those students, the ones I just described. They tend to put down the younger students like the ones that don't show as much confidence. So I have learned to kind of like get a firm way of being so they don't think they can get away with that with me, so it's not a problem for me. While I remember I was doing a presentation once and usually the type of question you would ask is related to whatever you're presenting and you are not going to try and ask someone a really difficult question because chances are they probably don't know the answer and you don't want to make them look stupid in front of class. Or maybe you want to ask in person, you know, in a moment to not them on the spot but anyway I was doing a presentation and it was my first semester so all of the information was all fresh to me this was all new. Nobody knew their research methods yet. I hadn't taken that class yet, I need to take it next semester. So um anyway one of the older students asked me about some research question and I really didn't know the answer... I felt like he was testing me as something students do because they want they want to get the credit that they know more than you.

Lulu described the student in her programs as organized in cliques that would humiliate outsiders who disagreed with their perspectives. As the interview progressed, Lulu cited this incident as the reason she became less likely to share her ideas within the classroom 
or in front of her peers. She regarded these missed opportunities for openly discussing her ideas as a barrier to learn more by engaging in active academic discourse and as a disadvantage to being a student in her program.

Other students described the lack of competition in their graduate programs as one of the major reasons why they liked their academic environment. Gabby and Rick both agreed that the non-competitive nature of their program helped them in their creative process as they critiqued other student's work and received critiques back. As Rick described,

That's something that differs in this program from what I've heard from a lot of other programs. Is that they don't find it to be competitive at all. I find it to be a lot of camaraderie and admiration amongst the students, but I never really understood how much competition you can have [in this type of] program, but I hear a lot of horror stories about other programs that have a lot of competition among students to be the best. And I don't know how you can be the best in a poetry class.

These descriptions depicted competition as a negative aspect of peer interactions and greatly differentiate the impact of competitive and supportive peers.

\section{Faculty Interaction}

Students mentioned their positive interactions with the professors as key to their success in graduate school. The support that their professors gave them both by encouraging them in an academic context and by sharing their ideas in a personal context was often cited as life changing experiences that affected them professionally long after some the interactions took place. On the other hand, negative interactions lead to delays in graduation, confusion, and frustrations amongst the students. The category that encompassed these divergent outcomes was labeled as academic and personal support. The other category under this theme was availability and related to how available the 
faculty members in their program were aside from level of support they shared with their students.

Academic and personal support. Many students spoke of the value they placed on faculty interactions as they progressed through their degrees. The graduate students in the study viewed faculty members as mentors and guides who greatly affect their entire programs, their success within those programs, and their professional careers thereafter. Many times students described the impact of the major professors they interacted with as affecting their motivation, degree of confidence, drive, and other psychological aspects of their lives as graduate students. Another finding obtained from the interviews was that students often distinguished between their academic interactions with their faculty members and their personal interactions. As described in the paragraphs below, both of these dimensions impacted the overall perceptions of students shaping the connection they felt with their programs.

In terms of academic support, many students cited how positive interactions led them to feel that they could progress successfully through their programs. Most of the students mentioned at least one professor who they felt, helped them achieve success within their programs. The only exceptions were Lulu and Ava, who as part time students, found themselves unable to connect with any faculty members due to scheduling and other factors. As Ava described, she did not have much time to interact with the faculty in her program because of her full time job,

Ava: There was some interaction, but very minimum because I could only show up to class and leave because I worked full-time. I didn't have much time to spare to socialize with faculty and or spend the time with them in their office hours, which were during the day and I had to work. So there is very little or no interaction. 
As for the positive interactions, all of the students in the humanities found a very high level of interaction and support from their faculty members both inside and outside of the classroom. Two of these students explained how this positive interaction affected them in their programs and in their professional lives,

Rick: I guess during my thesis year I was dealing directly with an advisor with faculty in the program. And a lot of those interactions for very process oriented, like I was bringing him my thesis documents, which were like a book length collection of once. So a lot of that was a discussion about my writing process and the advice he would give me to write, sort of the production and revision of these poems. So yes, I guess in that sense, some of those interactions have really kind of stuck with me and they have not only affected my academic success, but my teaching style as well.

Gabby: So I never felt like I was like annoying them or being a burden to them, because they were so welcoming and so enthusiastic to see what I would accomplish, and to have that type of, you know, that was a really big factor and I don't think that all graduate students necessarily have that type of experience with their faculty members...

Other students also discussed how their faculty members helped them complete their programs through direct and consistent intervention and support. Nancy, for example, described how coming from another country made her have less connections to people from her field and how her major professor was able to assist her in overcoming these obstacles,

She was my major professor and she's always there and I call her anytime like a call her at home. I call her at the office bother her anywhere. That was something that was very significant and she would give you feedback like immediately so that would help. You know it helped to strengthen the interactions between us so that was one very unique experience... When I was collecting my data, it took me about 2 years to get my data collected, but she was always there like "Okay, you don't have any more participants" and you know, she would call somebody over for me. You know "Okay, you don't have anybody. Can you wait?" and she would call and see that person and that person wouldn't respond, she would call somebody else. So that helped. 
That was an experience that it felt was worth my being with her because if not that she was calling and she was there and I'm not from here so I don't know who to talk to and who not to talk to. But she, you know, would link up with somebody and that person would help us with somebody else, but she was the one that was always here to help me out every time I need to talk to somebody.

Positive personal interactions with their professors also made the students in this study feel more integrated into the environment of their programs. Some of the students extensively discussed examples where they felt encouraged by their faculty when they felt a personal bond as well as an academic one. Fabiola described how her mentor made the obstacles she faced as a student easier because of the close relationship she had with her mentor. Fabiola felt that her mentor cared for her and that her mentor was "like an aunt", which in turn made her feel more comfortable in overcoming obstacles. Other students also faced a lot of challenges that were aided by a more personable touch from their mentors and professors. In the following two examples, both student faced challenges. Nessie had financial troubles and Marilyn had an unexpected family tragedy in the middle of one semester. These are the stories they told about their experiences,

Nessie: My head of department she is, I have a wonderful relationship. And my advisor? One good thing, one positive thing that I have with her is when going to a conference, I didn't have any money so she paid with her credit card. And she didn't want to be paid back. I...I gave it to her anyways, but that is how and she'd ask "you hungry" and if you don't have money, she'd buy you food. That is how nice she is.

Marilyn: This one professor, I had a family tragedy when I was. It was my second semester and I had to ask him for an incomplete at the very end of the semester and he was very supportive very caring and he would ask me how I was doing, my family and then the next term coincidentally, it could take one of the last that he was teaching. So I would see him in class all the time and he would be very worried about how I was doing and he was very flexible in terms of me completing the work for the previous class that I had gotten an incomplete in. He was really good and then the other teacher that I also got an incomplete from during that semester. He was also very good he was respectable with me 
whenever I wanted to take the final test that they needed or finish my last project. They were both very very supportive.

In all of the examples above, students were very adamant in explaining the great difference that these positive interactions made in their personal, academic, and professional lives.

Just as students reported that their graduate success was facilitated by faculty support in their academic work, they also stated instances when they were hindered by either absence of interaction or negative interactions. In the case of Nessie, she found herself at odds when two of her professors were pulling her in two different directions without considering her professional interests until the very end. As she described,

That professor thinks that I'd be better in the lab as to where my advisor thinks I'd be better in the field. So, even though I do have good interactions with them, what I wanted to do, and what they want me to do are quite different. And so, when I advance a little bit, they kind of like, try to push the agenda into it and take me back a little ... and I went to my head of department to tell him that I was quitting the program. And so that drive just died. And then, I have been struggling since then to put one together now. So I felt that experience has hindered me a lot. I don't have the drive to, I don't know, because I feel like when I write that she is going to, you know, push it down again. But at least now, the consensus is that I belong in the field. At the time there was a confusion that I was supposed to be in the lab and wasn't supposed to be in the field.

A different student, Charlotte, described how early in her program, one of her professors discouraged her from pursuing her degree at FIU. In the story she described,

A particular faculty member that I worked with regularly, early in my curriculum before I switched everything, just did a lot of grumbling about, I mean, the first thing he said to me when he, when we talked seriously of what I had done and what I wanted to do and stuff and he goes, "Why are you here?" .... [these interactions] would absolutely make you question what you are doing. I mean, like I was saying first, it's extremely tough to do this, it's, you're lonely, isolated, how many ways you try to fight these people, right? The rest of the people in the world, don't really don't get it. They just can't, because it's so bizarre, right? It's so crazy what we're doing' and then in some ways it's so lonely it requires 
incredible discipline in time and energy and basically as much as yourself as you can get to it.

And it's scary there's no, especially, in this economic environment, there's absolutely no guarantee that you are going to have anything when done. You are going into debt, you are going broke, you know, I mean it's just a very tiring thing, so to have people who have everything you're aiming for, act like it's not a good thing in any way. I think it's devastating. I think it makes you question everything that you are doing. You look at how many people go for Ph.D. that don't get it?

Charlotte described how this interaction with her professor led her to question herself about her decision to be in the program and she felt discouraged because she felt she had made the wrong choice. However, encouragement from other faculty members allowed her to overcome these doubts and proceed with her doctoral program. This particular quote also was coded under "persistence/dedication" since Charlotte mentioned that she needed a lot of discipline to be able to dedicate herself to accomplishing her academic goals.

Availability. In addition to academic and personal support, many students also spoke of availability of the faculty members in their program. Though some students did not interact much with their faculty, they felt they could easily get in contact with their professors when they needed help. In one case, Marilyn described the fact that she could always reach her professors when she needed advice. Other students mentioned that some professors had open door policies which made them extremely accessible to students. The level of faculty availability was crucial in affecting students' perceptions of their program. When describing how the availability of her some of her faculty members to help her with teaching and everyday questions, Charlotte stated, "I couldn't have had success without it. I mean, it's completely dependent on it." Another example 
was stated by Ava who remarked that her professors "cared about the students. The chairperson was always available at any time even without an appointment, he had open doors. He was very much into helping students succeed, so his staff was also very helpful."

However, there were instances, where students found that availability was extremely rare. Lupe, for example, spoke about how difficult it was to find professors in her program and contrasted her experiences outside of her department with faculty who were more readily available in other disciplinary areas. In the social sciences, Lulu also found it difficult to find an appropriate time to reach her faculty when she was attempting to sort out her class schedule. When she was able to get an appointment, she felt it was very impersonal, as she described, "he was very like, cut to the chase type of attitude. He was really busy, I guess, when I got there." The fact that Lulu was a part-time student and that she was having difficulty reaching and connecting with her professors increased her sense of isolation in the program.

\section{Emergent Theories}

In the final stage of coding, two theories emerged. These theories helped me conceptualize how my "substantive codes" (Charmaz, 2006, p. 63) that came out of the previous coding phases helped to move my analysis in "a theoretical direction". They helped me "specify possible relationships between categories", allowing me to make the analysis of the data more clear and coherent.

The first of these emergent theories is that from the perspective of these successful graduate students, the GRE is a tool that may be helpful for admission policies, but is not necessarily the most relevant measure for predicting graduate student 
success. The second theory is that psychosocial student attributes and behaviors are important aspects of graduate student success. For instance, from the students' perspectives, success may be more related to whether they develop a sense of belonging and a dedication to their programs. Furthermore, they may perceive that particular aspects of their experiences may serve either as facilitators for or detractors from graduate student success; that is, faculty and peer interactions, external motivators, degree of student involvement, and department and program structure and organization. These theories will be further elaborated in the next chapter. The results from the two phases of this study will be combined and interpreted in the context of previous research. 


\section{CHAPTER V}

\section{DISCUSSION}

The main purpose of this study was to understand the characteristics that are most commonly linked to student success in graduate school. In this chapter, the findings of the previous chapter are briefly summarized as they relate to each of the research questions. Then these findings are analyzed and contrasted with previous research. The theoretical framework of this study in which student characteristics are separated into two distinct dimensions, proximal and distal facilitators, is also used as a lens from which the data are analyzed and interpreted. The chapter concludes with the limitations of the study, recommendations for higher education policy, and suggestions for future research.

\section{Predictive Validity of the GRE Across Disciplines}

The first research question in this study asked: How well does the GRE predict graduate student success in a minority serving institution across academic disciplines? Data were analyzed through the regression analysis and discriminant function analysis in Phase I of the study. Starting with graduate success as determined by graduate GPA, it was determined through a multiple regression analysis that the GRE scores of both master's and doctoral students accounted for significant proportions of the variance of students' final GPA scores after controlling for disciplinary area $\left(R^{2}=.02\right)$. When analyzing data for master's students, being in physical sciences or social sciences also accounted for significant variance in the graduate GPA scores. Among doctoral students, the GRE Verbal accounted for a larger proportion of the variance of the grade point averages than the GRE Quantitative though they were both significant. This is consistent with Luthy's (1996) study in which GRE V was more related to graduate GPA than the 
GRE Q. However, Luthy's study also found that GRE Q was a better predictor of GPA for disciplines in the physical sciences and for one of the social sciences disciplines (psychology) that were included as variables in the study. Contradicting Luthy's study and the current study, a meta-analysis by Kuncel, Hezlett, and Ones (2001) found that GRE Q was a better or equal predictor of first year graduate GPA when compared to GRE V for most disciplinary areas in their study. In that study, these disciplines were life sciences, math/science, and social science. The only exception was humanities, in which GRE V was a better predictor of GPA.

In terms of graduation rates, all disciplinary areas were significant in predicting classification into graduation status for master's students. The discriminant function analysis indicated that humanity majors and physical science majors were more likely to be classified as "graduated" and education and life science majors were more likely to be classified as "not graduated" at the master's level. However, for the doctoral level, the only significant disciplinary area was education whereby education majors were less likely to be classified as "graduated." Previous research on the predictive validity of the GRE within different disciplines has been quite limited and has not included this type of analysis in their methods. Furthermore, this study analyzed data for both master's and doctoral students independently in order to be able to compare both groups. This type of separate analysis has not been conducted in other studies that used disciplinary area as a variable.

\section{Predictive Validity of the GRE and Other Student Characteristics}

The second research question in this study asked: Does the GRE predict graduate student success when controlling for discipline, race/ethnicity, sex, and age? As in the 
previous research question, the second research question was answered in the first phase of the study.

\section{GRE Validity}

Generally, when looking at graduate GPA, GRE scores (both verbal and quantitative) for master's and doctoral students accounted for significant proportions of the variance of grade point averages. For master's students, the results indicated that $1 \%$ of the variance can be accounted for over and above all other student characteristics. In the case of doctoral students, $3 \%$ of the variance in GPA can be accounted for over and above the other variables in the study. These proportions, though low, are significant (estimated to be non-zero in the population). This is unusual since range restriction in both the GRE and the GPA scores usually results in correlations of zero between these two variables. Even with low proportions of the variance accounted for by the GRE, the large number of applicants to graduate schools would yield a considerable number of students whose GRE scores may predict graduate GPA.

When analyzing graduation status as a measure of success, results of the discriminant function analysis demonstrated significance for the QRE V in predicting "graduated" among doctoral students. However, when considering of the GRE Q for doctoral students, it was not significantly related to graduation rate though it was related to graduate student GPA. In a similar study by Smaby, Maddus, Richmond, Lepkowski, and Packman (2005), it was found that only GRE V predicted graduate student success. Though this finding coincides with the current study's finding on doctoral student graduation, it contradicts the findings on doctoral student GPA. However, their study focused on master's level students in a counselor education program whereas the current 
study only found this correlation in doctoral students, thus it differs in terms of the graduate population studied. Furthermore, the measure of success used in the study was the Skilled Counselors Scale (SCS), which is different from the two success measures used in this study.

Other studies have combined GPA scores as a success measure and have found high correlations between the GRE scores and grades. In two of these studies, GRE scores were predictors of graduate GPA (Nilsson, 1995; Powers 2004). However, in Nilsson's study only the combined score of the GRE was used and therefore it is not possible to distinguish between the predictive validity of each part of the GRE as separate variables. Also, for Powers' study, the GRE Q had a higher correlation to GPA than the GRE V $(r=.26$ vs. $r=.21)$, which was not the case for the current study in which GRE Q was not correlated to graduate success for doctoral students across all statistical analyses utilized for both measures of success. It should also be noted that Powers' study only included students from 27 colleges of veterinary medicine and not a wide range of fields as in the current study. Another important note is that in Powers' and Nilsson's studies, the GPA scores used were of students who were either first year students or had only completed half of their program (respectively). This is different from the cumulative GPA used in the current study.

In two meta-studies that explored the predictive validity of the GRE with graduate GPA, Chernyshenko and Ones (1999) and Kencel, Hezlett, and Ones (2001) found that GRE V and GRE Q had equivalent predictive validity for total graduate GPA and first year's graduate GPA respectively. However, Chernyshenko and Ones only included studies that only included psychology majors for their meta-analysis and Kencel, Hezlett, 
and Ones found that GRE V had slightly better predictive validity when using cumulative GPA scores instead of only first year GPA ( GRE V $r=.23$ and GRE Q $r=.21$ ). These studies contrast with the current study which found GRE V to be a better predictor of graduate GPA and graduation across both master's and doctoral students.

\section{Graduate Student Characteristics}

Additionally, there were other characteristics that were also significantly related to GPA scores and to graduate rates. The first characteristic was age. For master's students, age accounted for significant variance in GPA scores according to the regression analysis. Furthermore, as determined by the discriminant function analysis, older students were more likely to be classified into the graduated status than younger students within 6 years. No such significant findings were found for doctoral students.

While GRE scores were still significant predictors of success for students when controlling for age, it is important to note that older master's students were successful in graduate school despite the findings that GRE score and age are negatively correlated (Awad, 2007). Additional studies such as Lightfoot and Doerner's (2008) study where older master's level students had lower GRE scores and were less likely the complete their criminal justice degree contradicts the trends illustrated in the current study. However, when analyzing the findings for the doctoral students, age was not significantly related with either of the two success variables in this study. This finding is similar to Lightfoot and Doermer's finding where there were no significant relations with age, GRE score, and graduation rates for doctoral student in criminal justice. A problem in comparing the results from this study and that of other studies is that the term "older students" was either poorly defined such as in the case of Lightfoot and Doerner's study 
or defined by a very restricted range such as Luthy's (1996) study where older students were defined as older than 24 . In the current study, age was a variable that was analyzed as a continuous variable. This means that the statistical analysis took into account the broad range of ages and then identified a positive correlation between age and success rates.

The second characteristic is sex differences. For both master's and doctoral levels there was a significant relationship between sex and GPA scores in the regression analysis. This is consistent with other studies that have linked sex and GPA. In previous studies, graduate students who were women tended to have higher GPA scores than men (Chapell et al., 2005). In this study, the same conclusion was reached. The two regression analysis indicated that women were more likely to have a higher GPA than men at both the master's and doctoral levels.

In terms of graduation rates, women in master's level programs were less likely to graduate. This finding is surprising since women maintained a higher GPA score when compared to men. It is also important to note that GRE scores were predictive of success while controlling for sex as well as the previous variables mentioned. In other studies, women tended to have lower scores in the GRE when compared to men (ETS, 2008b; Templar \& Tomeo, 2002). Though this study did not compare scores between men and women, it is interesting to note that success rates were only negative for women in master's programs and not for women in doctoral programs. This contradiction leads to questions that would need to be further explored.

The final two characteristics were disciplinary area and race/ethnicity. The former was covered in greater depth in the previous section of this chapter. Thus, the 
next lines will close this section by analyzing race/ethnicity. The GRE was a significant predictor of success even when controlling for race/ethnicity. This is similar to previous research where GRE was a predictor for low grades for racial/ethnic minority students (Reisis \& DeJong, 2005). However, this also contradicts findings that indicate the minority test scores may not be the best indicators of overall success due to the phenomenon described by Steele (1997) as stereotype threat. For instance, in Steele's research, African American students performed worse in academic aptitude test conditions than in non-diagnostic test conditions (Steele, 1997; Steele \& Aronson, 1995). Similarly, Nguyen and Ryan (2008) found that racial/ethnic minority status accounted for $38 \%$ of the variance in student performance when conducting similar research about stereotype threat for women, African Americans, and Hispanic students. In the current study, when accounting for GPA as a success variable, two regression analyses indicated that students who were identified as African Americans, Hispanics, and Native Americans were significantly related to GPA for master's programs, while no significant correlations existed for doctoral students. However, when using graduation status as a success indicator, race served as a predictor for doctoral students since White students were more likely to be classified as "graduated," while there were no significant results for the other racial/ethnic groups. This leads to questions that are beyond the scope of this study, but may in part support previous stereotype threat research.

\section{Facilitators and Detractors of Achievement}

The third research question in this study asked: What are the facilitators and detractors of achievement for successful graduate students? The third research question in this study was answered both by the quantitative phase and the qualitative phase of the 
research. Answering this research question brings together both the phases of the study. Thus, this section of the chapter will discuss the findings in terms of both the quantitative and qualitative phases while using the theoretical framework as a lens to answer the research question.

\section{GRE and Demographic Characteristics as Facilitators and Detractors}

In Phase I, the quantitative analysis conducted answered this question at the same time as it answered the previous two research questions. To answer this particular question, I used the discriminant function analysis, which used graduation status as the success indicator. In general, graduate student characteristics that were significantly related to higher levels of graduate student success were considered facilitators while those that were significantly related to lower levels of graduate student success were considered detractors. For the master's students, high scores in both parts of the GRE seem to be facilitators of graduate student success as measured by graduation status. However, for doctoral students the GRE Quantitative was not a significant factor when classifying students into the graduated status.

Demographic characteristics were both facilitators and detractors for graduate student success. Age was with a significant variable when using a discriminant function analysis to predict classification into the graduated condition for master's students, but was not a significant variable for doctoral students. This means that older students for the master's were more likely to graduate than younger students. Another correlated facilitator was being a woman. Graduation rates were higher for women in master's programs. Race/ethnicity was a greater facilitator for White doctoral students when 
compared to all other groups since only White students were significantly more likely to be classified into the graduating group than into the "not graduated" group.

Disciplinary field was also difficult to classify as either facilitating or detracting students from higher levels of success. For master's students, when considering graduation, education and life science disciplinary areas were considered detractors while humanities and physical sciences were considered facilitators since students in these disciplinary areas were more likely to be correctly classified as "graduated" rather than "not graduated." For doctoral students, the only detractor for either success variable was education majors who were significantly less likely to graduate.

As discussed in previous sections of this chapter, other researchers have used some of these characteristics. However, other studies about the predictive validity of the GRE did not take into account the relationship of each of these variables to graduate success separate from GRE scores. Also, when considering the theoretical framework of this study, Phase I of the study also helped to inform the theory that both distal and proximal characteristics are related to graduate student success. The GRE was the primary distal moderator used in this study and when viewed through the lens of the research question, was a facilitator of success in terms of graduation rates for master's students, but was only a partial facilitator of success for doctoral student since only the GRE V was a predictor of success across all success measures and statistical tests.

In Phase II, the category "predictive value of the GRE" was difficult to classify as either a facilitator or detractor. Out of all of the previous categories and themes mentioned in association with the qualitative phase of the study, this was the only distal moderator of success noted by the interviewees. Though some students mentioned that 
they thought that previous academic GPA would also be a predictor of success for graduate students, it was not a major theme or category that emerged when interpreting the data for all of the interviews. The reason why classifying this category as a facilitator or detractor was because some students viewed the GRE as simply another task to complete for the admission process, while others viewed the GRE as a barrier for admission. Three of the students reported having desired better scores for admission into more selective programs, so in that sense the GRE was seen more as a barrier than a facilitator. Simultaneously, some of the students with the higher GRE scores described the GRE as a way to get into graduate school and thus, from that perspective it seemed like a facilitator. However, students did not feel the GRE was relevant to the skills needed for graduate school nor did they feel it influenced graduate success once admitted in graduate school. Thus, after serving to admit students into the program, the GRE was seen as neither a facilitator nor a detractor for success.

These findings are difficult to compare to the quantitative findings of this and other studies about the GRE since no studies have taken into account student perspectives as data sources for determining the validity of the GRE for measuring student success. However, some of the students in the interviews mentioned that only one part of the GRE (either the verbal or quantitative sections) was more relevant to their major than the test as a whole. This coincides with quantitative research suggesting that GRE subject specific subtests or only one section of the GRE according to major, may be more predictive of graduate student success then using the GRE V and GRE Q for across all majors (Bridgeman \& Cline, 2004; Payne, Briel, Hawthorn, \& Riedeburg, 2006). 


\section{Facilitators for Academic Success}

In Phase II, both proximal and distal moderators were explored through the interviews. Throughout the interviews, the majority of these moderators were classified as proximal facilitators by the students. This section will explain each of these moderators in terms of the categories and themes that were interpreted from the data and how each one was a facilitator and/or a detractor for graduate student achievement.

Personality traits. The first moderators described in this section were attributed as perceived facilitators of success. First of all, two of the categories under the theme of personal traits were consistently mentioned as facilitators for success. These categories were persistence/dedication and time on task. Both master's and doctoral students mentioned that two of the characteristics that were most critical for success were dedication to completing your program and the ability to spend a large proportion of your time focusing on academics. Paglis, Green, and Bauer (2006) studied a similar variable in their research, which they defined as self efficacy. However, in their quantitative study, they found no significant relationships between self efficacy and graduate student success (as defined by publication productivity).

Motivators. Other perceived facilitators were financial/opportunities and love of field which were classified under the theme of motivators. These two categories were often mentioned as some of the primary things that motivated them to initiate and to persist in their degree. For example, students mentioned how love of the field made them less likely to quit when encountering hardships and how they felt that they were motivated to complete their degree in order to obtain better job opportunities. However, no previous research has focused on either of these categories. 


\section{Detractors for Academic Success}

Two categories emerged as perceived detractors for student success; academic access and language/academic culture under the theme of importance of admission criteria. Some of the students whose first language was not English and/or who were international students felt that they were at a disadvantage for getting the necessary scores needed to get into graduate school. Even when admitted, they felt access and choice was limited due to inadequate test scores. They felt the GRE V was not easy for students whose first language was not English or felt that the multiple choice format of American tests undermined their performance since they were used to essay tests in their countries of origin. These findings coincide with research that states that admission tests may not accurately reflect student success or student capacity for minorities because of language and/or cultural differences (Nguyen \& Ryan, 2008; Steele, 1997; Steele \& Aronson, 1995).

\section{Characteristics Serving Both as Facilitators and Detractors}

This study also found that some moderators can have attributions that may facilitate or detract graduate success. Graduate students often reported the perceptions of having a mixture of positive and negative experiences that either helped or hindered their academic pursuits. These experiences are described below as divided by major category or theme.

Faculty interactions. The first of these was faculty interaction. Similar to prior research, this study found that students who actively and consistently interacted with their program's faculty felt more engaged and encouraged to complete their programs than those who did not feel the same level of interaction (Paglis, Green, \& Bauer, 2006; 
Quarterman, 2008). As in Kram's (1985) study, it was found that there were two dimensions in which students interacted with faculty. Kram defined these as psychosocial mentoring and career mentoring. The current study found that both of these dimensions held value in allowing students to progress through their programs. Personal support or psychosocial mentoring in the form of things such as counseling emerged as frequently in the interviews as academic support or career mentoring. However, lack of support or availability also was a detractor for students. They described how negative experiences with faculty members delayed progress in their dissertations or coursework and how lack of faculty availability made them feel isolated from the program and unmotivated to persist. This finding mirrored Quarterman's (2008) study which found that positive mentoring experiences were the most commonly emerging themes reported in student interviews.

Peer interactions. Similar to faculty involvement, students also described peer interaction as either a primary facilitator or detractor of their degree completion. Since this theme was often also linked to the category involvement, both will be described as a whole. Like previous studies on engagement, most of the students in this study who were successful were also highly involved in academics and with their peers. Similar to Tinto's theory of student departure, this study found that students often relied on peer interactions to help them cope with the stress of graduate school as well as help them with academic and day-to-day challenges of completing their programs. The findings also indicated that there were several types of involvement. These types of involvement were similar to those found in previous studied that included categories such as 
professional development, social connections, and connecting the class to real world experiences (Garner \& Barnes, 2007; Wang, 2003).

However, the three part-time students who had had to balance work and school were not as involved as the rest of the student in the study. They reported very minimum levels of involvement and though they were successful, they also reported more feelings of isolation than the full-time students. Another contradiction when compared to previous research on involvement is that some of the most involved students also mentioned that being too involved was a detractor from their progress in their programs. The felt they were sometimes so involved in activities, that they were unable to complete their academic goals on time (e.g., students would choose to go to attend their student organization tasks and neglect some of their goals required for completing their dissertation). Also, negative peer interactions were also mentioned as detractors. Students felt that high levels competition among peers led to a negative environment where they felt less apt to participate in discussions or in academic activities.

Family and friends. The category of family/friends was also both a facilitator and a detractor of student success. Most of the students mentioned family or friends outside of academics as great support mechanisms for helping them cope with the pressures of completing their degrees. However, some of the students also noted that in the case of romantic partners and children, it became difficult to balance the school life with home life. They felt increased pressure and guilt for not being able to be as dedicated to these relationships as would be normally expected. These students also shared some of the coping mechanisms they developed for balancing school and home (e.g., scheduling time to spend with significant others and escaping to the library when 
they were at school or work). These findings are mirrored in studies that find that family and personal relationships are important for persistence and motivation in racial/ethnic minority students. Two of these studies concluded that minority student family support and level of involvement were perceived to be contributing factors in facilitating and encouraging retention for undergraduate students (Fischer, 2007; Hurtado, Cater, \& Spuler, 1996).

Program structure. Another theme that was perceived as both a facilitator and a detractor for success was program structure, which included two categories: organization/structure and curriculum and resources. The graduate students interviewed described how important overall program structure was to their success. For instance, the ability to have resources such as computer labs within their departments (that suited the needs of their specific discipline) and variety in the curriculum helped foster learning in their programs. Lack of structure, poor course selection, or inadequate resources, however, were a detractor for learning and progressing through their degree. Some students even cited examples whereby their degrees were delayed or they almost lost hope in completing their degrees when faced with complex levels of structural problems (e.g., grades lost, lack of required courses offerings, and poor information disbursement). No other study reviewed has used program structure as factors in understanding student success.

\section{Summary}

Both proximal and distal moderators influence student behaviors and success in graduate school. In the first phase of the study, the GRE was the distal facilitator under analysis. Findings suggested that the GRE was generally a valid predictor of success, but 
the GRE Q was not predictive of success for doctoral students. Other student characteristics such as demographic variables and disciplinary area were also predictors of success for the population of students studied. In the second phase of the study, GRE was also ones of the factors under analysis. However, it was inconclusive whether it helped or hindered graduate student success. Furthermore, proximal moderators were perceived as facilitators and/or detractors for success.

Two main theories emerged from student perceptions and some of the corrections from the quantitative analysis. The first is that GRE scores may be helpful during the admission process, but may not be only or most relevant measure of predicting success. As described before it was difficult to determine whether it was solely a facilitator or a detractor to student success based on the qualitative information and there are other factors that were perceived to be related to graduate success. The second theory generated from the data was that psychosocial student attributes and behaviors are important aspects of graduate student success. For instance, a balanced level of involvement and positive faculty and peer interactions is crucial to graduate student success. Furthermore, student characteristics such as external motivators (e.g., family/friends, opportunities, love of field) and internal traits (e.g., student dedication, time on task) serve as factors that affect success in graduate programs. Also, students' progress through the program can be affected by the structure and organization of their programs and departments. These two theories encompass the majority of the findings of this study. 


\section{Limitations}

There are various limitations to consider when interpreting the finding of this study. The first limitation was both a strength and a weakness in this study. Historically, minorities do not represent a large percentile of the sample sizes in studies about the GRE. This study took place in a university where the majority of the students in the sample were of racial/ethnic minority groups, thus, while broadening our knowledge on the predictive validity of the GRE amongst minorities, the results of this may not be generalizable to other universities where Hispanics are not a majority. Also, the Hispanic population in Miami may not be culturally similar than the Hispanic populations of other HSIs. This is an additional factor to consider when trying to compare FIU's population to that of other institutions. Furthermore, only admitted students were included in the sample for both phases of the study. Potentially, students who did not meet the admission criteria for graduate school could have been successful students and were not counted. This is a major flaw of most student success research whereby selection is narrowed by the availability of data and student participants.

In Phase II, there were several limitations that were exclusive to that phase of the study. The first of these limitations is that the sample was made up of 10 women and only one man. As discussed in Chapter 3, other men were contacted, but only one chose to participate in the interview. This disparity between the percentile of women and men in the sample limits the transferability of the data found in the qualitative phase since results may have been different if more men were included. However, in this study, the researcher did not find any differences between the categories and themes coded for the men who participated when compared to the women who participated. Another 
limitation is that the sample only contains two to three students from each of the five disciplinary areas. This small number of students for each discipline may not be reflective of the perspectives of the majority of successful students in that discipline. Finally, another limitation is that part-time vs. full-time employment status while attending graduate school seemed to be significant factors that affected student perceptions. However, this study was only able to include three of these students in the sample. More students who worked full-time may add more insight on potential resiliency factors that facilitate their success as they try to balance longer working hours with completing graduate school.

\section{Implications and Recommendations}

This study has various implications for policy change in higher education admission standards and procedures and for future research in assessment validity. First of all, as also suggested by the ETS, the GRE should not be the only measure of success used in determining admission to graduate school (ETS, 2008b). In fact, the GRE Q may not be a strong predictor of success for doctoral students. It is recommended that future studies revisit the relevance of the quantitative section of the GRE for doctoral students. Also, recommended is for graduate programs to also consider other measures of success along with the GRE. This may help in providing a broader picture on the candidates applying for admission.

Since this study had some limitations as previously described, it is also suggested that future studies analysis three variables more in depth. The first variable is demographic characteristics. A comparison should be made to compare how high or low GRE scores are for each of demographic characteristics explored in this study. The 
second variable is to include a new demographic variable to differentiate between native and non-native English speakers. This would provide information that would be especially important for universities where a large proportion of the students speak English as a second language (such as in the case at FIU). Furthermore, tests of statistical interactions between race and GRE scores should also be conducted in future studies in order to yield valuable data.

Another strategy to consider for future studies is to replicate in other HSIs within the U.S. This is important since this study is conducted in only at one Hispanic Serving Institution and the findings would be more generalizable if the study was replicated in multiple HSIs. For the same reason, these studies should also include more men in the qualitative phase as well as more students from each discipline and graduate degree level. By improving the generalizability of the findings in this study, these suggestions for future research would take in account any differences that may be particular only to one HSI in South Florida and any differences that would be generated by linguistic or demographic characteristics among graduate students. All of these suggestions would serve to inform future higher education policies and would add to the evidence that this study has presented. 


\section{REFERENCES}

Astin, A.W. (1984). Student involvement: A developmental theory for higher education. Journal of College Student Personnel, 25, 297-308.

Astin, A. W. (1996). Involvement in learning revisited: Lessons we have learned. Journal of College Student Development, 37, 123-134.

Astin, A. W. (1999). Student involvement: A developmental theory for higher education. Journal of College Student Development, 40, 518-529.

Awad, G. H. (2007). The role of racial identity, academic self-concept, and self-esteem in the prediction of academic outcomes for African American students. Journal of Black Psychology, 33, 188-207.

Baez, B., Gasman, M., \& Viernes Turner, C. S. (2008). On Minority-Serving Institutions. In M. Gasman, B. Baez, \& C. S. Viernes Turner (Eds.), Understanding MinorityServing Institutions (pp. 3-17). Albany, NY: State University of New York Press.

Bell, N. E. (2008). Findings from the 2008 CGS International Graduate Admissions Survey Phase III: Final Offers of Admission and Enrollment. Washington, DC: Council of Graduate Schools.

Braxton, J. M. \& Lien, L. A. (2000). The viability of academic integration as a central construct in Tinto's interactionalist theory of college student departure. In J. M. Braxton (Ed.), Reworking the student departure puzzle (pp. 11-28). Nashville, TN: Vanderbilt University Press.

Bridgeman, B., Burton, N., \& Cline, F. (2003) Substituting SAT II: Subject tests for SAT I: Reasoning tests: Impact on admitted class composition and quality. Research in Higher Education, 44(1), 83-98.

Bridgeman, B., \& Cline, F. (2004). Effects of differentially time-consuming tests on computer-adaptive test scores. Journal of Educational Measurement, 41, 137-148.

Bridgeman, B., Cline, F., \& Hessinger, J. (2004). Effect of extra time on verbal and quantitative GRE scores. Applied Measurement in Education, 17, 25-37.

Cattell, R. B. (1987). Intelligence: Its structure, growth, and action. New York, NY: Elsevier Science Publishing Company.

Ceci, S. J., Williams, W. M., \& Barnett, S. M. (2009). Women's underrepresentation in science: Sociocultural and biological considerations. Psychological Bulletin, 135, 218-261. 
Chapa, J., \& De La Rosa, B. (2006). The problematic pipeline: Demographic trends and Latino participation in graduate science, technology, engineering, and mathematics programs. Journal of Hispanic Higher Education, 5, 203-221.

Chapell, M. S., Blanding, Z. B., Silverstein, M. E., Takahashi, M., Newman, B., Gubi, A., et al. (2005). Test anxiety and academic performance in undergraduate and graduate students. Journal of Educational Psychology, 97, 268-274.

Charmaz, K. (2000). Grounded theory: Objectivist \& constructivist methods. In N. Denzin \& Y. S. Lincoln (Eds.), Handbook of qualitative research, (2nd ed.) (pp.509535). Thousand Oaks, CA: Sage.

Charmaz, K. (2006). Constructing grounded theory: A practical guide through qualitative analysis. Thousand Oaks, CA: Sage.

Chernyshenko, O. S., \& Ones, D. S. (1999). How selective are psychology graduate programs? The effects of the selection ratio on GRE score validity. Educational and Psychological Measurement, 59, 951-961.

Chickering, A., \& Gamson, Z. (1987). Seven principles for good practice in undergraduate education. AAHE Bulletin, 39(7), 3-7.

Cohen, L., Manion, L., \& Morrison, K. (2000). Research methods in education (5th ed.). London, UK: Routledge Falmer.

Davidson, M. N., \& Foster-Johnson, L. (2001). Mentoring in the preparation of graduate researchers of color. Review of Educational Research, 71, 549-574.

Denzin, N. K., \& Lincoln, Y. S. (Eds.). (1994). Handbook of qualitative research. Thousand Oaks, CA: Sage.

Duarte Silva, A. P., \& Stam, A. (1995). Discriminant analysis. In L. G. Grimm and P. R. Yarnold (Eds.), Reading and understanding multivariate statistics (pp. 277-318). Washington, DC: American Psychological Association.

Educational Testing Services. (2008a). Graduate Record Examination: Guide to the use of GRE scores 2008-2009. Retrieved October 18, 2008, from http://www.ets.org/Media/Tests/GRE/pdf/gre_0809_guide.pdf

Educational Testing Services. (2008b). Graduate Record Examination: Factors that can influence performance on the GRE General Test 2006-2007. Retrieved October 18, 2008, from http://www.ets.org/Media/Tests/GRE/pdf/gre_0809_factors_2006-07.pdf 
Edwards, W. R., \& Schleicher, D. J. (2004). On selecting psychology graduate students: Validity evidence for a test of tacit knowledge. Journal of Educational Psychology. 96, 592-602.

Enright, M. K., Rock, D. A., \& Bennett, R. E. (1998). Improving measurement for graduate admissions. Journal of Educational Measurement. 35, 250-67.

Erlandson, D.A., Harris, E.L., Skipper, B.L., \& Allen, S.D. (1993). Doing naturalistic inquiry: A Guide to methods. Newbury Park, CA: Sage.

Ferguson, M. A., \& Crandall, C. S. (2007). Trends in graduate training in social psychology: Training social psychology's trainers. Basic and Applied Social Psychology, 29, 311-322.

Fischer, M. J. (2007). Settling into campus life: Differences by race/ethnicity in college involvement and outcomes. The Journal of Higher Education, 78, 125-156.

Florida International University. (2008a). FIU fact book: Enrollment data. Retrieved February 23, 2009, from http://w3.fiu.edu/irdata/_Fact\%20Book/Headcount/enrollment.pdf

Florida International University. (2008b). FIU fact book: Degree data. Retrieved February 23, 2009, from http://w3.fiu.edu/irdata/_Fact\%20Book/Degrees/degrees.pdf

Florida International University. (2011, March). About us.. Retrieved March, 13, 2011, from http://www.fiu.edu/about-us/

Gallagher, A., Bridgeman, B., \& Cahalan, C. (2002). The effect of computer-based tests on racial-ethnic and gender groups. Journal of Educational Measurement, 39, 133-47.

Gallagher, A., De Lisi, R., Holst, P. C., McGillicuddy-De Lisi, A. V., Morely, M. \& Cahalan, C. (2000). Gender differences in advanced mathematical problem solving, Journal of Experimental Child Psychology, 75, 165-190.

Gallagher, A., Levin, J., \& Cahalan, C. (2002). Cognitive patterns of gender differences on mathematics admissions tests. Retrieved October 18, 2008, from http://www.ets.org/Media/Research/pdf/RR-02-19-Gallagher.pdf

Gardner, S. K., \& Barnes, B. J. (2007). Graduate student involvement: Socialization for the professional role. Journal of College Student Development, 48, 369-387.

Glaser, B.G. (1998). Doing grounded theory. Issues and discussions. Mill Valley, CA: Sociology Press. 
Glaser, B. G., \& Strauss, A. L. (1967). A discovery of grounded theory: Strategies for qualitative research. Chicago, IL: Aldine.

Goldberg, E. L., \& Alliger, G. M. (1992). Assessing the Validity of the GRE for Students in Psychology: A Validity Generalization Approach. Educational and Psychological Measurement. 52, 1019-1027.

Hurtado, S., Carter, D. F., Spuler, A. (1997). Latino student transition to college: Assessing difficulties and factors in successful college adjustment. Research in Higher Education, 37(2), 135-157.

Kalat, J. W., \& Matlin, M. W. (2000). The GRE psychology test: A useful but poorly understood test. Teaching of Psychology, 27, 24-27.

Kanfer, R. (1992). Work motivation: New directions in theory and research. In C. L. Cooper \& I. T. Robertson (Eds.), International review of industrial and organizational psychology (Vol. 7, (pp. 1-53). Chichester, England: Wiley.

Kram, K. E. (1985). Mentoring at work: Developmental relationships in organizational life. Glenview, IL: Scott Foresman.

Kuncel, N. R. (2003). The prediction and structure of graduate student performance. Unpublished doctoral dissertation, University of Minnesota, Minneapolis.

Kuncel, N. R., Hezlett, S. A., \& Ones, D. S. (2001). A comprehensive meta-analysis of the predictive validity of the graduate record examinations: Implications for graduate student selection and performance. Psychological Bulletin, 127, 162-181.

Lewin, K. (1935). A dynamic theory of personality. New York, NY: McGraw-Hill.

Lightfoot, R. C., \& Doerner, W. G. (2008). Student success and failure in a graduate criminology/criminal justice program. American Journal of Criminal Justice, 33, 113 129.

Lincoln, Y. S. \& Guba, E. G. (1985). Naturalistic inquiry. Beverly Hills, CA: Sage.

Linn, R. L., Baker, E. L., \& Betebenner, D. W. (2002). Accountability systems: Implications of requirements of the No Child Left Behind Act of 2001. Educational Researcher, 31(6), 3-16.

Long, J. S., \& Freese, J. (2006). Regression models for categorical dependent variables using stata. (2nd ed.). College Station, TX: Stata Press.

Lovitts, B. E. (2001). Leaving the ivory tower: The causes and consequences of departure from doctoral study. Lanham, MD: Rowman \& Littlefield. 
Luthy, T. L. (1996). Validity and prediction bias of grade performance from Graduate Record Examination Scores for students at Northern Illinois University: Age and gender considerations (Doctoral dissertation). Retrieved from Dissertations \& Theses: A\&I database. (No. AAT 9716551)

Mc Neil, K., Newman, I. \& Kelly, F. J. (1996). Testing research hypothesis with the general linear model. Carbondale, IL: Southern Illinois University Press.

Newman, I., Fraas, J. W., \& Newman, C. (2002, February). The importance of matching the analytical technique with the research question: A discussion of current research issues. Paper presented at the meeting Annual Meeting of the Eastern Educational Research Association, Sarrasota, FL.

Newman, I., \& Newman, C. (1994). Conceptual statistics for beginners (2nd ed.). Lanham, Md: University Press of America.

Nilsson, J. E. (1995). The GRE and the GMAT: A comparison of their correlations to GGPA. Educational and Psychological Measurement. 55, 637-640.

Nguyen, H. D., \& Ryan, A. M. (2008). Does stereotype threat affect test performance of minorities and women? A meta-analysis of experimental evidence. Journal of Applied Psychology, 93, 1314-1334.

Norcross, J. C., Hanych, J., \& Terranova, R. D. (1996). Graduate study in psychology: 1992-1993. American Psychologist, 51, 631-643.

Okawa, G. Y. (2002). Diving for pearls: Mentoring as cultural and activist practice among academics of color. College Composition and Communication, 53, 507-532.

Paglis, L. L., Green, S. G., \& Bauer, T. N. (2006). Does adviser mentoring add value? A longitudinal study of mentoring and doctoral student outcomes. Research in Higher Education, 47, 451-476.

Patton, M. Q. (1990). Qualitative research and evaluation methods. Newbury Park, CA: Sage.

Payne, D. G., Briel, J. B., Hawthorn, J., \& Riedeburg, K. (2006). A GRE test for the STEM disciplines: Developing an assessment "of" and "for" learning. Journal of Hispanic Higher Education, 5, 238-257.

Pennock-Roman, M. (2002). Relative effects of English proficiency on general admissions tests versus subject tests. Research in Higher Education, 43, 601-623. 
Pontius, J. L., \& Harper, S. R. (2006). Principles for good practice in graduate and professional student engagement. In M. Guentzel \& B. E. Nesheim (Eds.), Supporting Graduate and professional students: The role of student affairs. New Directions for student services (pp. 47-58). San Francisco, CA: Jossey-Bass.

Powers, D. E. (2004). Validity of Graduate Record Examinations (GRE) General Test scores for admissions to colleges of veterinary medicine. Journal of Applied Psychology, 89, 208-219.

Powers, D. E., \& Kaufman, J. C. (2004). Do standardized tests penalize deep-thinking, creative, or conscientious students? Some personality correlates of Graduate Record Examinations test scores. Intelligence, 32, 145-153.

Reisig, M. D. \& DeJong, C. (2005). Using GRE Scores and prior GPA to predict academic performance among criminal justice graduate students. Journal of Criminal Justice Education, 16, 37-59.

Reuben, T. C. (2003). Investigating test fairness of GRE scores for veterinary student selection. Unpublished doctoral dissertation, Fordham University, New York City.

Quarterman, J. (2008). An assessment of barriers and strategies for recruitment and retention of a diverse graduate student population. College Student Journal, 42, 947967.

Sampson, C., \& Boyer, P. G. (2001). GRE scores as predictors of minority students' success in graduate study: An argument for change. College Student Journal, 35, 271279.

Scherbaum, C. A., \& Goldstein, H. W. (2008). Examining the relationship between racebased differential item functioning and item difficulty. Educational and Psychological Measurement, 68, 537-553.

Smaby, M. H., Maddux, C. D., Richmond, A. S., Lepkowski, W. J., \& Packman, J. (2005). Academic admission requirements as predictors of counseling knowledge, personal development, and counseling skills. Counselor Education and Supervision, 45(1), 43-57.

Stacy, A. M. (2006). Training future leaders. In C. M. Golde \& G. E. Walker (Eds.), Envisioning the future of doctoral education: Preparing stewards of the discipline (pp. 187-206). San Francisco, CA: Jossey-Bass.

Steele, C. M. (1997). A threat in the air: How stereotypes shape intellectual identity and performance. American Psychologist, 52, 613-629. 
Steele, C. M., \& Aronson, J. (1995). Stereotype threat and the intellectual test performance of African Americans. Journal of Personality and Social Psychology, 69, 797-811.

Sternberg, R. J., \& Williams, W. M. (1997). Does the Graduate Record Examination predict meaningful success in the graduate training of psychologists? A Case Study. American Psychologist. 52, 630-41.

Strauss, A., \& Corbin, J. (1990). Basics of qualitative research: Grounded theory procedures and techniques. Newbury Park, CA: Sage.

Stricker, L. J. (2004). The performance of native speakers of English and ESL speakers on the computer-based TOEFL and GRE General Test. Language Testing. 21, 146173.

Stricker, L. J., \& Bejar, I. I. (2004). Test difficulty and stereotype threat on the GRE General Test. Journal of Applied Social Psychology, 34, 563-597.

Stricker, L. J., \& Rock, D. A. (1995). Examinee background characteristics and GRE general test performance, Intelligence, 21, 49-67.

Sweitzer, V. B. (2009). Towards a theory of doctoral student professional identity development: A developmental networks approach. Journal of Higher Education, 80, $1-33$.

Tashakkori, A., \& Teddlie, C. (Eds.). (2003). Handbook of mixed methods in social and behavioral research. Thousand Oaks, CA: Sage.

Teddlie, C., \& Tashakkori, A. (2009). Foundations of mixed methods research: Integrating, quantitative and qualitative techniques in the social and behavioral sciences. Thousand Oaks, CA: Sage.

Teddlie, C., \& Yu, F. (2008). Mixed methods sampling: A typology with examples. In V. L Plano-Clark \& J. W. Creswell (Eds.), The mixed methods reader (pp.199-228). Thousand Oaks, CA: Sage.

Templer, D. I., \& Arikawa, H. (2006). Asian-White differences in aptitude and difficulty of chosen academic discipline. Personality and Individual Differences, 40, 183-188.

Templer, D. I., \& Tomeo, M. E. (2002). Mean Graduate Record Examination (GRE) score and gender distribution as function of academic discipline, Personality and Individual Differences, 32, 175-179. 
Templer, D. I., Tomeo, M. E., Arikawa, H., \& Williams, R. (2003). Asian-Black differences in aptitude and difficulty of chosen academic discipline. Personality and Individual Differences, 35, 237-241.

The Secretary of Education's Commission on the Future of U.S. Higher Education. (2006). A Test of Leadership: Charting the Future of U.S. Higher Education, Education Publications Center, U.S. Department of Education, Jessup, MD.

Tinto,V. (1975). Dropout from higher education: A theoretical synthesis of recent research. Review of Educational Research, 45, 89-125.

Tinto, V. (1997). Classrooms as communities: Exploring the educational character of student persistence. Journal of Higher Education, 68, 599-623.

Ugrin, J. C., Odom, M. D., \& Pearson, J. M. (2008). Exploring the importance of mentoring for new scholars: A social exchange perspective. Journal of Information Systems Education, 19, 343-350.

Walker, G. E., Golde, C. M., Jones, L., Conklin-Bueschel, A., \& Hutchings, P. (2008). The formation of scholars: Rethinking doctoral education for the twenty-first century. San Francisco, CA: Jossey-Bass.

Wang, H. (2003, May).What matters in graduate school? Exploring patterns of student engagement, academic and personal development. Paper presented at the meeting of the AIR Forum, Tampa, FL.

Yang, Y., \& Johnson-Laird, P. N. (2001). Mental models and logical reasoning problems in the GRE. Journal of Experimental Psychology: Applied, 7, 308-316.

Young, I. P. (2007). Predictive validity of grade point averages and of the Miller Analogies test for admission to a doctoral program in educational leadership. Educational Research Quarterly. 31(2), 44-54.

Young, M. D., \& Brooks, J. S. (2008). Supporting graduate students of color in educational administration preparation programs: Faculty perspectives on best practices, possibilities, and problems. Educational Administration Quarterly, 44, 391-423. 


\section{APPENDIX A}

\section{Informed Consent Form}

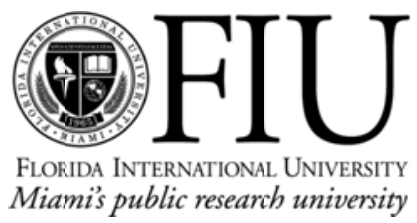

\section{CONSENT TO PARTICIPATE IN A RESEARCH STUDY}

\section{Predictors of Graduate Student Success at a Hispanic Serving Institution}

You are being asked to be in a research study. The investigator of this study is Katherine Perez, a doctoral student conducting research for her dissertation. Approximately six graduate students will be interviewed to discuss their experiences in their programs. If you decide to be part of the study, it will require approximately 1 hour of your time for the interview and short survey. You will also be contacted at a later date to review the transcripts of your interview.

We do not expect any harm to you by being in the study. You may skip any questions that you do not want to answer. If you get upset or feel discomfort during the interview or survey, you may ask to take a break. There is no cost or payment to you as a subject. You will not get any direct benefit from being in the study. However, your information will provide valuable information about the predictors of success for graduate students at FIU.

Both your interview and your survey will be identified by a pseudonym and not your real name. All of your answers are private and will not be shared with anyone unless required by law. You may ask questions about the study at any time. If you choose not to participate no one will be upset with you. You may also choose to stop your participation at any time.

If you would like more information about this research after you are done, you can contact Katherine Perez at 305-349-1418 or kpere014@,fiu.edu. If you feel that you were mistreated or would like to talk with someone about your rights as a volunteer in this research study you may contact Dr. Patricia Price, the Chairperson of the FIU Institutional Review Board at 305-3482618 or $305-348-2494$.

Your signature below indicates that all questions have been answered to your liking. You are aware of your rights and you would like to be in the study.

$\overline{\text { Signature of Participant }} \quad \frac{\text { Printed Name }}{\text { Date }}$

I have explained the research procedure, subject rights and answered questions asked by the participant. I have offered him/her a copy of this informed consent form. 


\section{APPENDIX B}

\section{Demographic Survey}

Please tell us a little about yourself:

1. Sex (circle one): Male Female

2. Age:

3. How would you describe your racial or ethnic background?

4. Employment status (select one):

Full time employee

Part time employee

Currently not employed

5. Student Status (select one):

Full time student

_ Part time student

6. Program and degree type (e.g. Chemistry, MS):

7. Term and year of enrollment:

8. Expected term and year of graduation:

9. GRE Scores:

10. Level of involvement with academia outside of the classroom (select one):

_ Only attend classes and required events

Involved with a few activities; limited interaction with faculty/peers

Publications; attend academic events/groups; interact regularly with faculty/peers

11. Are you currently a graduate assistant (circle one): $\quad$ Yes $\quad$ No

Thank you very much for completing the survey! 


\section{APPENDIX C}

\section{Interview Protocol}

Premier: Introductions; providing a description of the study; discussing length of interview and addressing any questions

Preliminary Questions

1. How would you describe yourself and your life as a graduate student?

2. What kinds of factors motivate you to pursue your degree?

\section{GRE Influence}

3. What do you think of the GRE?

Mentoring Relationships

4. Think of the faculty in your program. Could you describe a couple of interactions you have experienced with faculty members?

5. Could you specify why the experiences you shared are significant to you?

6. How have these interactions affected you academically?

Academic Environment

7. How would you define the academic environment in your program?

8. How does this environment influence your view of your discipline or your program?

9. In what ways does environment facilitate or hinder your successes and failures?

Involvement Experiences

10. What kinds of activities are you involved within your program?

11. In what ways have your current academic experiences influenced your professional decisions?

12. If applicable, describe any experiences with research, publications, or any related scholarly activity.

13. What is the role of classmates or peers in your academic and professional development?

\section{Closing Statements}

14. Is there anything else you would like to describe about your experiences as a graduate student? 
VITA

\section{KATHERINE PEREZ}

2002

2001-2002

2003-2007

2003-2007

2006

2007-Present
B.A. Psychology

Florida International University

Miami, Florida

Research Assistant

Child Anxiety and Phobia Program

Florida International University

Miami, Florida

Graduate Research Assistant

Miami-Dade-Monroe County SIG

Florida International University

Miami, Florida

Graduate Research Assistant

Miami-Dade-Monroe County PDP

Florida International University

Miami, Florida

M.S. Higher Education Administration

Florida International University

Miami, Florida

Coordinator, Institutional Effectiveness

Academic Planning and Accountability

Florida International University

Miami, Florida

\section{PUBLICATIONS AND PRESENTATIONS}

Peña, J. \& Perez, K. (2010, December). Assessment for continuous improvement: Using assessment results across disciplines at a large four-year institution. Paper presented at Southern Association of Colleges and Schools Commission on Colleges: Annual Meeting, Louisville, KY.

Perez, K., Garcia, K., \& Peña, J. (2010, December). Choosing an assessment management system that is right for you. Paper presented at Southern Association of Colleges and Schools Commission on Colleges: Annual Meeting, Louisville, KY. 
Peña, J. \& Perez, K. (2010, February). Cultivating a culture of assessment through a communities of practice model. Paper presented at Texas A\&M Assessment Conference, College Station, TX.

Perez, K. \& Peña, J. (2010, February). Strategies for implementing a systematic institutional assessment process. Paper presented at Texas A\&M Assessment Conference, College Station, TX. 